\title{
Supporting Information \\ Inactivation and site-specific oxidation of aquatic extracellular bacterial leucine aminopeptidase by singlet oxygen
}

\author{
Christine M. Egli ${ }^{1,2}$, Michael A. Stravs ${ }^{3}$ and Elisabeth M.-L. Janssen ${ }^{2, *}$ \\ ${ }^{1}$ Institute of Biogeochemistry and Pollutant Dynamics (IBP), ETH Zürich \\ ${ }^{2}$ Eawag, Swiss Federal Institute of Aquatic Science and Technology \\ ${ }^{3}$ Institute of Molecular Systems Biology, ETH Zürich \\ ${ }^{*}$ Corresponding author: elisabeth.janssen@eawag.ch \\ phone: +41587655428, fax +4158765 5802 \\ 49 Pages, 9 Figures, 5 Tables
}




\section{Contents}

S1 Chemicals and protein sample preparation 3

S2 Photochemical parameters $\quad 3$

S3 Measured site-specific reaction rate constants 5

S4 Predicted site-specific reaction rate constants based on singlet oxygen $\begin{array}{lr}\text { accessible surface area }\left({ }^{1} \mathrm{O}_{2} \text {-ASA }\right) & \mathbf{1 0}\end{array}$

$\begin{array}{lll}\text { S5 Transformation products } & 14\end{array}$

S6 Degradation of Met-containing peptides $\quad 19$

S7 Singlet oxygen-induced histidine degradation pathway $\quad 20$

S8 Degradation of tyrosine-containing peptides $\quad 22$

S9 Chromatograms and $\mathrm{MS}^{2}$ fragment comparison $\quad 22$

\section{List of Figures}

S2.1 Light exposure conditions .......................... . . 4

$\mathrm{S} 2.2$ Inactivation kinetics . . . . . . . . . . . . . . . . . . . . . 4

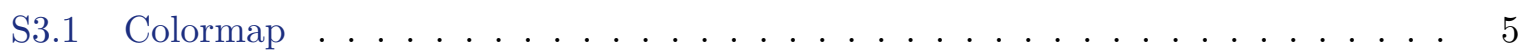

S3.2 Log-normalized degradation of all parent peptides . . . . . . . . . . . . . 7

S4.1 Measured versus predicted reaction rate constants based on His- ${ }^{1} \mathrm{O}_{2}-\mathrm{ASA}$ with previous literature . . . . . . . . . . . . . . . . . . . . 10

S6.1 Met-containing aminopeptidase peptides . . . . . . . . . . . . . . . 19

S7.1 Singlet oxygen-induced histidine degradation pathways . . . . . . . . . . . . . 20

S8.1 Degradation of Tyr-containing BLAP-12 . . . . . . . . . . . . . . . . 22

\section{List of Tables}

$\mathrm{S} 2.1 \mathrm{k}_{\mathrm{rxn}}$ and ${ }^{1} \mathrm{O}_{2}$-ASA of freely dissolved amino acids $\ldots \ldots \ldots \ldots \ldots$

S3.1 Information on aminopeptidase parent peptides . . . . . . . . . . . . 6

S4.1 Tabulated ${ }^{1} \mathrm{O}_{2}$-ASA for all aminopeptidase amino acids . . . . . . . . . 11

S5.1 Aminopeptidase transformation products . . . . . . . . . . . . . 15 


\section{S1 Chemicals and protein sample preparation}

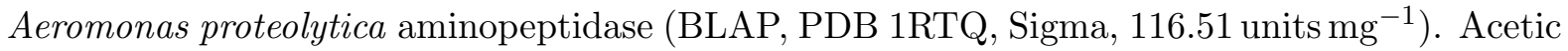
acid $(\geq 99.99 \%)$, ethylenediaminetetraacetic acid disodium salt dihydrate (EDTA, BioUltra, $\geq 99.5-101.5 \%$ ), iodoacetamide (IAM, $\geq 99 \%$ ), DL-dithio-threitol (DTT, $\geq 99 \%$ ), ammonium bicarbonate (BioUltra, $\geq 99.5 \%$ ), perinaphtenone (PN, 97\%), 7-hydroxy-4-methylcoumarin, 7leucine-7-amido-4-methylcoumarin hydrochloride, 7-amino-4- methylcoumarin, from SIGMA and acetonitrile (acros organics, HPLC grade), methanol (Fisher Scientific, OPTIMA LC/MS Grade), furfuryl alcohol (FFA, Merck, 98\%, distilled), ProteaseMAX ${ }^{\mathrm{TM}}$ (Promega, lyophilized, V207A), sequencing grade chymotrypsin (Promega, lyophilized, V106A), iRT peptides (iRT Kit, Biognosys).

Sample preparation for the enzyme was optimized for whole sequence coverage and consisted of steps for (1) metal chelation, (2) reduction of the disulfide bridges, (3) alkylation of thiols, and (4) digestion. ${ }^{1-3}$ To achieve full sequence coverage, different steps in the sample preparation were tested to optimize denaturation of the protein before digestion. Satisfying results require addition of EDTA to remove metal co-factors, heating the solution during reduction by DTT and adding an additional detergent during the thiol capping. Therefore, the sample preparation for BLAP consisted of (1) $30 \mathrm{~min}$ incubation with $2.2 \mu \mathrm{L}$ of $500 \mathrm{mM}$ EDTA solution to $60 \mu \mathrm{L}$ sample $\left(0.13 \mu \mathrm{g} \mu \mathrm{L}^{-1} \mathrm{BLAP}\right)$ and heating to $95^{\circ} \mathrm{C}(10 \mathrm{~min}),(2)$ addition of $0.72 \mu \mathrm{L}$ of a $200 \mathrm{mM}$ DTT solution (in Ambic buffer $50 \mathrm{mM}, \mathrm{pH}$ 8) and sonication at $85^{\circ} \mathrm{C}$ (30 min), (3) addition of $2.01 \mu \mathrm{L}$ of $1 \%$ ProteaseMAX detergent and $4.21 \mu \mathrm{L}$ of $400 \mathrm{mM}$ iodacetamide (at $37^{\circ} \mathrm{C}$ for $60 \mathrm{~min})$, and (4) addition of $1 \mu \mathrm{L}$ chymotrypsin $\left(0.25 \mu \mathrm{g} \mu \mathrm{L}^{-1}, \mathrm{~S} / \mathrm{E}\right.$ of $\left.25: 1\right)$ with incubation of 12 hours, (5) stopping digestions with $3.7 \mu \mathrm{L}$ glacial acidic acid. All temperature settings of $60-95{ }^{\circ} \mathrm{C}$ were achieved in a water bath and constant temperature incubators were used for $37^{\circ} \mathrm{C}$ setting.

\section{S2 Photochemical parameters}

Table S2.1 Bimolecular singlet oxygen reaction rate constants $\left(k_{r \times n}\right.$, freeAA $)$ and ${ }^{1} \mathrm{O}_{2}$-ASA values for the five photolabile amino acids. Values of $k_{r \times n}$, freeAA have been previouly published (references in superscipt), cysteine ${ }^{1} \mathrm{O}_{2}$-ASA were calculated in this work and numbers for histidine, tryptophan, methionine and tyrosine were obtained from Lundeen \& McNeill, 2013. ${ }^{3}$

\begin{tabular}{lcc}
\hline AA & $\begin{array}{c}\mathrm{k}_{\text {rxn, freeAA }} \\
{\left[\mathrm{x} 10^{7} \mathrm{M}^{-1} \mathrm{~s}^{-1}\right]}\end{array}$ & $\begin{array}{c}{ }^{1} \mathrm{O}_{2}-\mathrm{ASA} \\
{\left[\AA^{2}\right]}\end{array}$ \\
\hline histidine $^{4}$ & $7.01 \pm 0.10$ & 160.11 \\
tryptophan $^{5}$ & $3.43 \pm 0.02$ & 222.42 \\
methionine $^{6}$ & $1.6 \pm 0.48$ & 166 \\
tyrosine $^{6}$ & $0.8 \pm 0.24$ & 194.37 \\
cysteine $^{7}$ & 0.83 & 58 \\
\hline
\end{tabular}



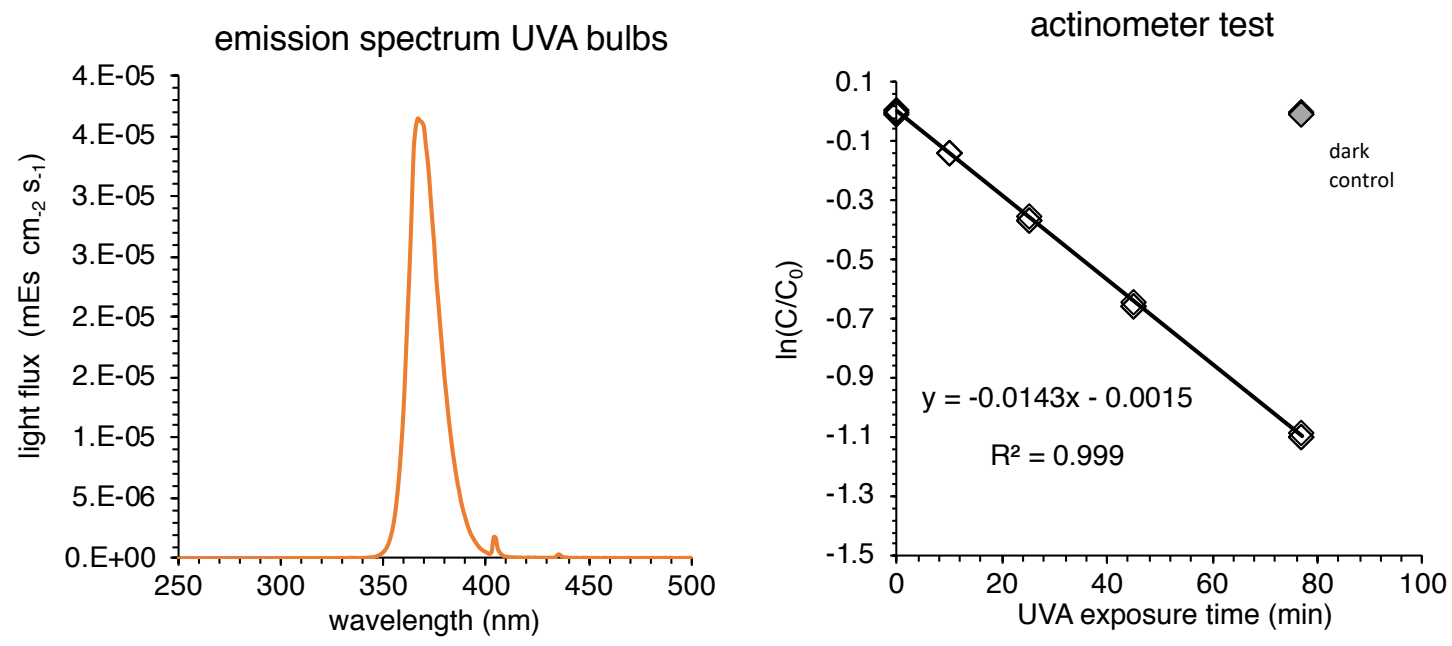

Figure S2.1 Light flux of UVA light used in the photoreactor ( 8 bulbs and heat shield, left) and degradation kinetics of PNA for the actinometer tests (PNA $8 \mu \mathrm{M}$, pyridine $0.5 \mathrm{mM}$ ) showing stable decay over the experimental time period and stable dark control samples with linear regression parameters.

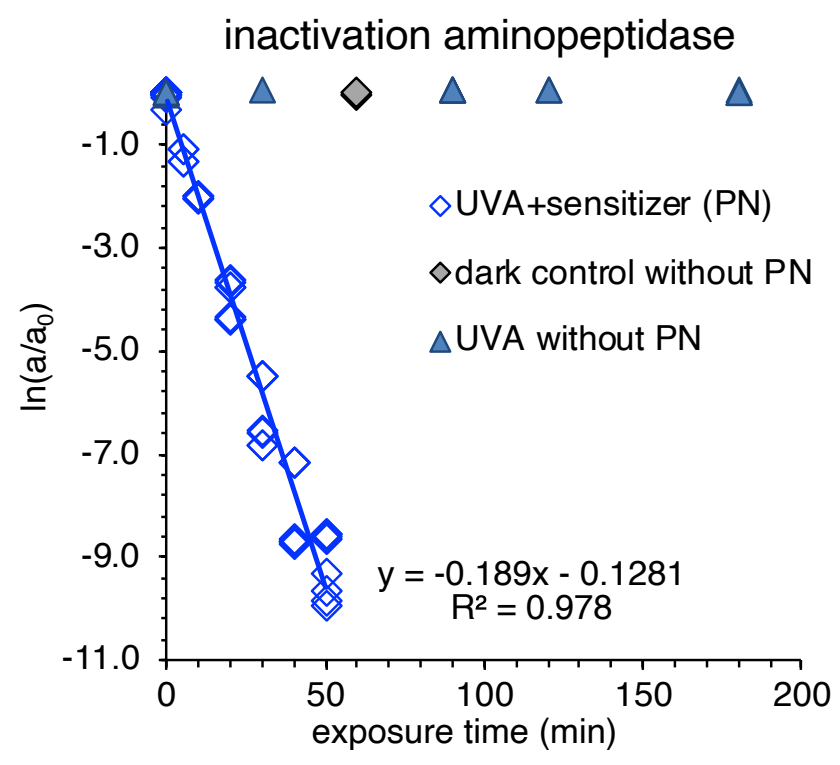

Figure S2.2 Inactivation of aminopeptidase during exposure to singlet oxygen showing stable decay over the experimental time period and stable dark control samples with linear regression parameters. The ${ }^{1} \mathrm{O}_{2}$ steady-state concentration at room temperature was calculated to $8.37 \times 10^{-11} \mathrm{M}$ and consequently the bimolecular inactivation rate constant to $3.7 \times 10^{7} \mathrm{M}^{-1} \mathrm{~s}^{-1}$. 


\section{S3 Measured site-specific reaction rate constants}

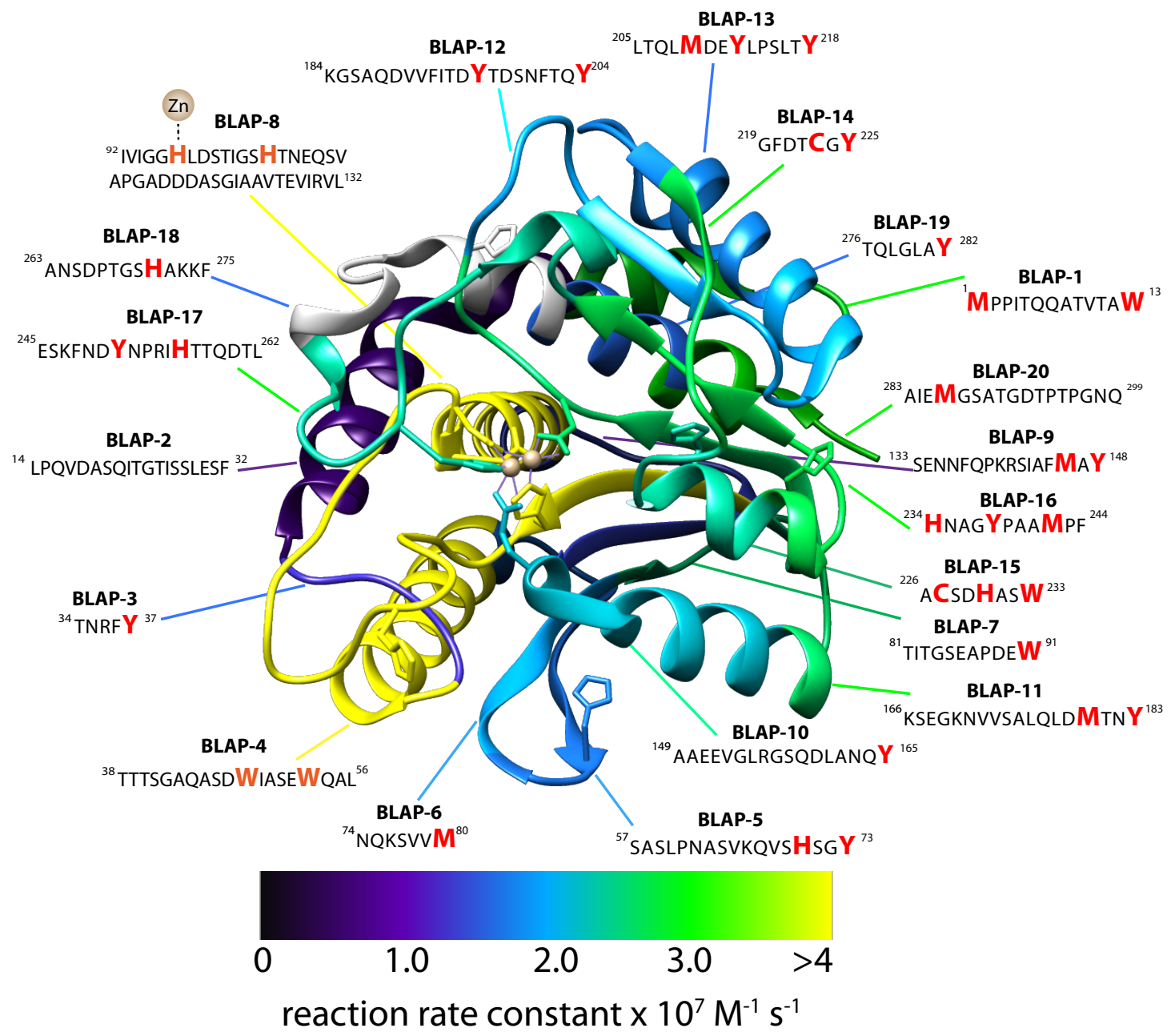

Figure S3.1 Color map with bimolecular singlet oxygen reaction rate constants for Aeromonas proteolytica leucyl aminopeptidase (BLAP, EC3.4.11.10, PDB 1RTQ). Detected peptides are indicated with the amino acid sequence and the respective number of the peptide corresponding to data in Table S3.1. Methionine (M), histidine $(\mathrm{H})$, tryptophan $(\mathrm{W})$, tyrosine $(\mathrm{Y})$, and cysteine $(\mathrm{C})$ are highlighted in red. Peptides with reaction rates with $\mathrm{R}^{2}<0.6$ are colored in grey. 


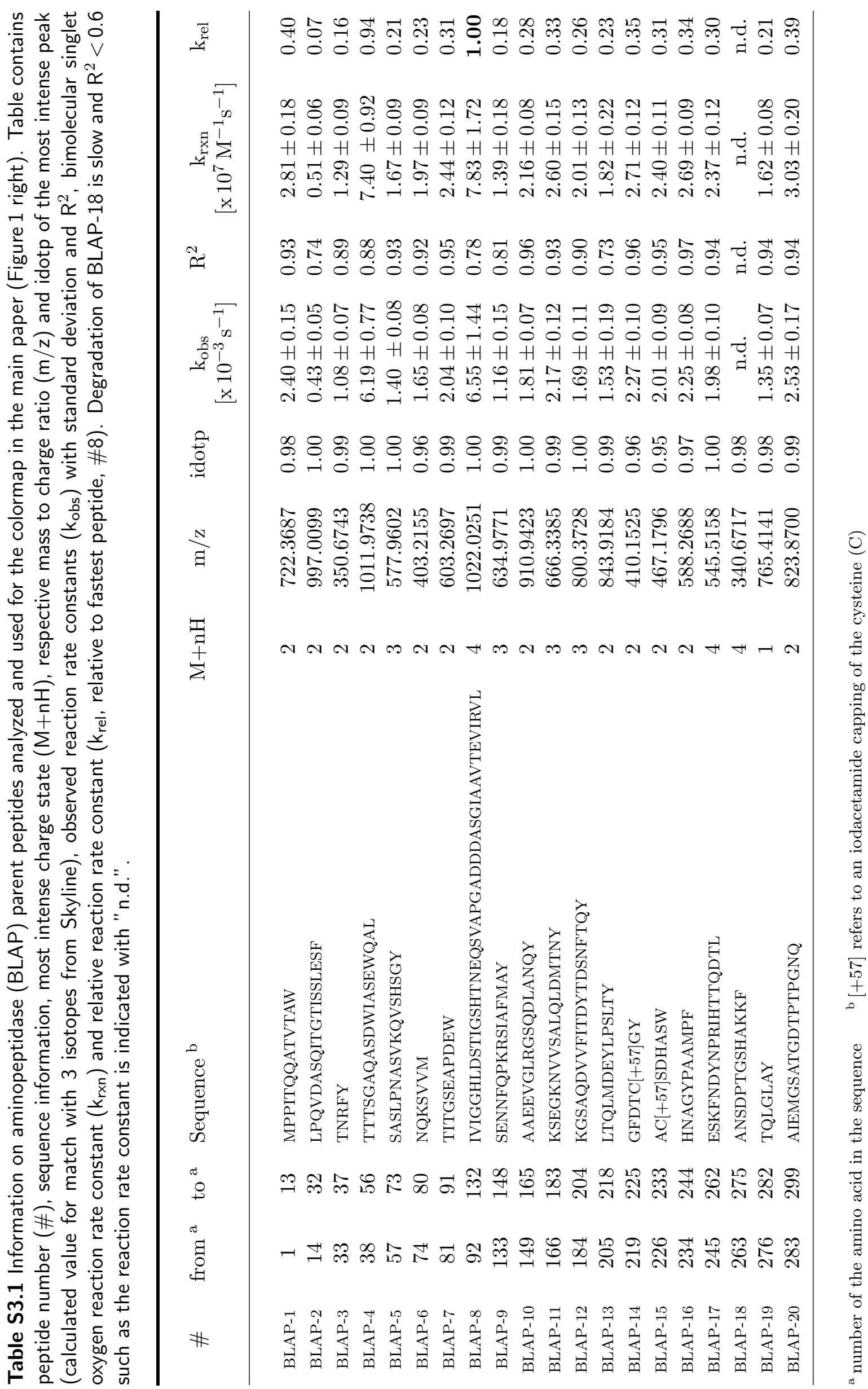



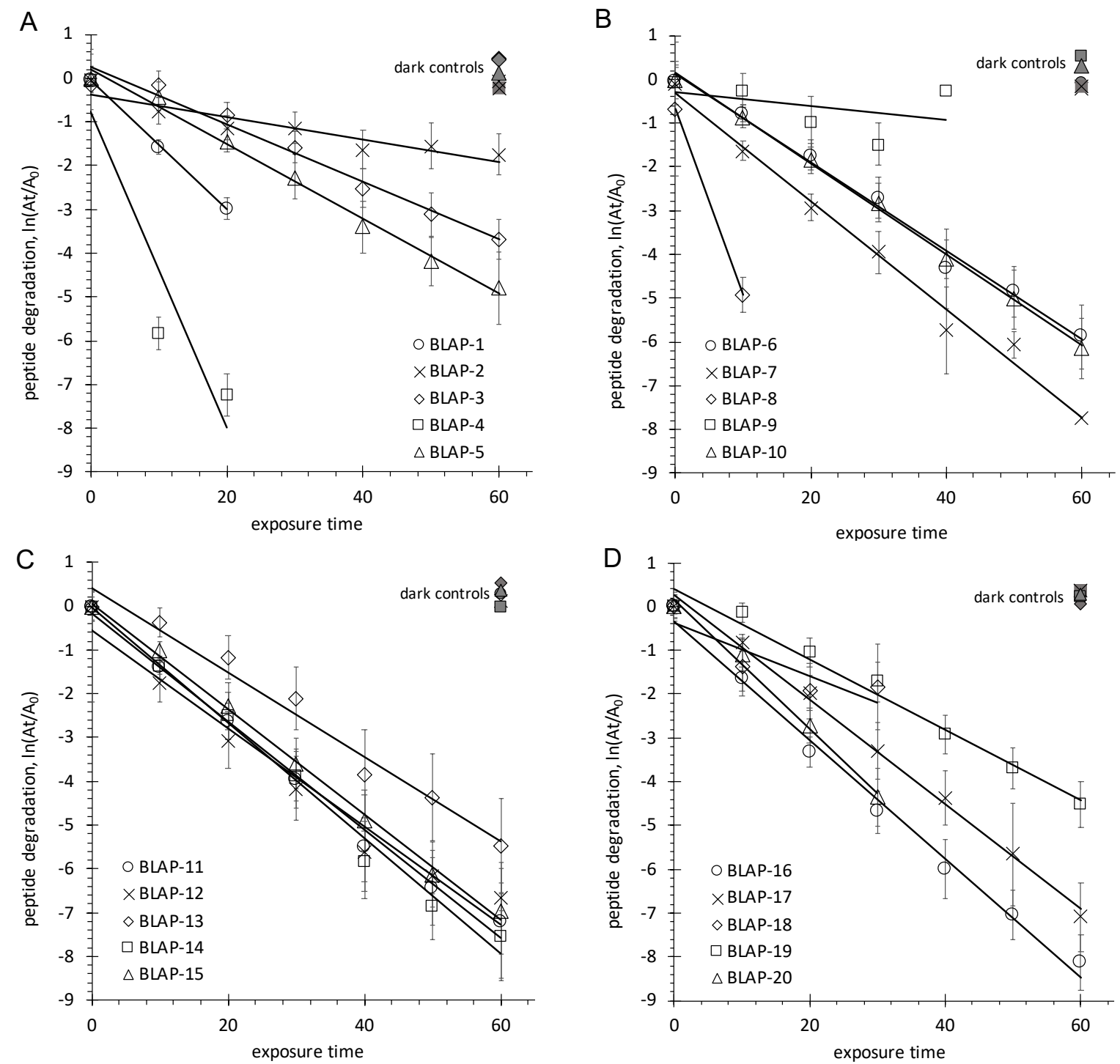

Figure S3.2 Log-normalized degradation of all parent peptides including dark controls analyzed after 60 min. A) Parent peptides number 1-5, B) 6-10, C) 11-15, and D) 16-20. Peptide numbers correspond to data in TableS3.1. 
Table S3.2 List of all detected peptides without transformation. Information on sequence, charge state $(\mathrm{M}+\mathrm{nH})$, according mass to charge ratio $(\mathrm{m} / \mathrm{z})$ and idotp value.

\begin{tabular}{|c|c|c|c|c|c|}
\hline from $^{a}$ & $t^{a}$ & Sequence & $\mathrm{Mn}+\mathrm{H}$ & idotp & $\mathrm{m} / \mathrm{z}$ \\
\hline 1 & 13 & MPPITQQATVTAW & 2 & 0.9844 & 722.3687 \\
\hline 1 & 32 & MPPITQQATVTAWLPQVDASQITGTISSLESF & 3 & 0.9941 & 1139.9131 \\
\hline 14 & 32 & LPQVDASQITGTISSLESF & 2 & 0.9974 & 997.0099 \\
\hline 14 & 37 & LPQVDASQITGTISSLESFTNRFY & 3 & 0.9860 & 892.1168 \\
\hline 27 & 56 & YTTTSGAQASDWIASEWQAL & 3 & 0.9978 & 729.3394 \\
\hline 30 & 37 & ESFTNRFY & 2 & 0.9783 & 532.2458 \\
\hline 33 & 36 & TNRF & 2 & 0.9484 & 269.1426 \\
\hline 33 & 37 & TNRFY & 2 & 0.9908 & 350.6743 \\
\hline 33 & 48 & TNRFYTTTSGAQASDW & 2 & 0.9781 & 903.4081 \\
\hline 37 & 53 & YTTTSGAQASDWIASEW & 2 & 0.9938 & 937.4156 \\
\hline 38 & 48 & TTTSGAQASDW & 2 & 0.9820 & 562.7464 \\
\hline 38 & 53 & TTTSGAQASDWIASEW & 2 & 0.9947 & 855.8839 \\
\hline 38 & 56 & TTTSGAQASDWIASEWQAL & 2 & 0.9962 & 1011.9738 \\
\hline 49 & 53 & IASEW & 1 & 0.9833 & 605.2930 \\
\hline 49 & 56 & IASEWQAL & 2 & 0.9775 & 459.2400 \\
\hline 54 & 56 & QAL & 1 & 0.9522 & 331.1976 \\
\hline 54 & 73 & QALSASLPNASVKQVSHSGY & 3 & 0.9964 & 682.0201 \\
\hline 57 & 73 & SASLPNASVKQVSHSGY & 3 & 0.9951 & 577.9602 \\
\hline 74 & 80 & NQKSVVM & 2 & 0.9625 & 403.2155 \\
\hline 74 & 80 & NQKSVVM & 1 & 0.9411 & 805.4236 \\
\hline 74 & 80 & NQKSVVM & 2 & 0.9637 & 403.2155 \\
\hline 74 & 91 & NQKSVVMTITGSEAPDEW & 2 & 0.9746 & 996.4726 \\
\hline 81 & 91 & TITGSEAPDEW & 2 & 0.9866 & 603.2697 \\
\hline 92 & 98 & IVIGGHL & 2 & 0.9420 & 354.7238 \\
\hline 92 & 132 & IVIGGHLDSTIGSHTNEQSVAPGADDDASGIAAVTEVIRVL & 4 & 0.9974 & 1022.0251 \\
\hline 93 & 204 & ITDYTDSNFTQY & 2 & 0.9901 & 734.3174 \\
\hline 99 & 132 & DSTIGSHTNEQSVAPGADDDASGIAAVTEVIRVL & 3 & 0.9100 & 1132.5569 \\
\hline 133 & 145 & SENNFQPKRSIAF & 3 & 0.9972 & 513.2634 \\
\hline 133 & 148 & SENNFQPKRSIAFMAY & 3 & 0.9902 & 634.9771 \\
\hline 138 & 145 & QPKRSIAF & 3 & 0.9831 & 316.1871 \\
\hline 146 & 148 & MAY & 1 & & 384.1588 \\
\hline 146 & 154 & MAYAAEEVGL & 2 & 0.9284 & 527.2497 \\
\hline 146 & 165 & MAYAAEEVGLRGSQDLANQY & 3 & 0.9923 & 729.3443 \\
\hline 149 & 155 & AAEEVGL & 1 & 0.9743 & 688.3512 \\
\hline 149 & 161 & AAEEVGLRGSQDL & 2 & 0.9881 & 672.8413 \\
\hline 149 & 165 & AAEEVGLRGSQDLANQY & 3 & 0.9972 & 607.6306 \\
\hline 149 & 165 & AAEEVGLRGSQDLANQY & 2 & 0.9953 & 910.9423 \\
\hline 156 & 165 & RGSQDLANQY & 2 & 0.9919 & 576.2756 \\
\hline
\end{tabular}




\begin{tabular}{|c|c|c|c|c|c|}
\hline from $^{a}$ & $\mathrm{t}^{\mathrm{a}}$ & Sequence & $\mathrm{Mn}+\mathrm{H}$ & idotp & $\mathrm{m} / \mathrm{z}$ \\
\hline 166 & 176 & KSEGKNVVSAL & 3 & 0.9883 & 377.8838 \\
\hline 166 & 179 & KSEGKNVVSALQL & 3 & 0.9858 & 458.2647 \\
\hline 166 & 183 & KSEGKNVVSALQLDMTNY & 3 & 0.9932 & 666.3385 \\
\hline 177 & 183 & QLDMTNY & 2 & 0.9508 & 442.6946 \\
\hline 178 & 196 & DMTNYKGSAQDVVFITDY & 2 & 0.9903 & 1033.9724 \\
\hline 184 & 192 & KGSAQDVVF & 2 & 0.9891 & 475.7507 \\
\hline 184 & 196 & KGSAQDVVFITDY & 2 & 0.9906 & 721.8617 \\
\hline 184 & 204 & KGSAQDVVFITDYTDSNFTQY & 3 & 0.9988 & 800.3728 \\
\hline 184 & 204 & KGSAQDVVFITDYTDSNFTQY & 2 & & 1200.0555 \\
\hline 184 & 205 & KGSAQDVVFITDYTDSNFTQYL & 3 & 0.9710 & 838.0675 \\
\hline 197 & 204 & TDSNFTQY & 2 & 0.9918 & 488.2063 \\
\hline 202 & 210 & TQYLTQLMDEY & 2 & 0.9741 & 702.8212 \\
\hline 205 & 218 & LTQLMDEYLPSLTY & 2 & 0.9925 & 843.9184 \\
\hline 206 & 218 & TQLMDEYLPSLTY & 2 & 0.9835 & 787.3764 \\
\hline 213 & 218 & LPSLTY & 1 & 0.9334 & 693.3818 \\
\hline 219 & 225 & GFDTC $[+57] \mathrm{GY}$ & 2 & 0.9642 & 410.1525 \\
\hline 219 & 233 & GFDTC ++57$]$ GYAC $[+57]$ SDHASW & 2 & 0.9847 & 867.3196 \\
\hline 226 & 233 & $\mathrm{AC}[+57] \mathrm{SDHASW}$ & 2 & 0.9452 & 467.1796 \\
\hline 226 & 244 & AC[+57]SDHASWHNAGYPAAMPF & 3 & 0.9862 & 697.2930 \\
\hline 234 & 244 & HNAGYPAAMPF & 2 & 0.9654 & 588.2688 \\
\hline 234 & 248 & HNAGYPAAMPFESKF & 3 & 0.9905 & 556.2609 \\
\hline 245 & 247 & ESKF & 2 & 0.9668 & 255.6316 \\
\hline 245 & 250 & ESKFNDY & 2 & 0.9777 & 451.6982 \\
\hline 245 & 262 & ESKFNDYNPRIHTTQDTL & 4 & 0.9974 & 545.5158 \\
\hline 245 & 275 & ESKFNDYNPRIHTTQDTLANSDPTGSHAKKF & 4 & 0.9928 & 880.6776 \\
\hline 249 & 262 & NDYNPRIHTTQDTL & 3 & 0.9959 & 563.2727 \\
\hline 249 & 275 & NDYNPRIHTTQDTLANSDPTGSHAKKF & 4 & 0.9642 & 757.8681 \\
\hline 252 & 262 & NPRIHTTQDTL & 3 & 0.9802 & 432.5616 \\
\hline 263 & 275 & ANSDPTGSHAKKF & 4 & 0.9809 & 340.6717 \\
\hline 276 & 278 & TQL & 1 & 0.9527 & 361.2082 \\
\hline 276 & 280 & TQLGL & 1 & 0.9767 & 531.3137 \\
\hline 276 & 282 & TQLGLAY & 2 & 0.9812 & 383.2107 \\
\hline 276 & 282 & TQLGLAY & 1 & 0.9840 & 765.4141 \\
\hline 276 & 299 & TQLGLAYAIEMGSATGDTPTPGNQ & 3 & 0.9959 & 798.3812 \\
\hline 279 & 282 & GLAY & 1 & 0.9700 & 423.2238 \\
\hline 281 & 299 & AYAIEMGSATGDTPTPGNQ & 2 & 0.9985 & 940.9202 \\
\hline 283 & 299 & AIEMGSATGDTPTPGNQ & 2 & 0.9887 & 823.8700 \\
\hline
\end{tabular}

${ }^{\mathrm{a}}$ number of the amino acid in the sequence 


\section{S4 Predicted site-specific reaction rate constants based on sin- glet oxygen accessible surface area $\left({ }^{1} \mathrm{O}_{2}\right.$-ASA $)$}
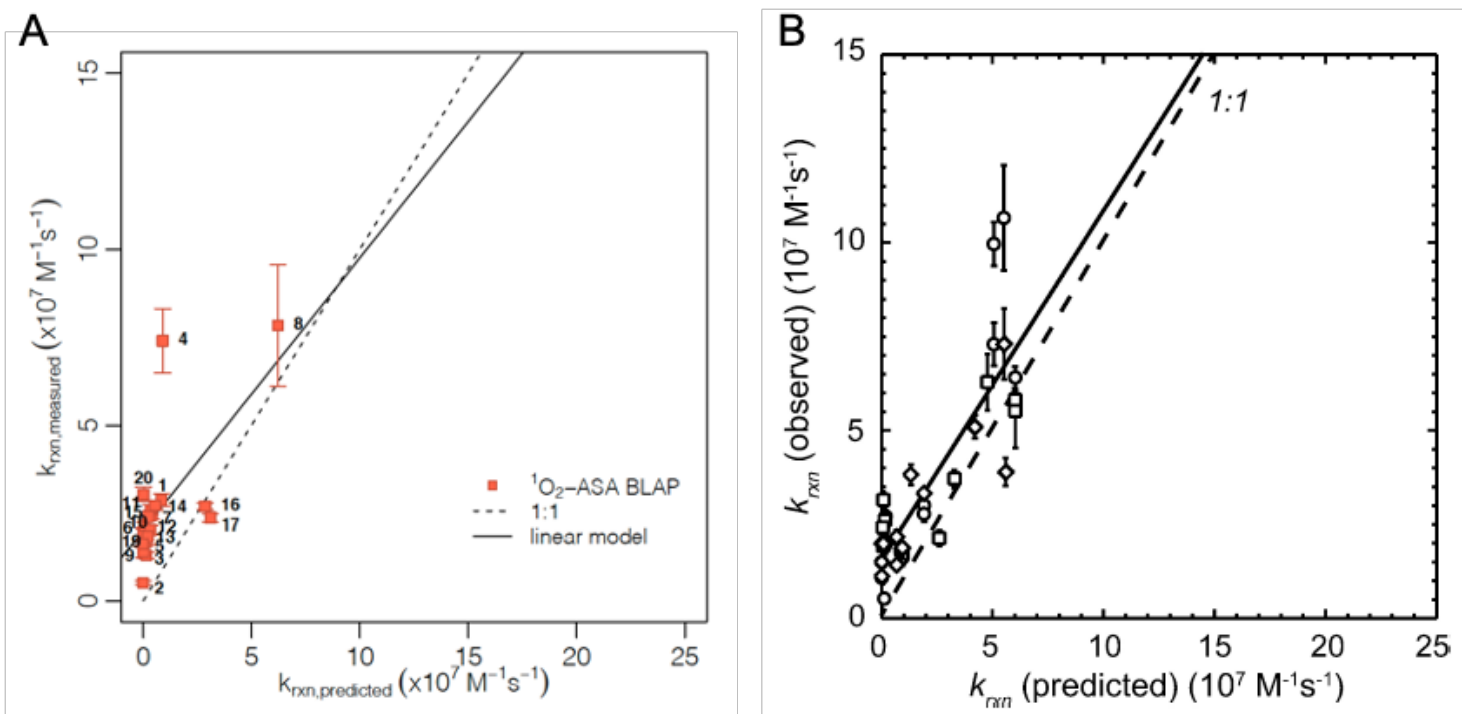

Figure S4.1 A) Measured vs. predicted reaction rate constant of all peptides of aminopeptidase (BLAP, red) with 1:1 line (dashed line) and linear regression of measured data; $y=0.78 \cdot x+2.0 \cdot 10^{7}$, $\mathrm{R}^{2}=0.44$ (solid line). Predicted reaction rate constants were calculated according to Equation 1 as suggested earlier. ${ }^{3}$ B) Measured versus predicted reaction rate constant of glyceraldehyde-3phosphate dehydrogenase (GAPDH) peptides from ${ }^{1} \mathrm{O}_{2}$ experiments with $1: 1$ line (dashed line) and the linear regression; $y=0.93 \cdot x+1.53 \cdot 10^{7}, R^{2}=0.72$ (solid line). Panel $B$ is reprinted with permission from (Lundeen and McNeill, "Reactivity Differences of Combined and Free Amino Acids: Quantifying the Relationship between Three-Dimensional Protein Structure and Singlet Oxygen Reaction Rates", Environmental Science \& Technology, 2013). Copyright (2019) American Chemical Society. ${ }^{3}$ 


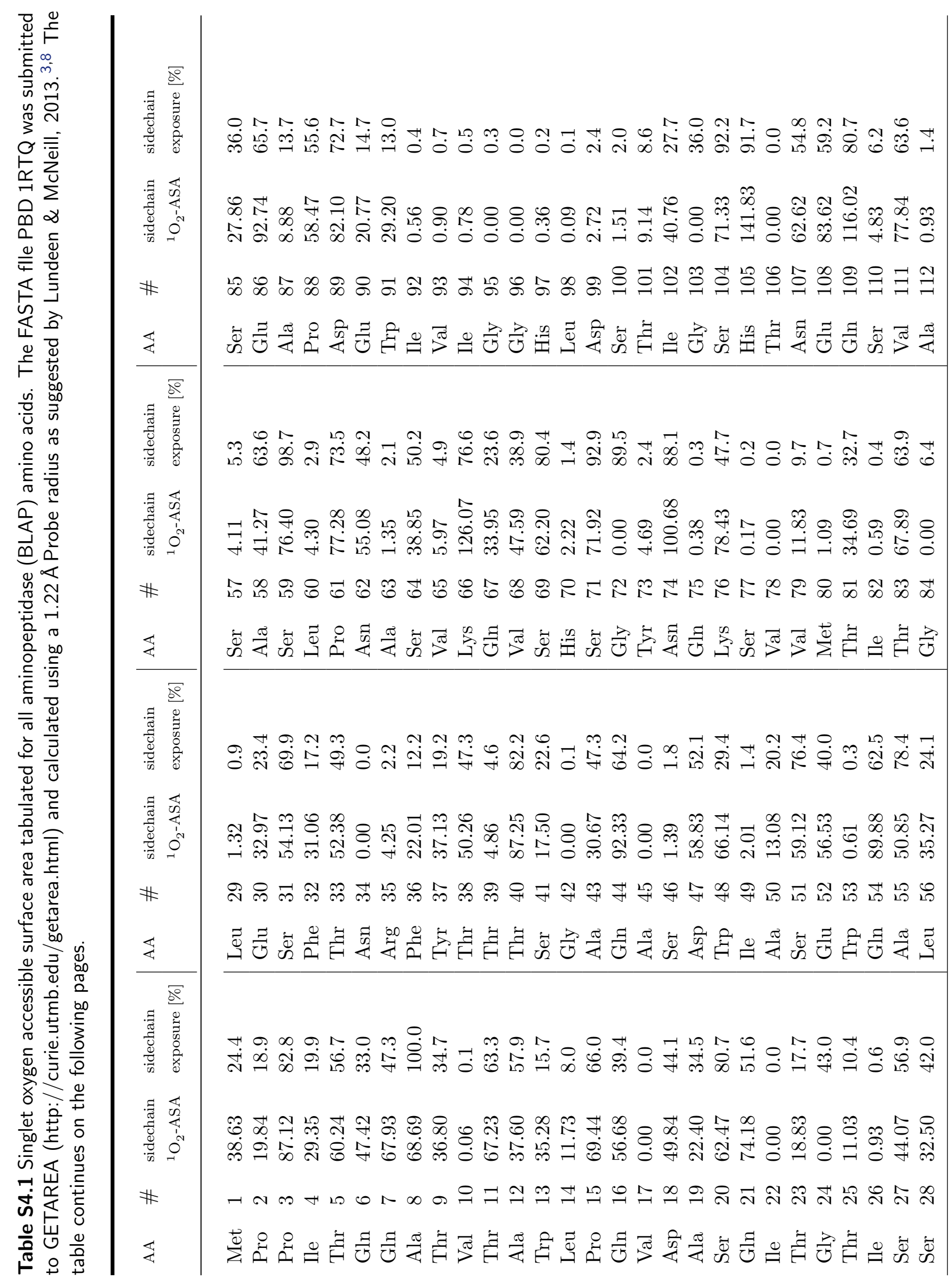




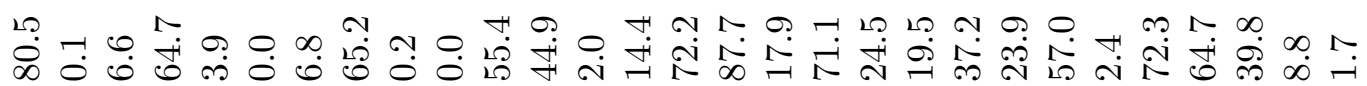

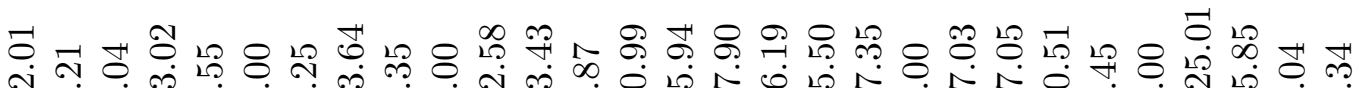
ठำ

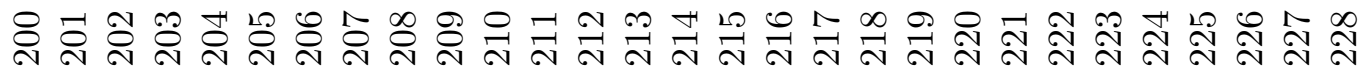

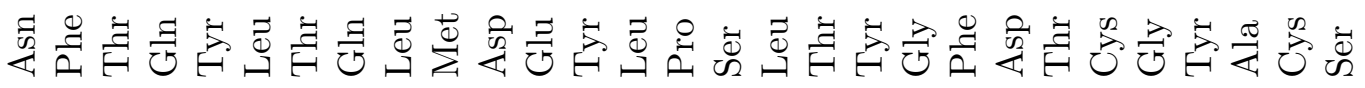

绾

수웅 ஷ்

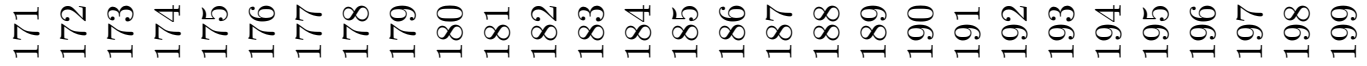

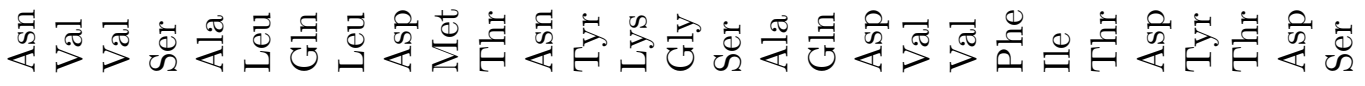

Ғ

药 円

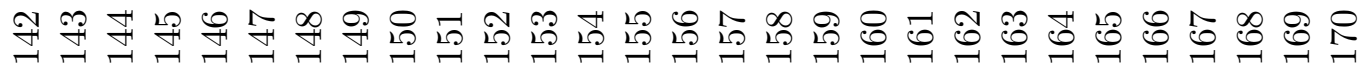

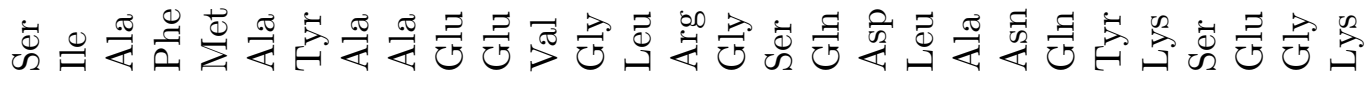



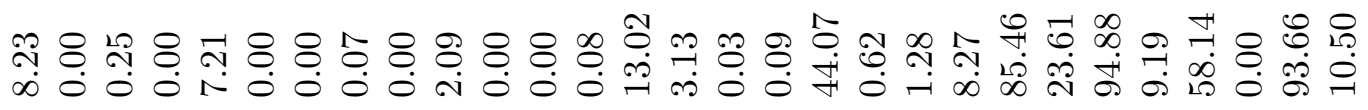
\#

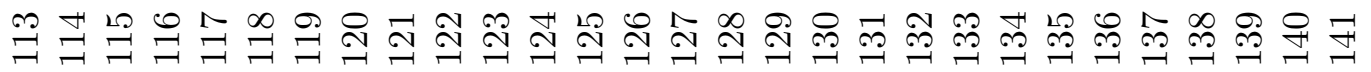
$\varangle$

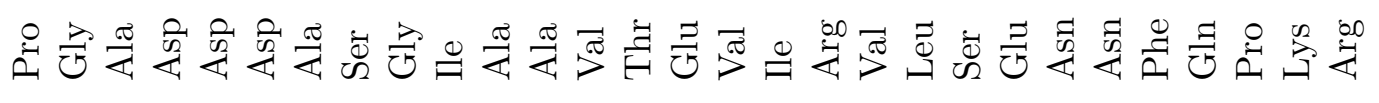




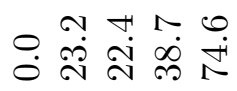

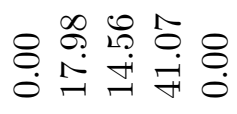

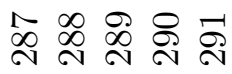

\#

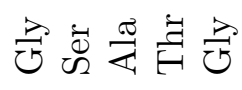

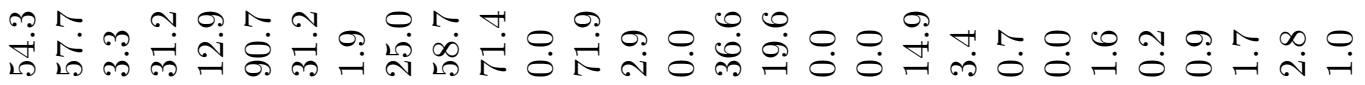

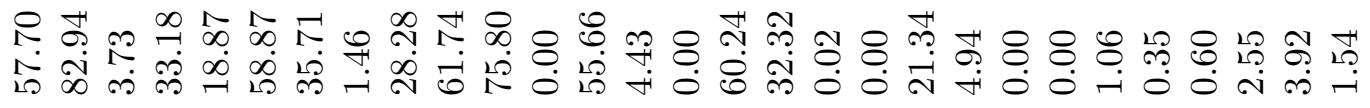

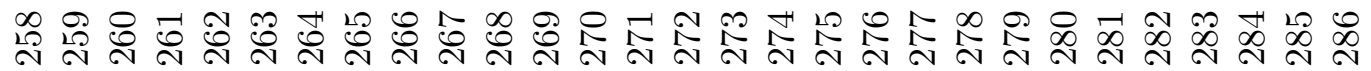

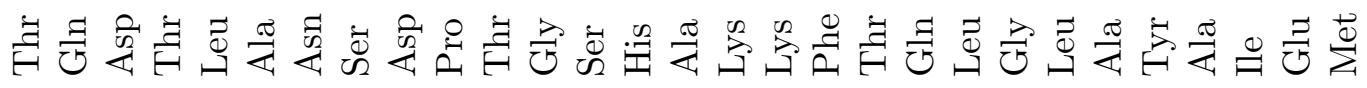

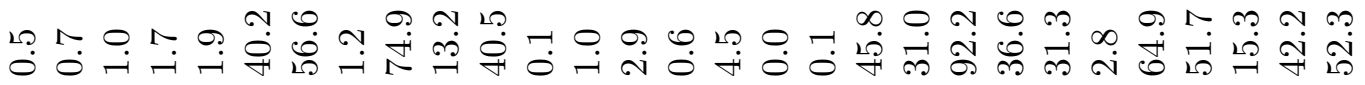

ชำ

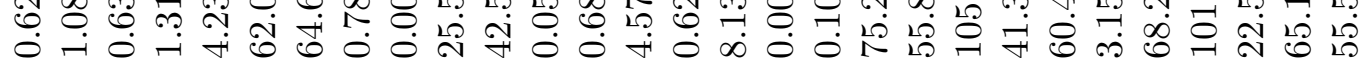

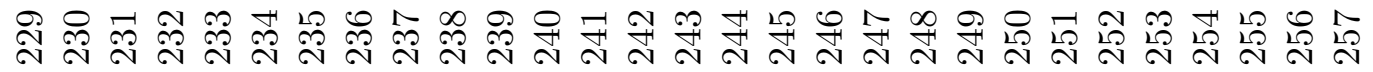
$\ll$

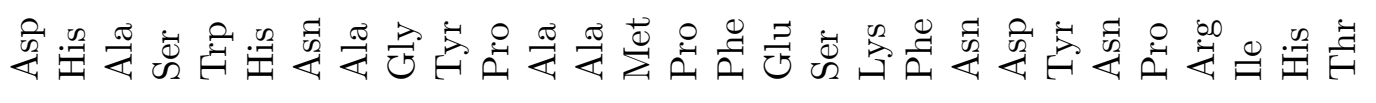


S5 Transformation products 


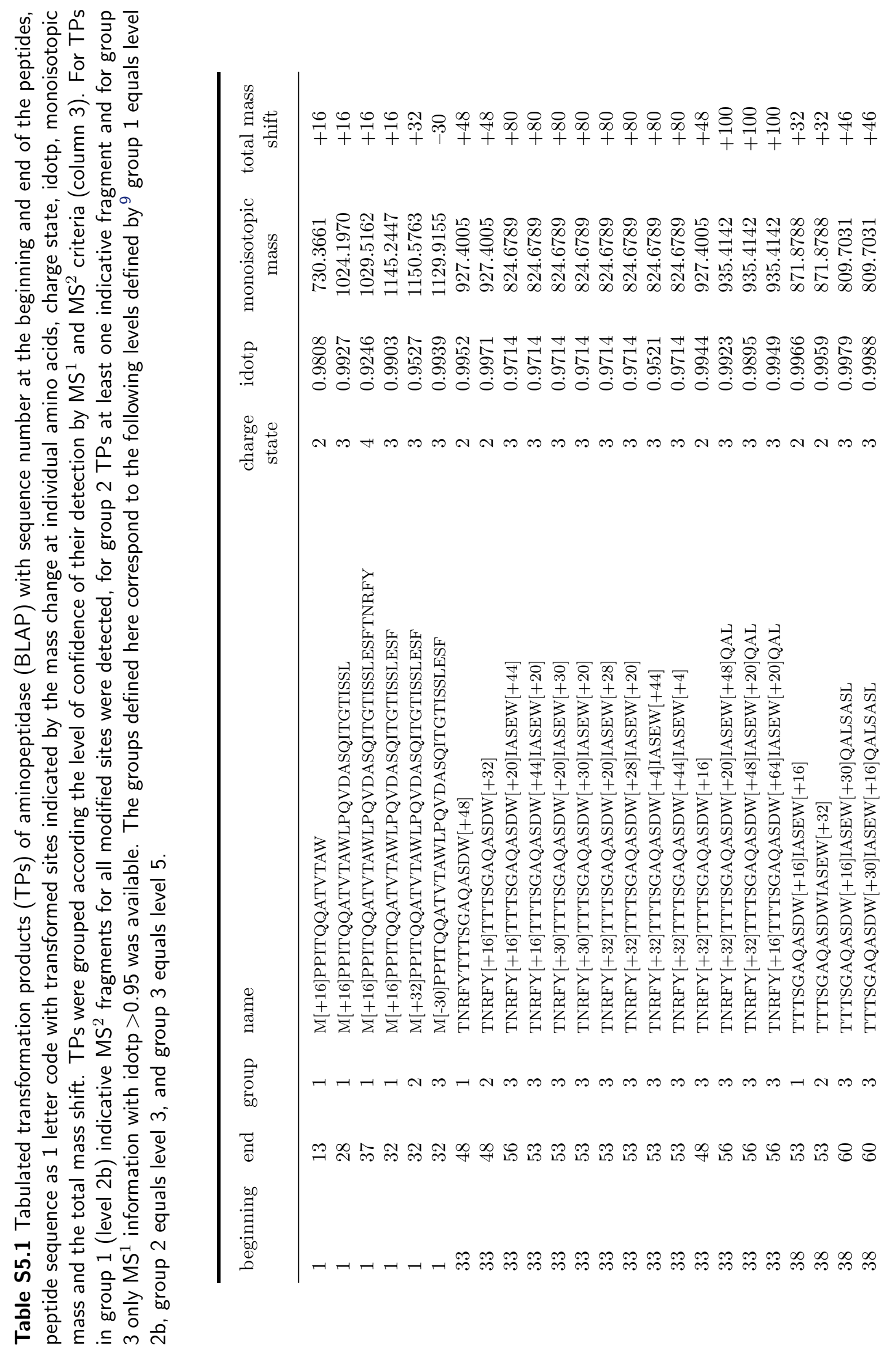




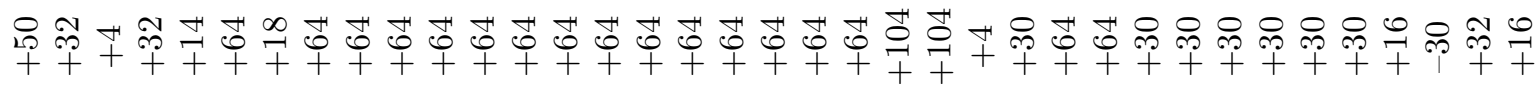

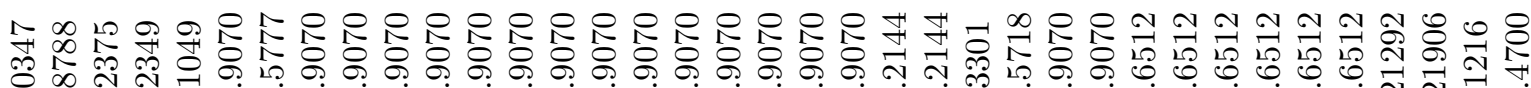

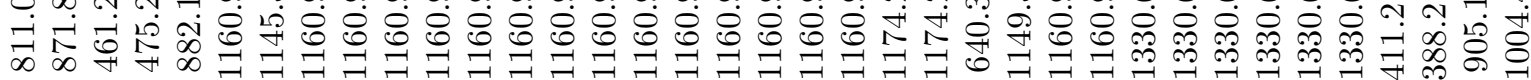

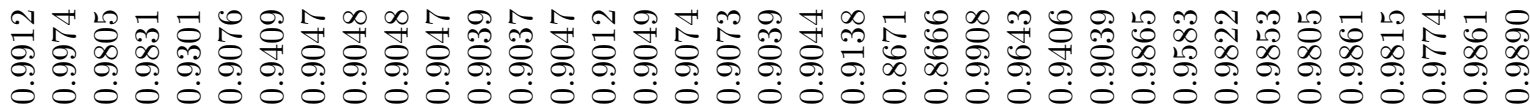

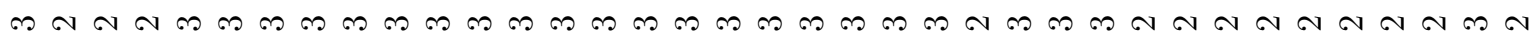

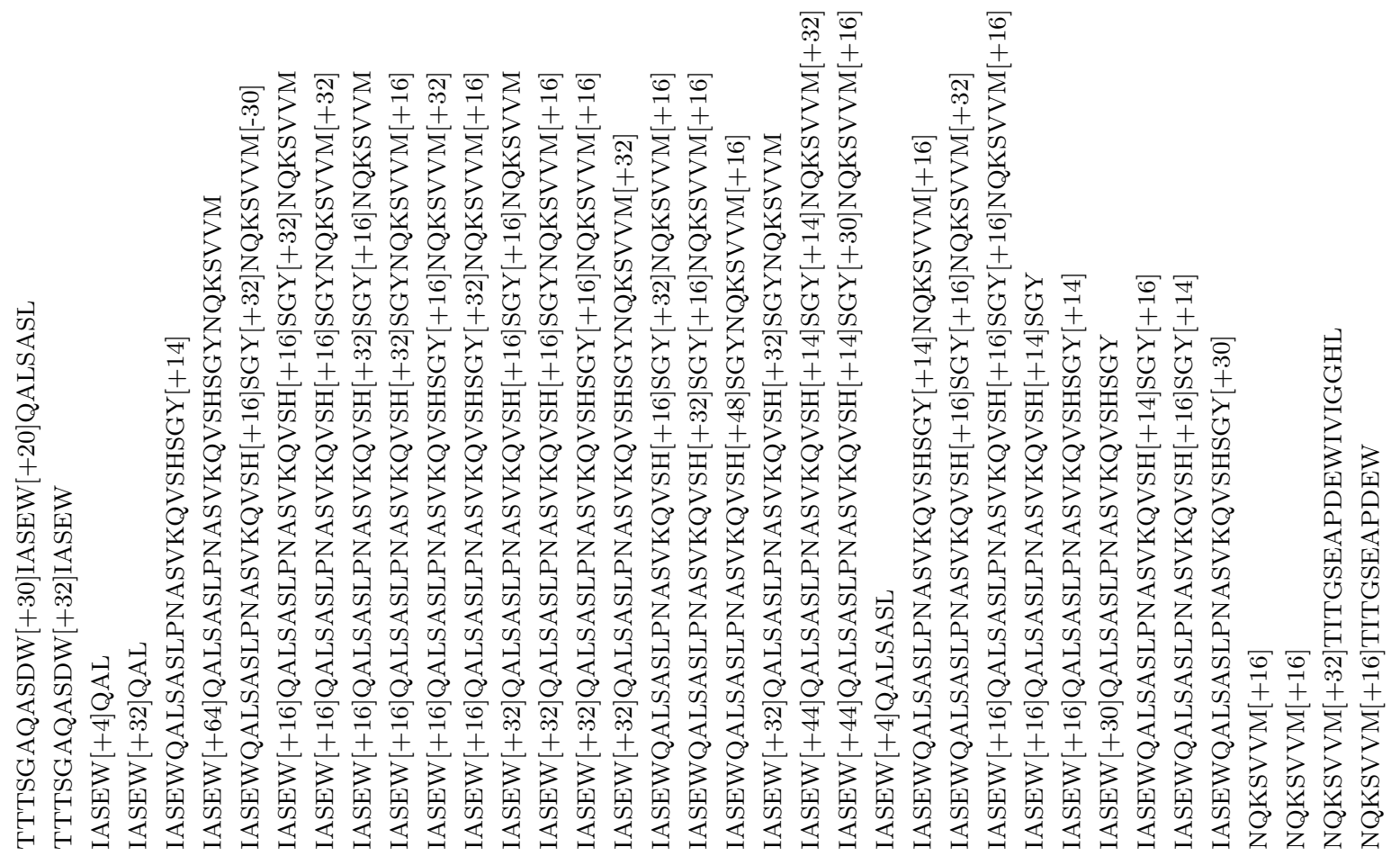

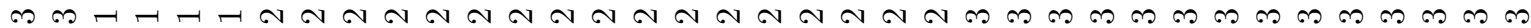

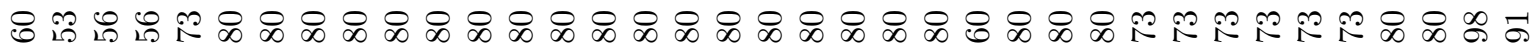

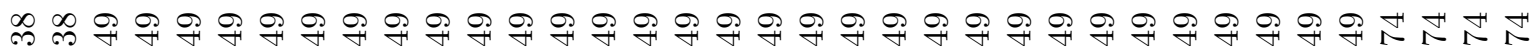




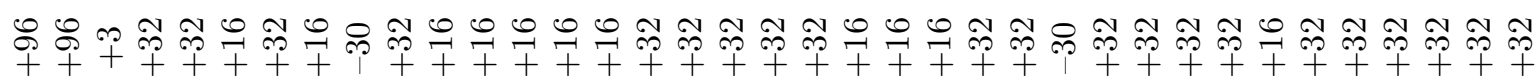

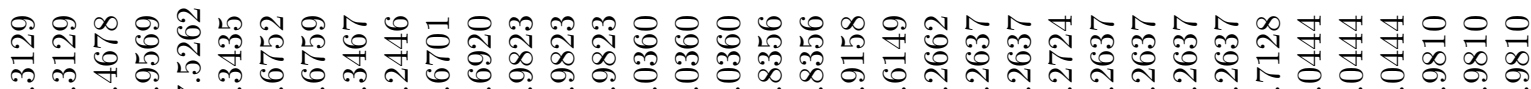

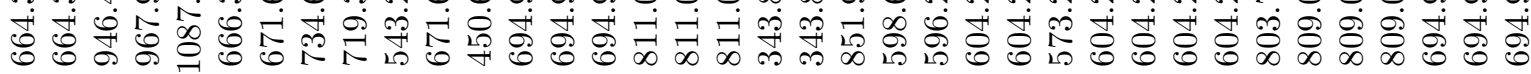

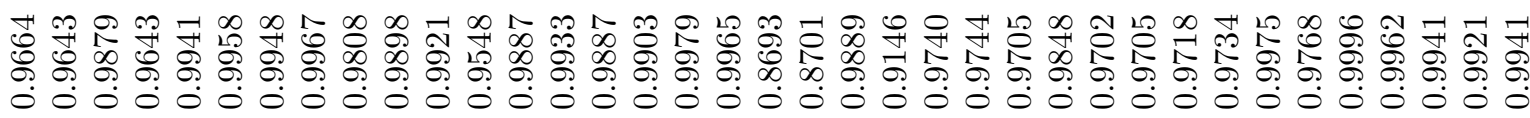

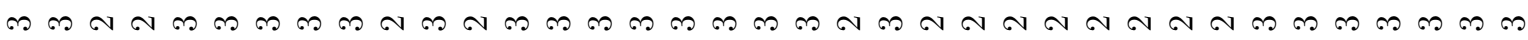

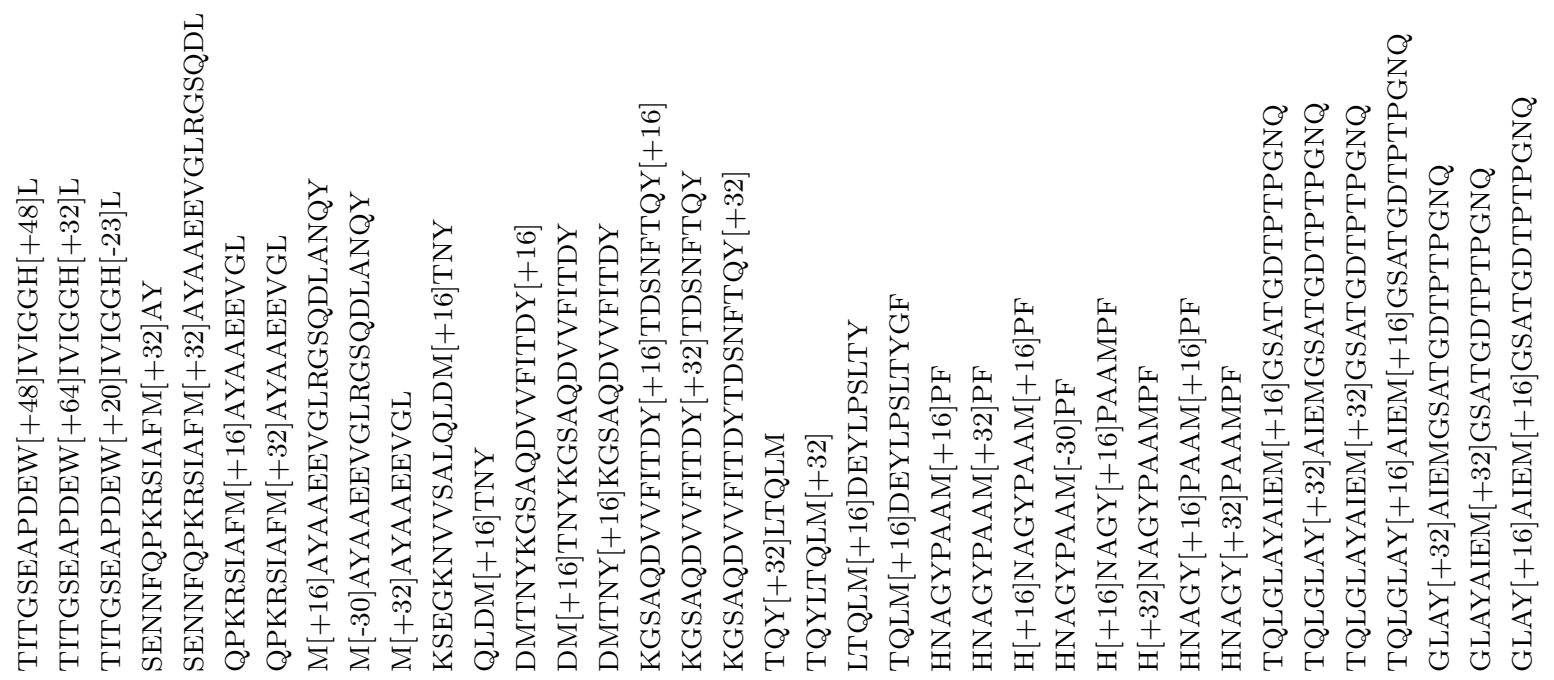

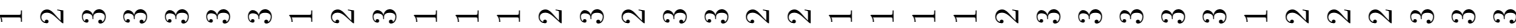

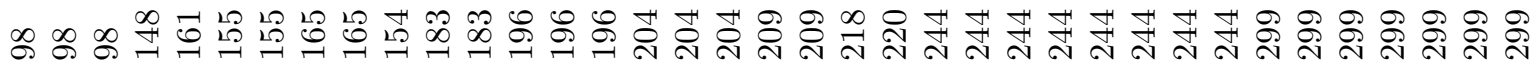

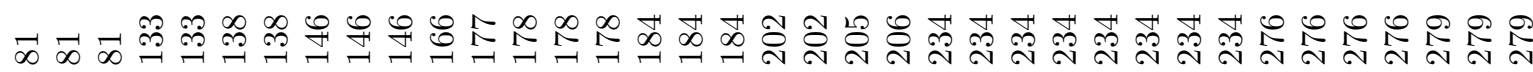


0 웅
$+\underset{+}{+}$
+

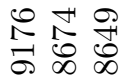

के

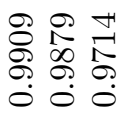

$\sim \sim \sim$

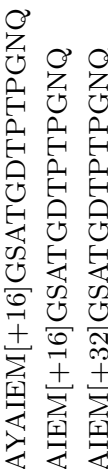

$\infty-\infty$

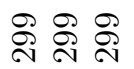

$\underset{\sim}{\infty} \stackrel{\infty}{\infty} \underset{\sim}{\infty} \stackrel{\infty}{\sim}$ 


\section{S6 Degradation of Met-containing peptides}
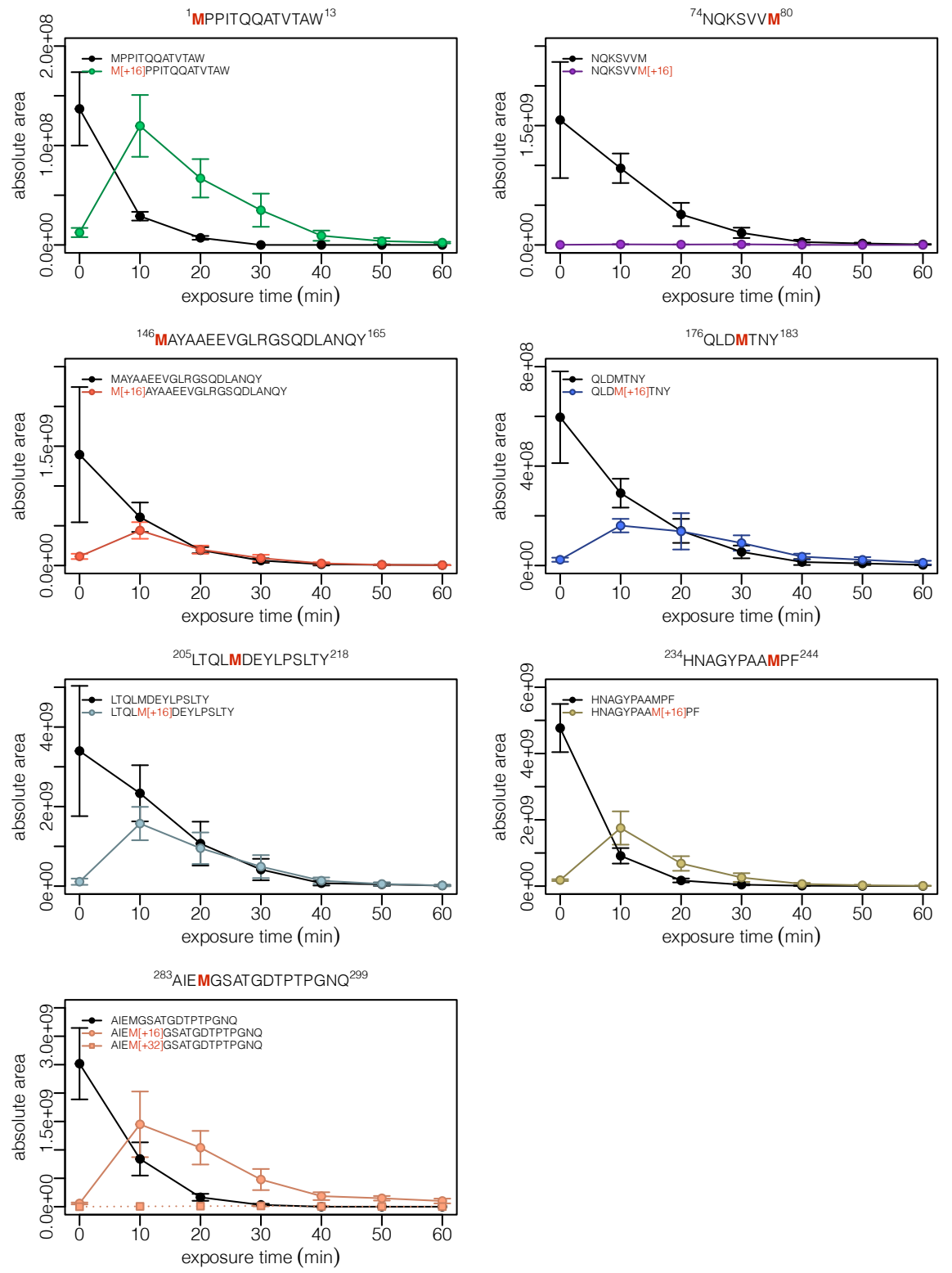

Figure S6.1 Degradation of all Met-containing aminopeptidase (BLAP) peptides and formation of the corresponding methionine sulfoxide products. Titles describe the corresponding peptide sequence with 1-letter-code and respective sequence numbers. Data is given in absolute peak areas over the time course of UVA irradiation experiment in presence of singlet oxygen. 


\section{S7 Singlet oxygen-induced histidine degradation pathway}

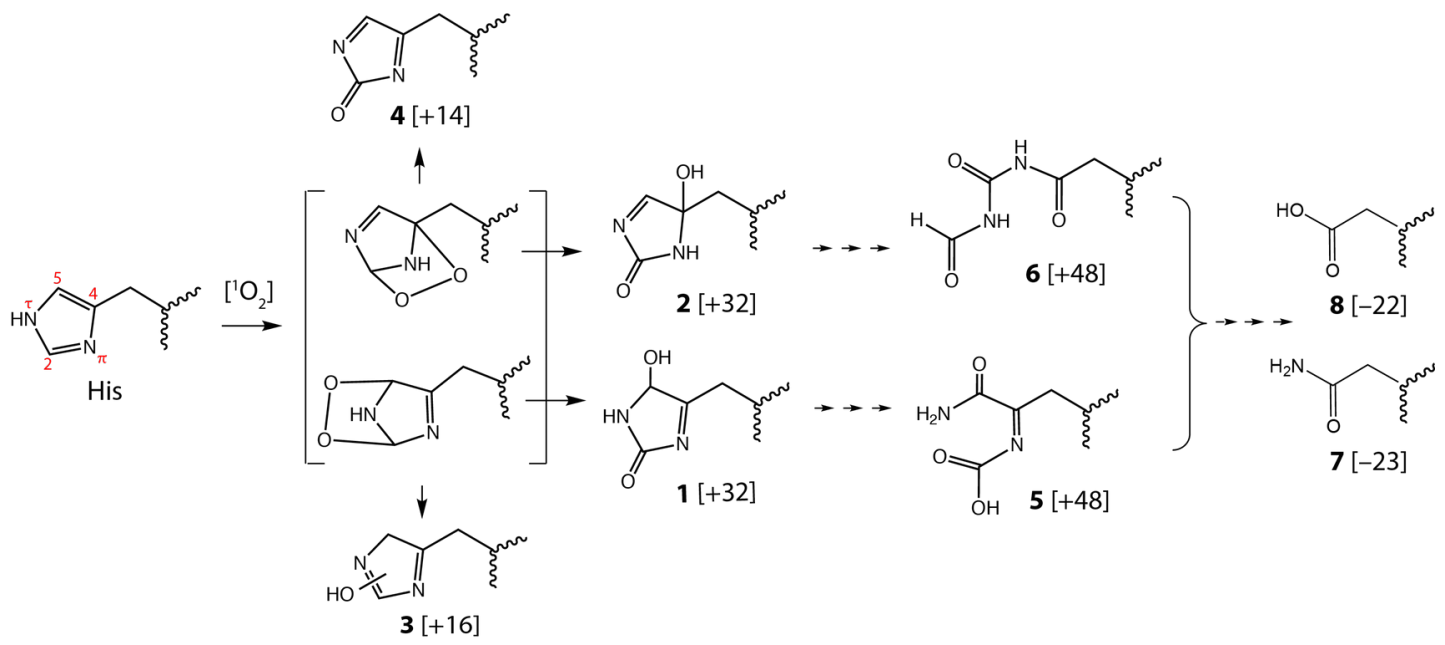

Figure S7.1 Proposed ${ }^{1} \mathrm{O}_{2}$-induced histidine degradation pathways based on published literature. Histidine oxidation by ${ }^{1} \mathrm{O}_{2}$ is initiated by the formation of endoperoxides at the imidazole ring via 2,4or 2,5-cycloaddition. The endoperoxides react further to a 5- or 4-hydroxy-2-oxo-histidine (hydroxyimidazolones) with a mass shift of $+32 \mathrm{Da}(\mathbf{1}$ and 2$)$. These intermediates have been found to react further via radical-based ring opening to form products including triply oxidized histidine with +48 Da (5 and 6), asparagine with -23 Da (7), and aspartic acid with -22 Da (8). The endoperoxides have also been proposed to form other intermediates such as hydroxy-histidine with $+16 \mathrm{Da}(3)$ or 2-oxo-histidine (imidazolones) with $+14 \mathrm{Da}$ (4). Whereas, the hydroxy-histidine could be present in a form that is hydroxylated at $\mathrm{C} 2, \mathrm{C} 4$ or $\mathrm{C} 5$ or as the ketone at $\mathrm{C} 4$ or $\mathrm{C} 2$ (keto-enol tautomers). ${ }^{10-14}$ 

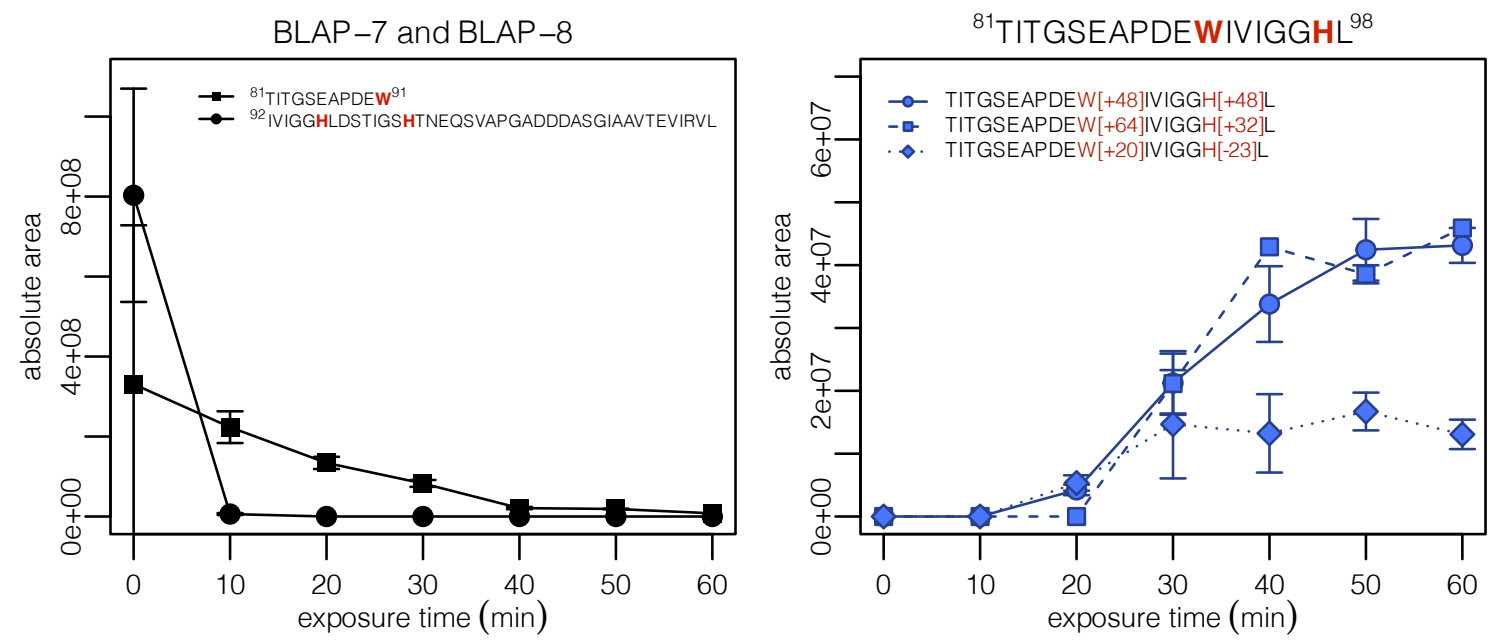

Figure S7.2 (left) Degradation of BLAP-7 (black squares) and BLAP-8 (black circles). BLAP-8 transforms almost completely within 10 minutes and represents the fastest degrading aminopeptidase peptide with $\mathrm{k}_{\text {rel, }} \mathrm{BLAP}-8=1.00$. Anterior $\mathrm{BLAP}-7$ degrades much slower and has a $\mathrm{k}_{\text {rel, }} \mathrm{BLAP}-7=0.31$. (right) Late formation of combined TPs covering W91 of BLAP-7 together with $\mathrm{H} 97$ of BLAP-8. We did not detect the unmodified parent for this peptide or TPs at $\mathrm{H} 105$. Solid lines correspond to a TP with confidence level $2 b$, dashed lines to level 3 , dotted lines to level 5. Relative reaction rate constants $\left(\mathrm{k}_{\text {rel }}\right)$ are expressed relative to the fastest degrading peptide of the respective enzyme. 


\section{S8 Degradation of tyrosine-containing peptides}
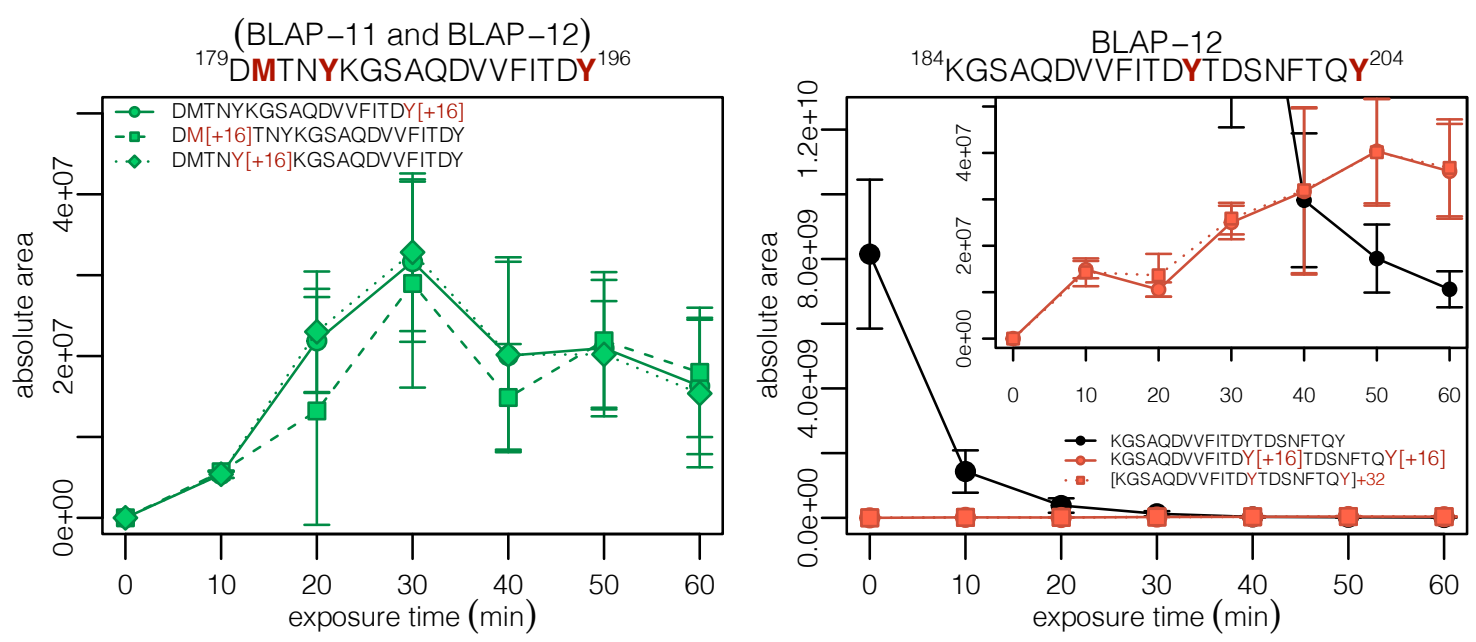

Figure S8.1 (left) Formation of peptides covering the partial sequence of BLAP-11 and -12 , including TPs containing modifications of M180, Y183 and Y196 with a molecular change of +16 Da, each (green squares, diamonds and circles, respectively). (right) Degradation of tyrosine-containing BLAP-12 (black) and formation of transformation products, including a TP with Y196 and Y204 DOPA ( $+16 \mathrm{Da}$, red circles) as well as one with Y196 or Y204 TOPA (+32 Da, red squares). Solid lines correspond to a TP with confidence level $2 b$, dashed lines to level 3 , and dotted to level 5 (Tables S5.1).

\section{S9 Chromatograms and $\mathrm{MS}^{2}$ fragment comparison}

The following section shows for all parent peptides and transformation products: (1) overlay of chromatograms for sampled time points and control (number 79 or 81) and (2) a comparison of the measured (red) to the in silico predicted $\mathrm{MS}^{2}$ fragments (grey). The header of each figure pair contains the amino acid sequence numbers, and the name of the respective enzyme and peptide as the 1 letter amino acid code. Fragments that match the in silico predicted fragment with $\pm 0.005 \mathrm{~m} / \mathrm{z}$ are indicated with black dots. The chromatograms were not retention time aligned. The in silico prediction data was generated and extracted from Skyline. The MS ${ }^{2}$ plots were generated using the R packages MSMSsim and RMassBank. ${ }^{15,16}$ 


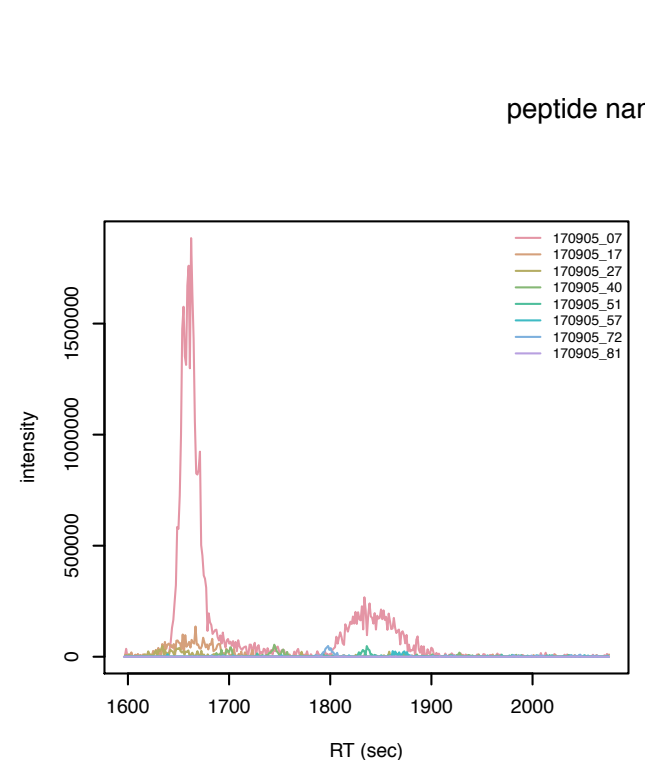

$1-13$

BLAP

peptide name: MPPITQQATVTAW

MPPITQQATVTAW

170905_07.mzXML_mz722_37_rt30_60_HCD20.txt

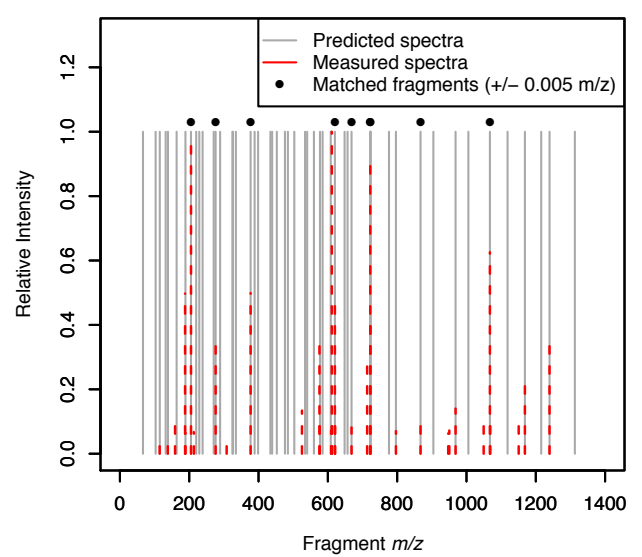

$1-32$

BLAP

peptide name: MPPITQQATVTAWLPQVDASQITGTISSLESF

MPPITQQATVTAWLPQVDASQITGTISSLESF 170905_07.mzXML_mz1139_91_rt57_39_HCD20.txt
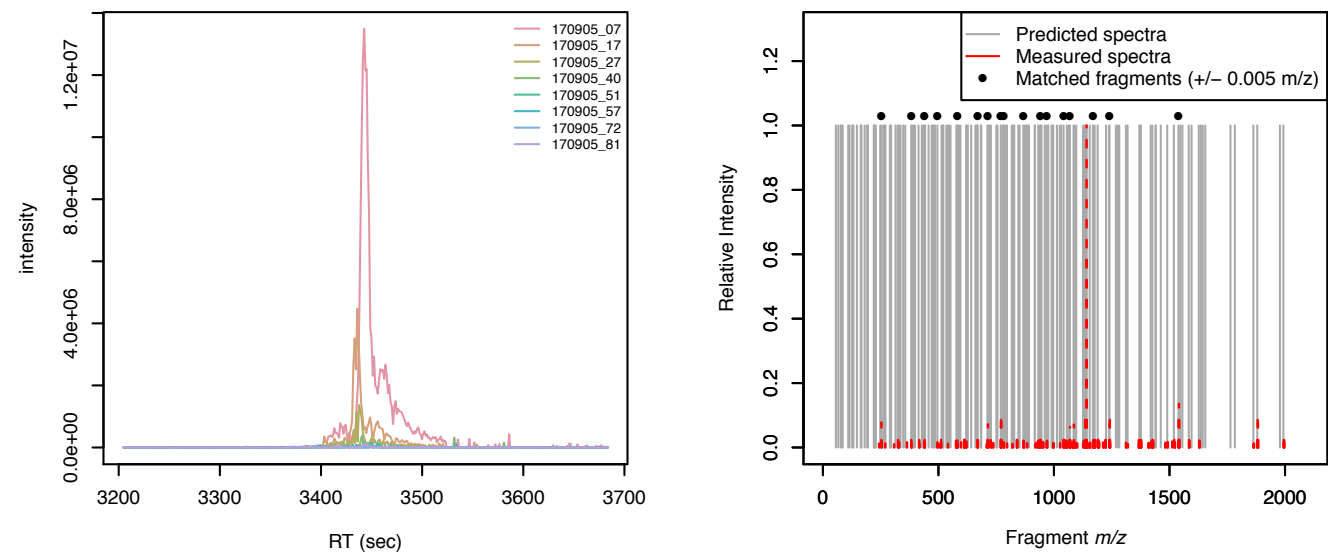

14-32

BLAP peptide name: LPQVDASQITGTISSLESF

LPQVDASQITGTISSLES 170905_07.mzXML_mz997_01_rt51_57_HCD20.txt
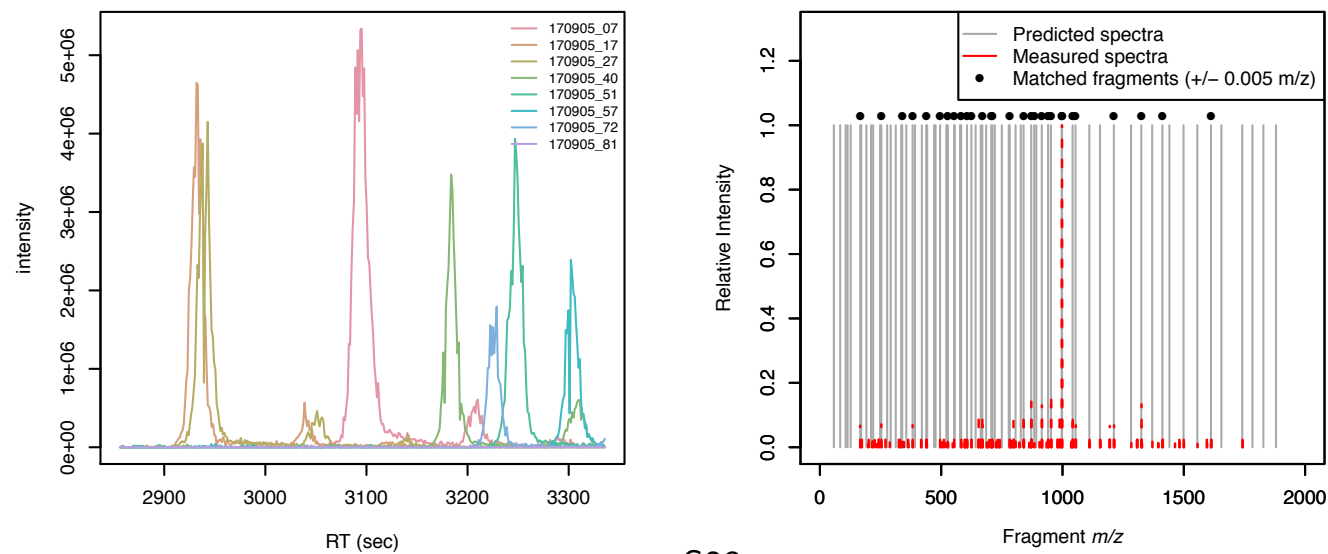


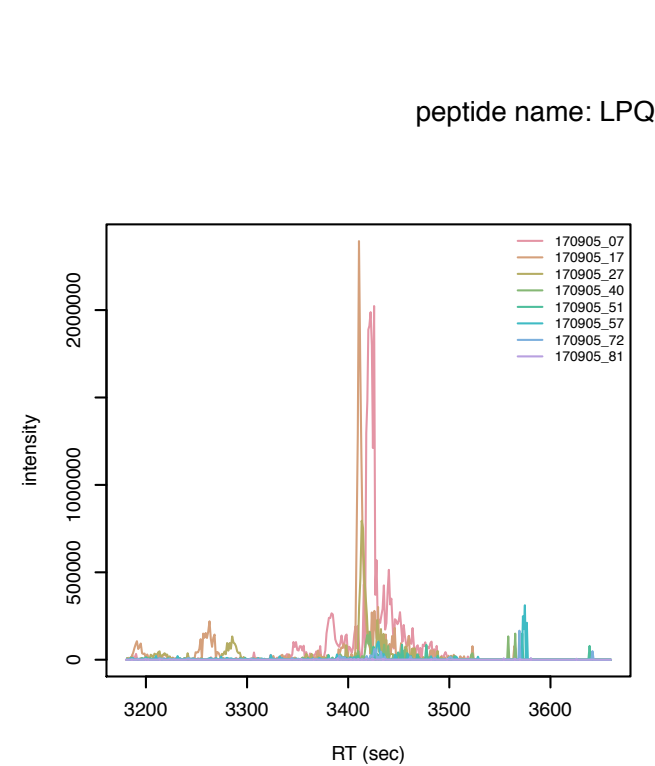

$14-37$

BLAP

peptide name: LPQVDASQITGTISSLESFTNRFY

LPQVDASQITGTISSLESFTNRFY

170905_09.mzXML_mz892_12_rt56_55_HCD20.txt

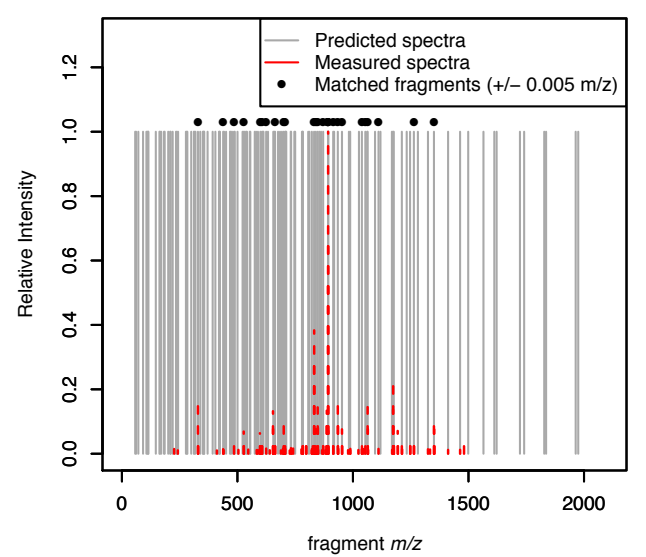

30-37

BLAP

peptide name: ESFTNRFY

ESFTNRFY

170905_09.mzXML_mz532_25rrt17_22_HCD20.txt
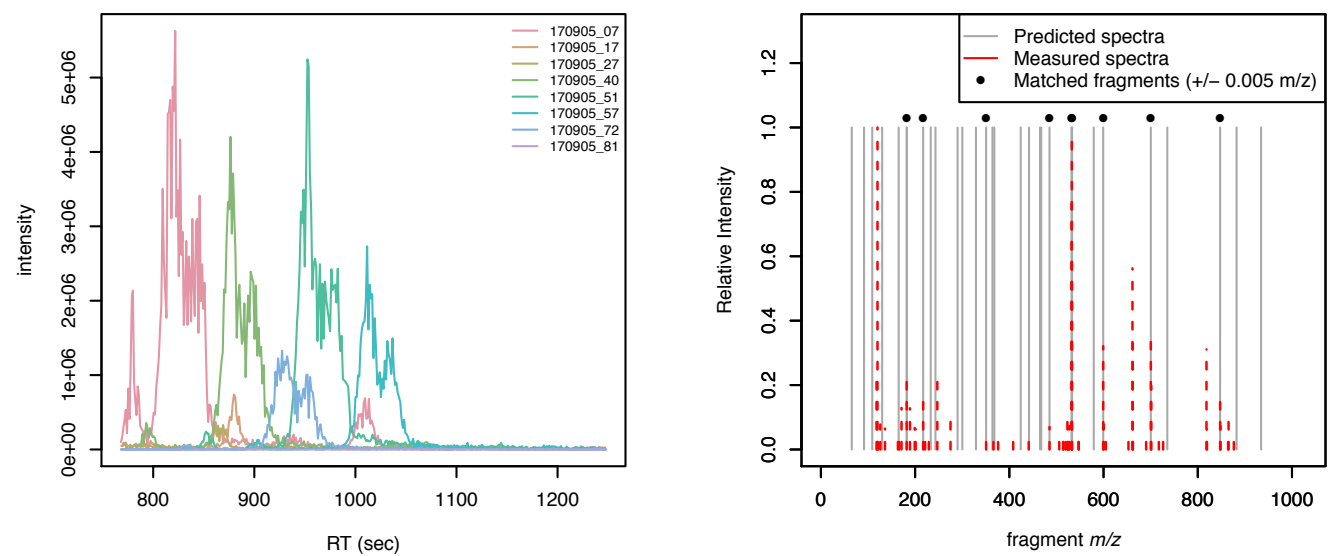

33-37

BLAP

peptide name: TNRFY

170905_07.mzXML_mz350_67_rt6_77_HCD20.txt
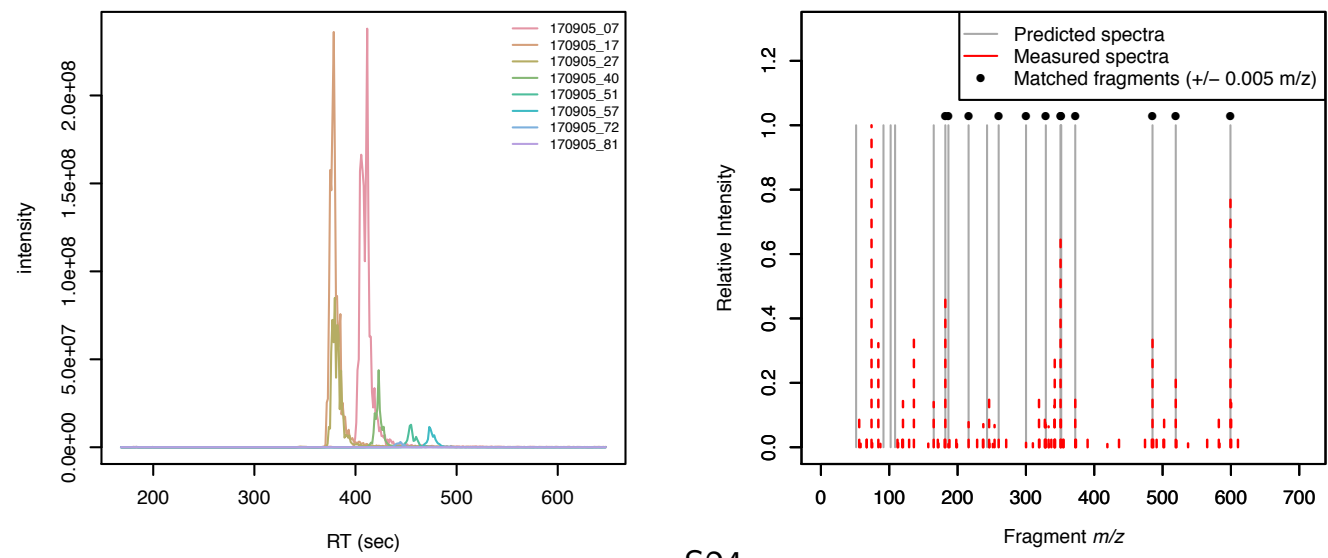


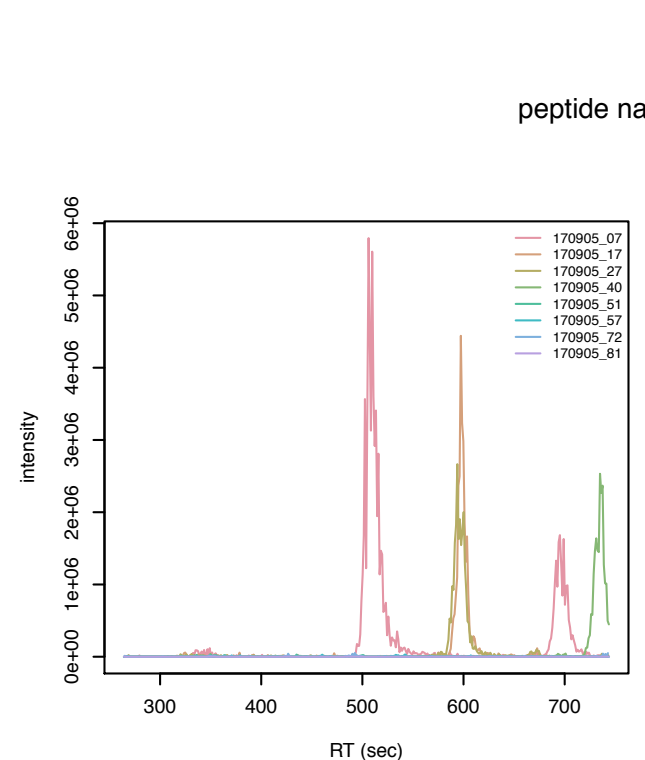

$38-48$

BLAP

eptide name: TTTSGAQASDW

TTTSGAQASDW

170905_07.mzXML_mz562_75_rt8_50_HCD20.txt

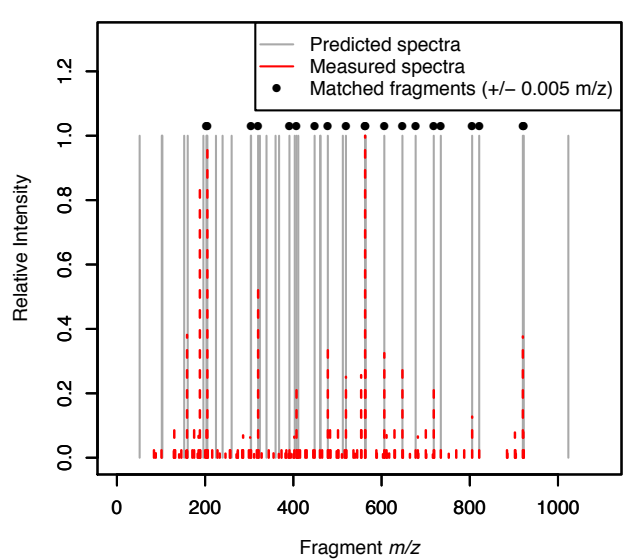

38-53

BLAP

peptide name: TTTSGAQASDWIASEW

TTTSGAQASDWIASEW

170905 07.mzXML mz855 88_rt38 40 HCD20.txt
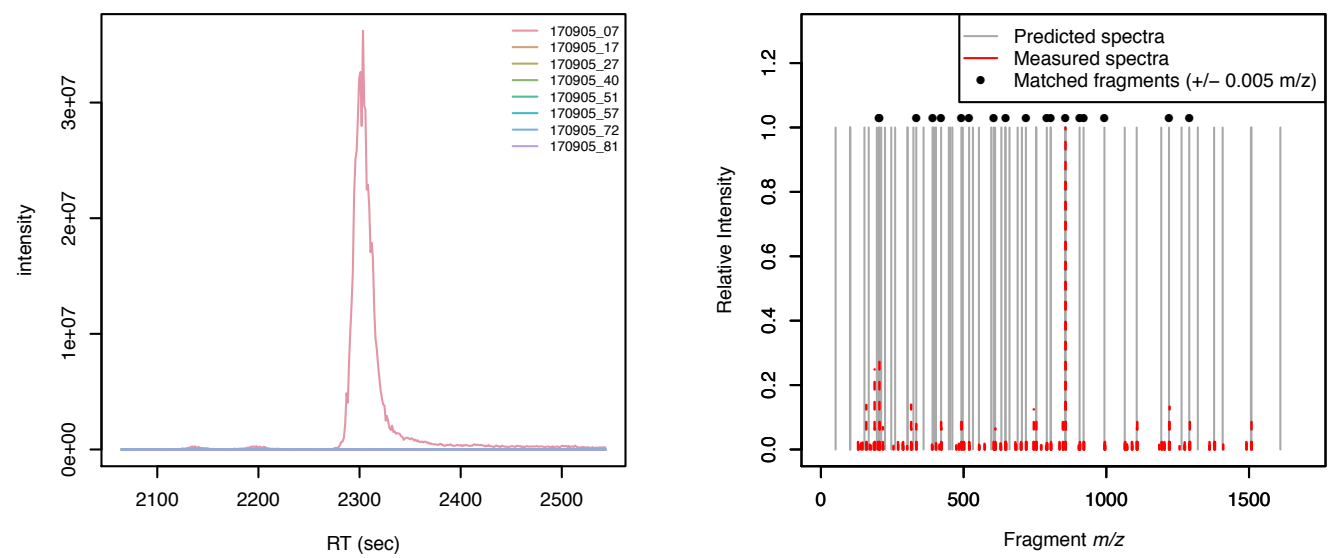

38-56

BLAP

peptide name: TTTSGAQASDWIASEWQAL

TTTSGAQASDWIASEWQAL

170905_07.mzXML_mz1011_97_rt50_62_HCD20.txt
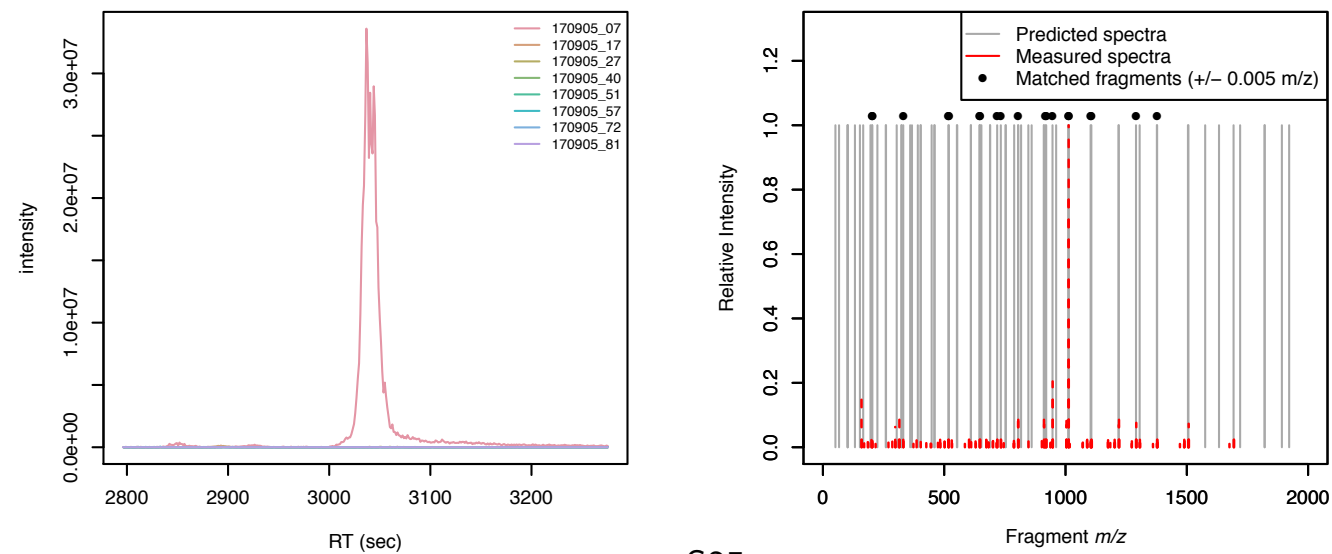


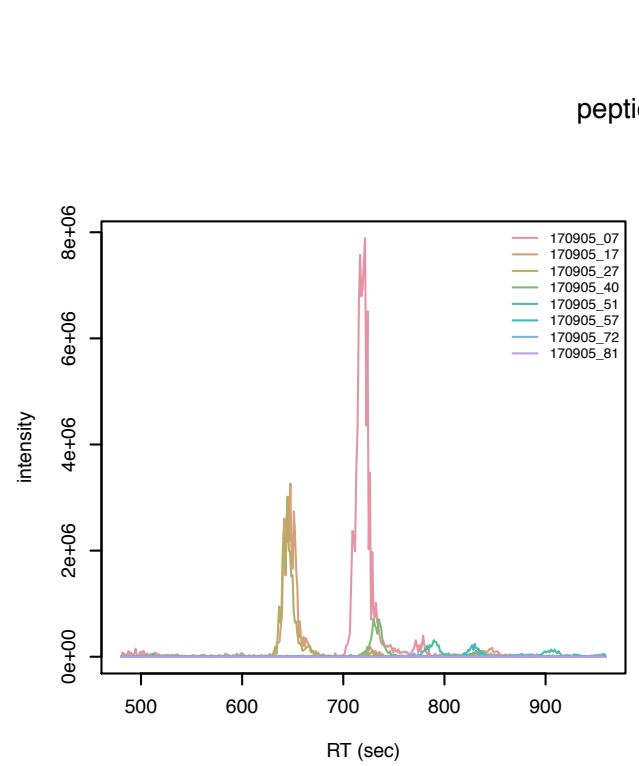

$49-53$

BLAP

peptide name: IASEW

170905_07.mzXML_mz605_29_rt11_95_HCD20.txt

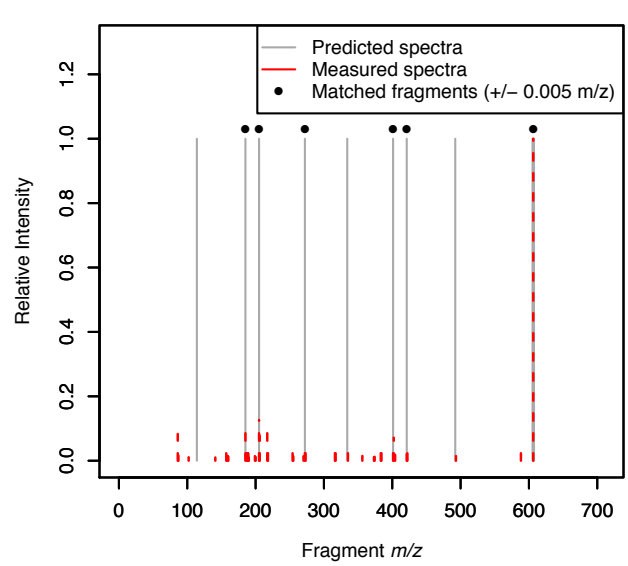

49-56

BLAP

peptide name: IASEWQAL

IASEWQAL

170905 07.mzXML_mz45924_rt25 80 HCD20.txt
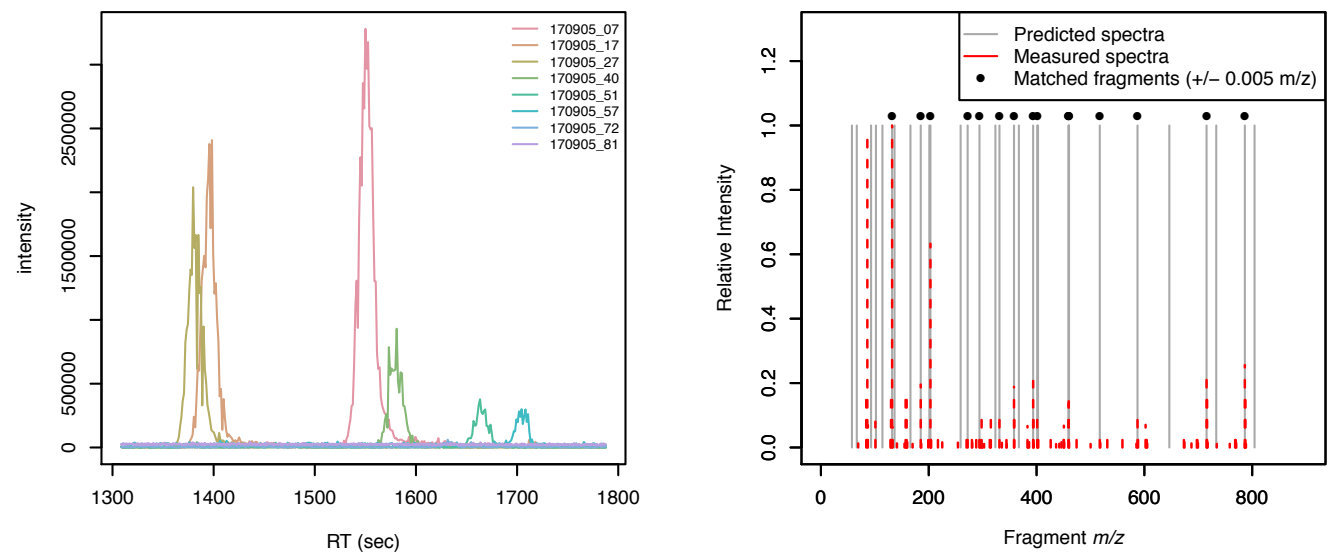

$54-56$

BLAP

peptide name: QAL

170905_07.mzXML_mz331_20_rt4_33_HCD20.txt
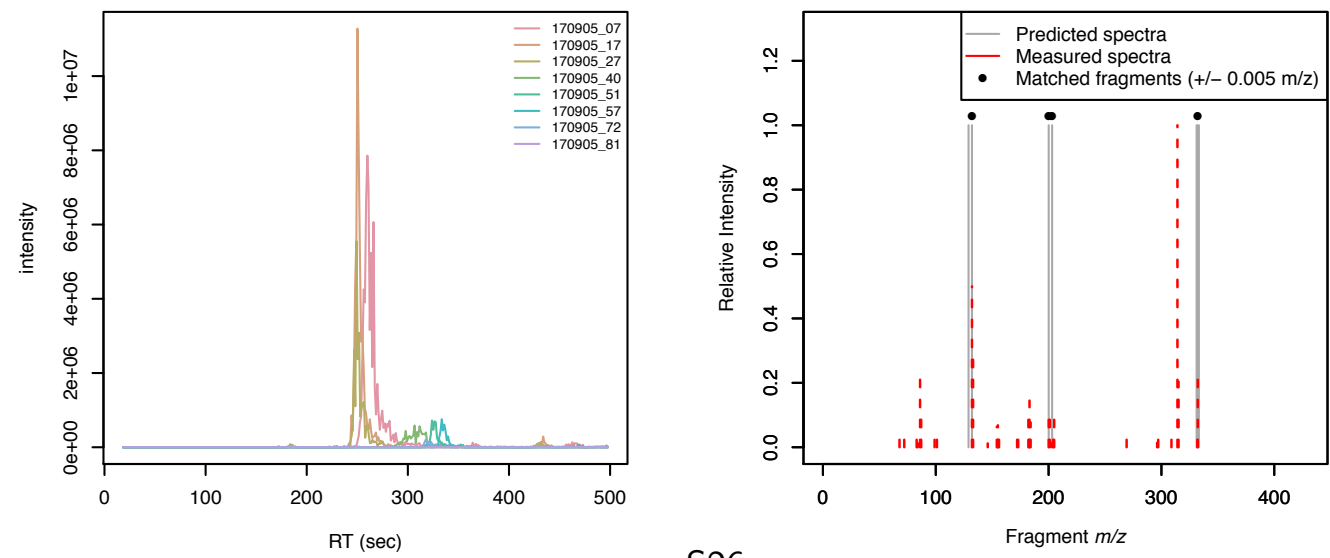
SASLPNASVKQVSHSGY 170905_07.mzXML_mz577_96_rt7_14_HCD20.txt
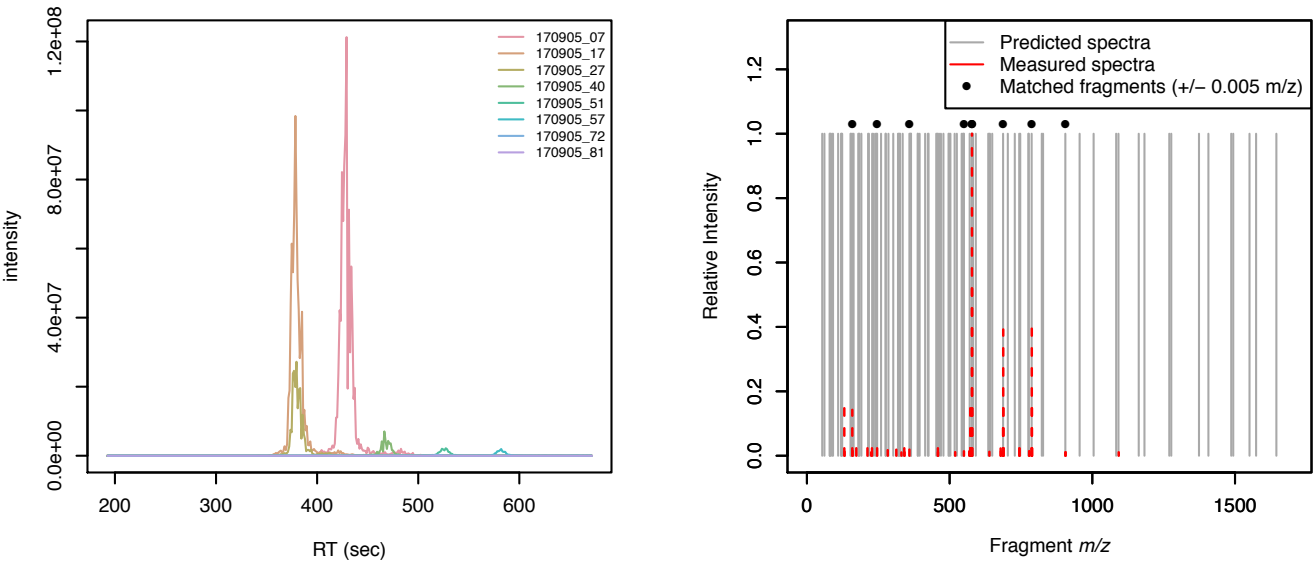

74-80

BLAP

peptide name: NQKSVVM

NQKSVVM

170905_09.mzXML_mz403_22_rt5 94_HCD20.txt
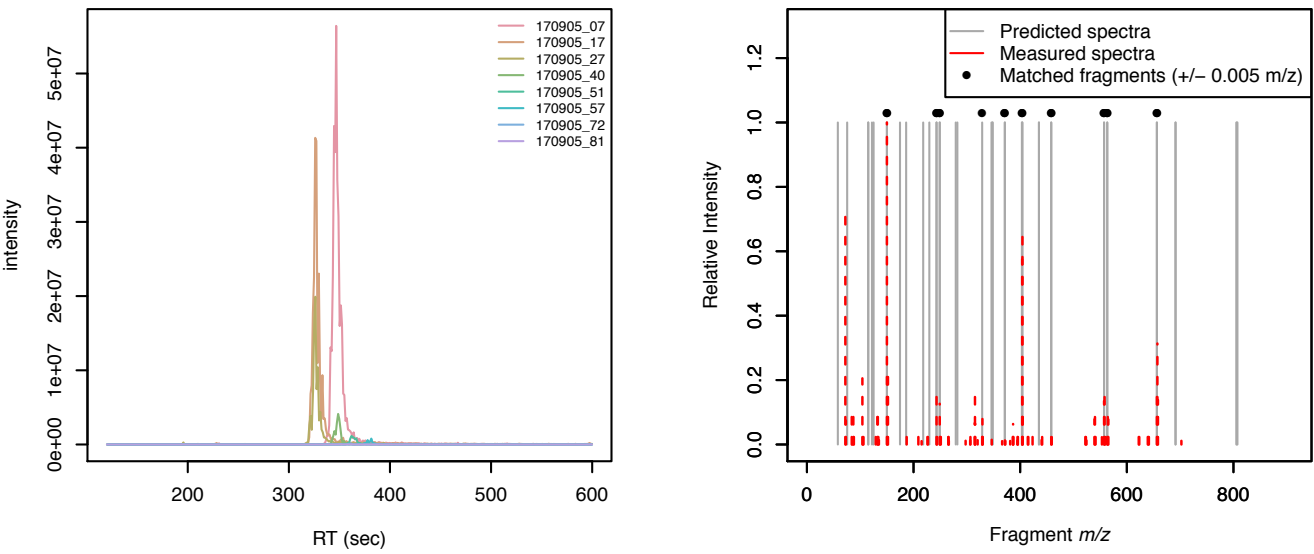

81-91

BLAP

peptide name: TITGSEAPDEW

TITGSEAPDEW

170905_07.mzXML_mz603_27_rt17_60_HCD20.txt
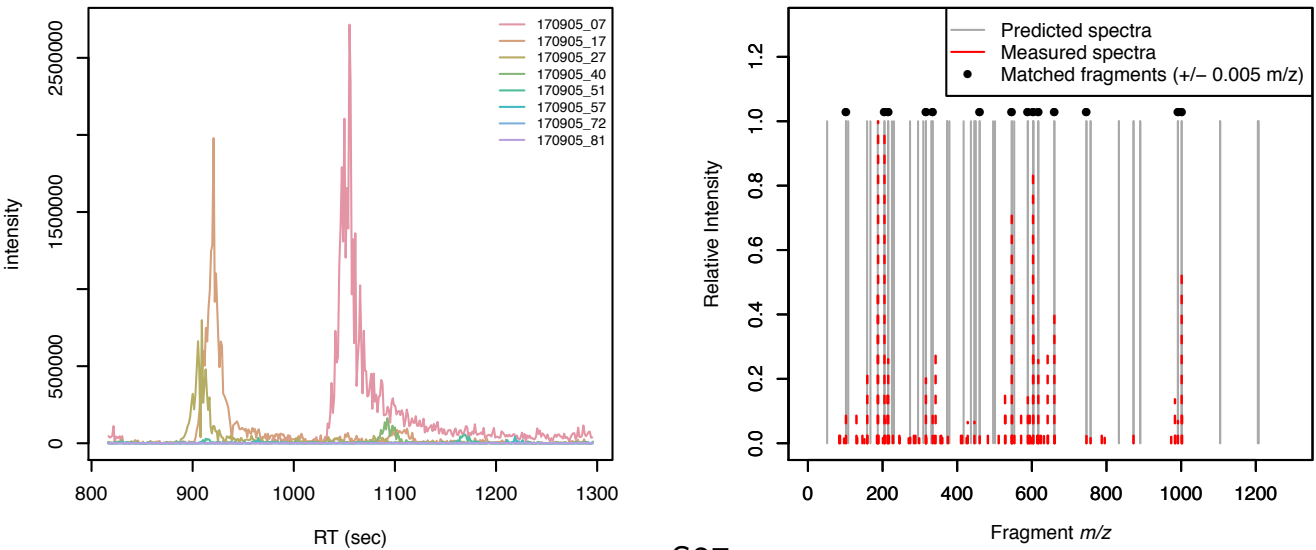
92-132

BLAP

peptide name: IVIGGHLDSTIGSHTNEQSVAPGADDDASGIAAVTEVIRVL

IVIGGHLDSTIGSHTNEQSVAPGADDDASGIAAVTEVIRVL 170905_07.mzXML_mz1022_03_rt55_50_HCD20.txt
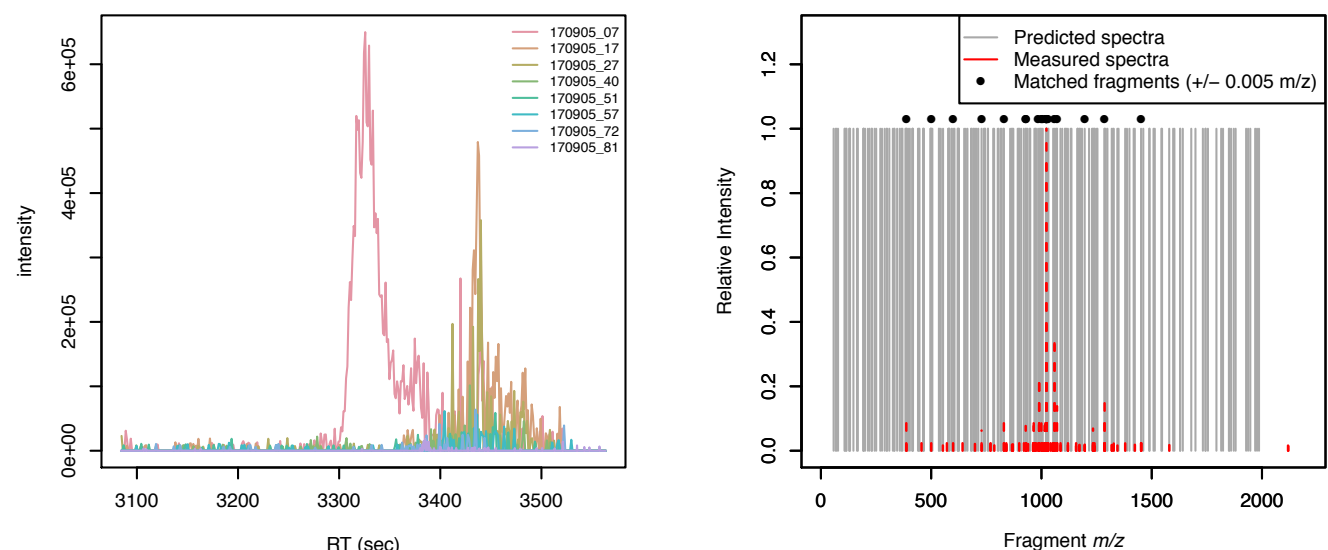

93-204

BLAP

peptide name: ITDYTDSNFTQY

ITDYTDSNFTQY

170905 07.mzXML_mz734_32_rt17 69_HCD20.txt
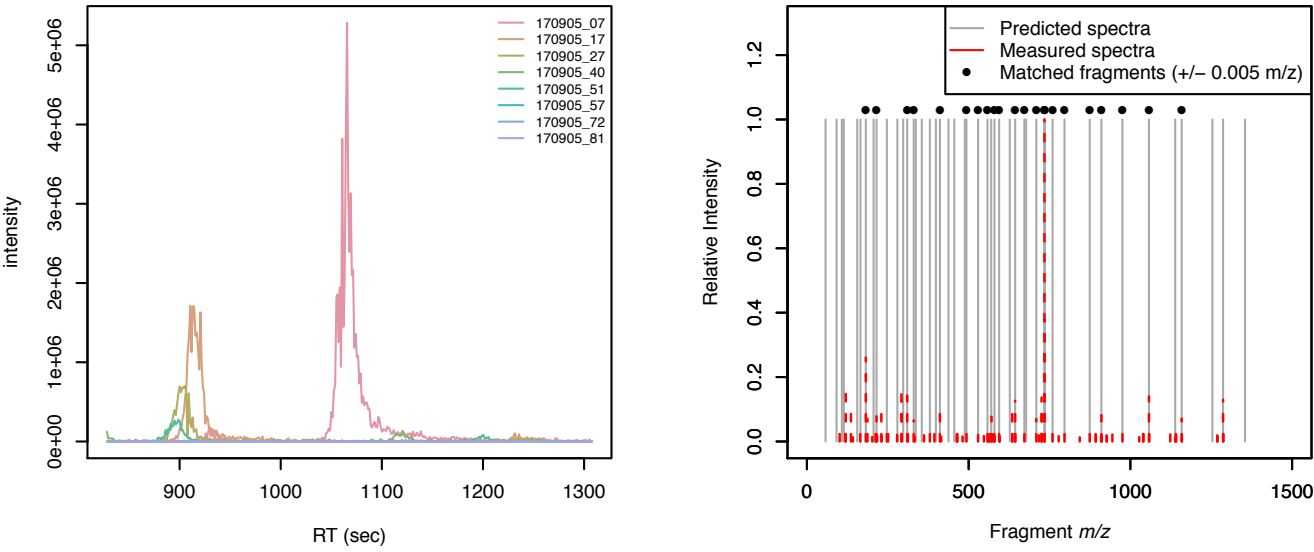

133-145

BLAP

peptide name: SENNFQPKRSIAF

SENNFQPKRSIAF

170905_07.mzXML_mz513_26_rt13_79_HCD20.txt
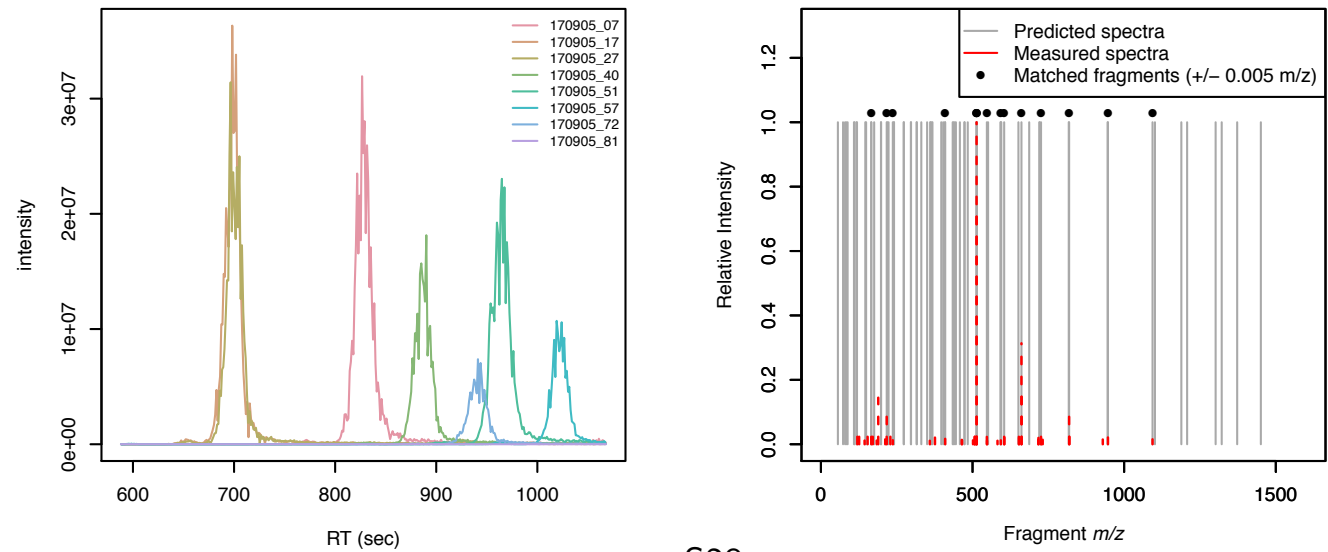
133-148

BLAP

peptide name: SENNFQPKRSIAFMAY

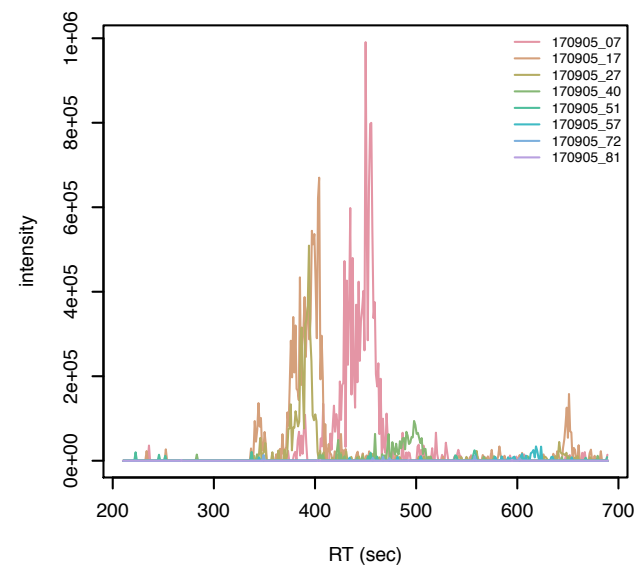

SENNFQPKRSIAFMAY

170905_07.mzXML

$138-145$

BLAP

peptide name: QPKRSIAF

170905 09.mzXML mz316 19 rt7 76 HCD20.txt
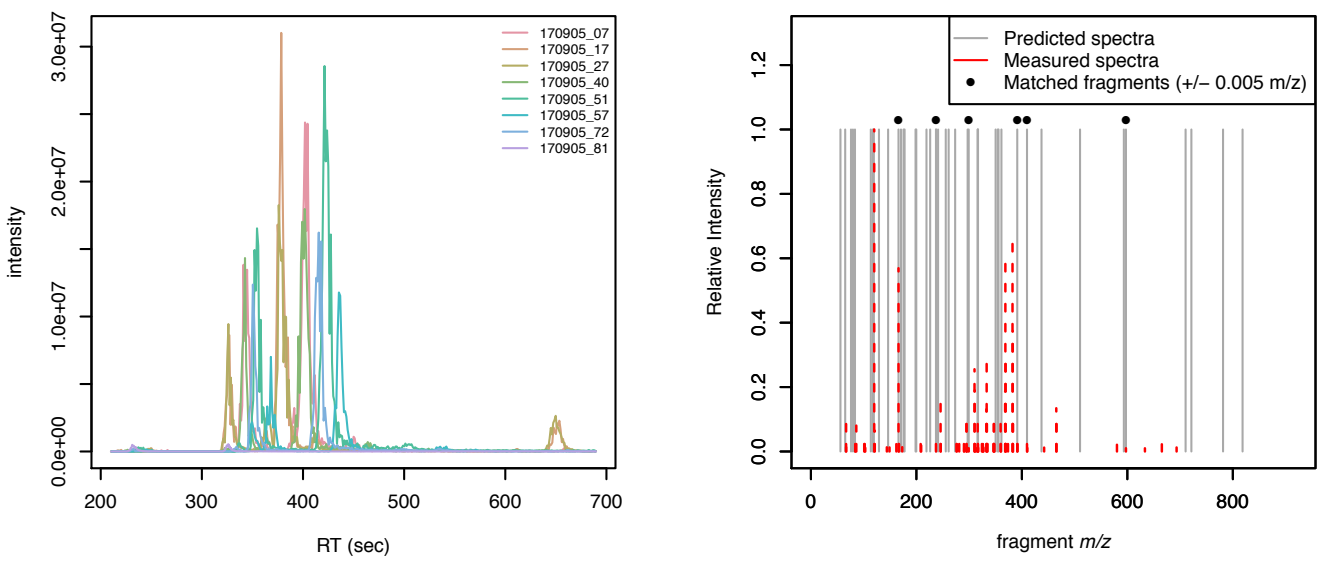

$146-148$

BLAP

peptide name: MAY

170905_07.mzXML_mz384_16_rt6_04_HCD20.txt
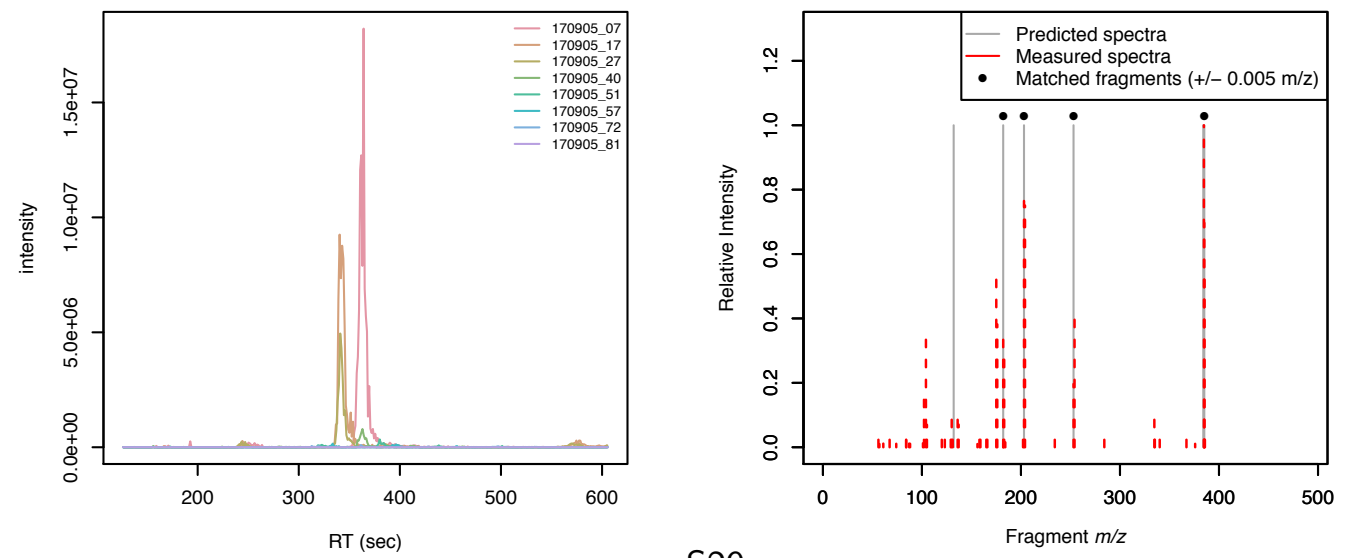


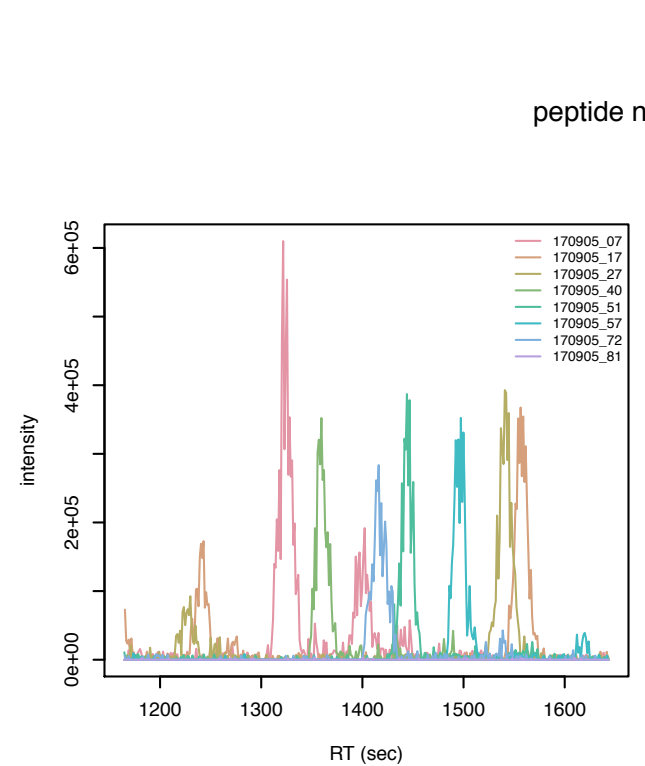

146-154

BLAP

peptide name: MAYAAEEVGL

MAYAAEEVGL

170905_72.mzXML_mz527_25_rt23_60_HCD20.txt

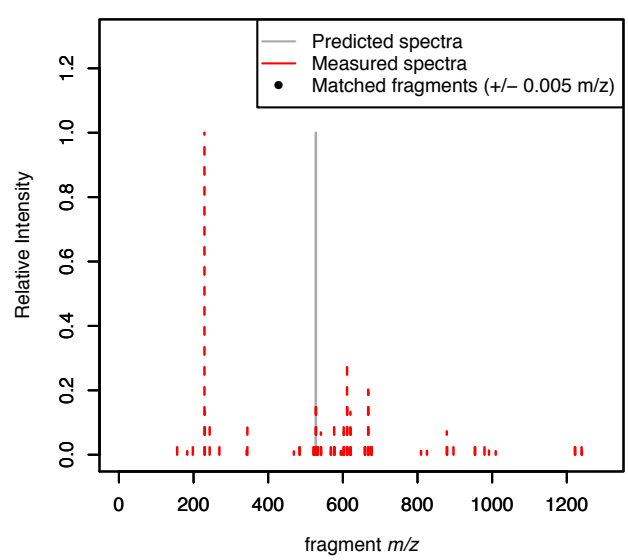

$146-165$

BLAP

peptide name: MAYAAEEVGLRGSQDLANQY

MAYAAEEVGLRGSQDLANQY

170905_07.mzXML_mz729_34_rt23_38_HCD20.txt
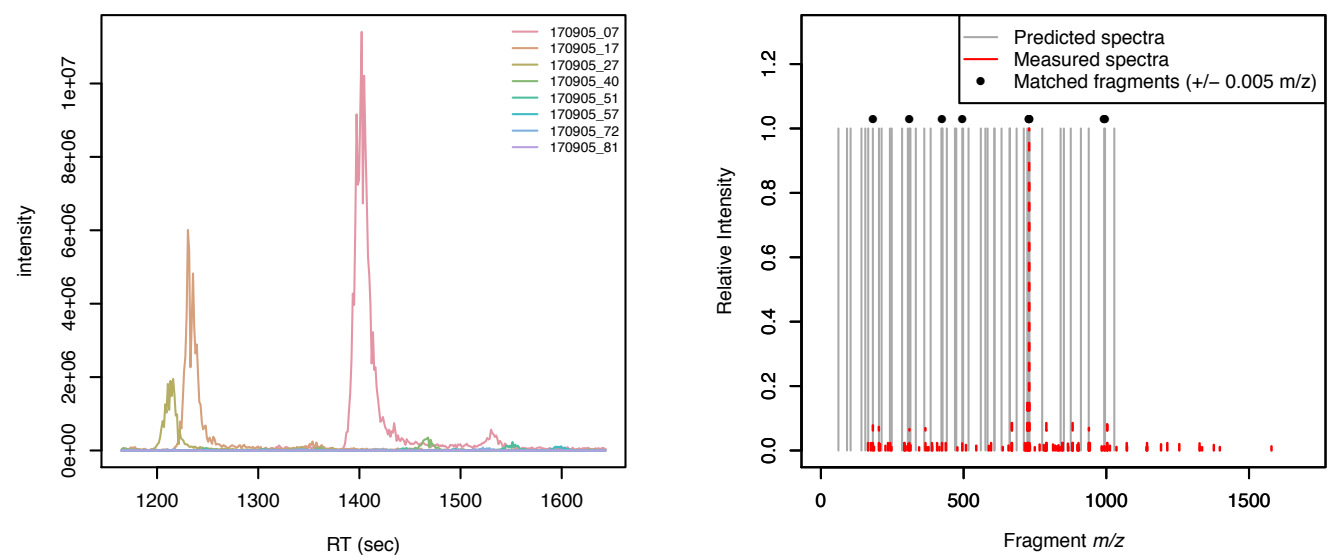

149-155

BLAP

peptide name: AAEEVGL

AAEEVGL

170905_07.mzXML_mz688_35_rt9_81_HCD20.txt
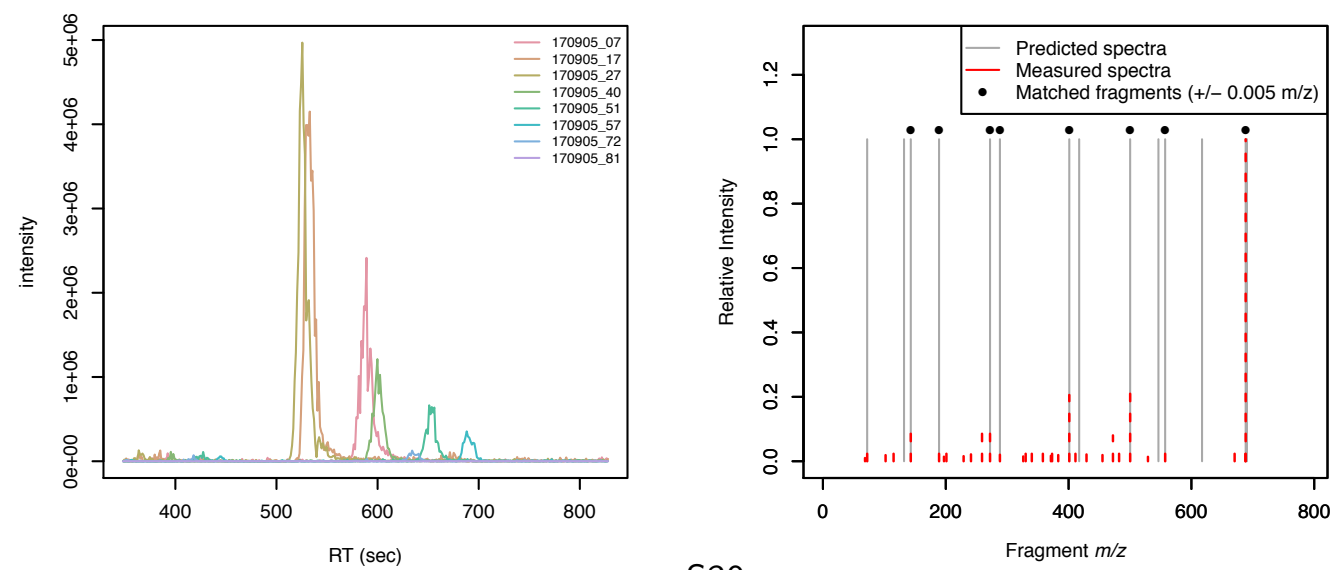


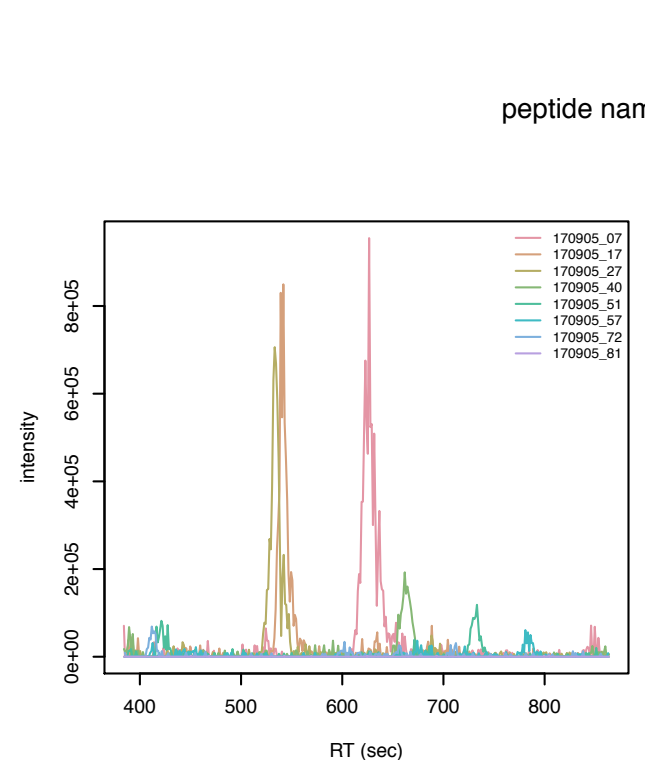

\section{$149-161$}

BLAP

peptide name: AAEEVGLRGSQDL

AAEEVGLRGSQDL

170905_07.mzXML_mz672_84_rt10_40_HCD20.txt

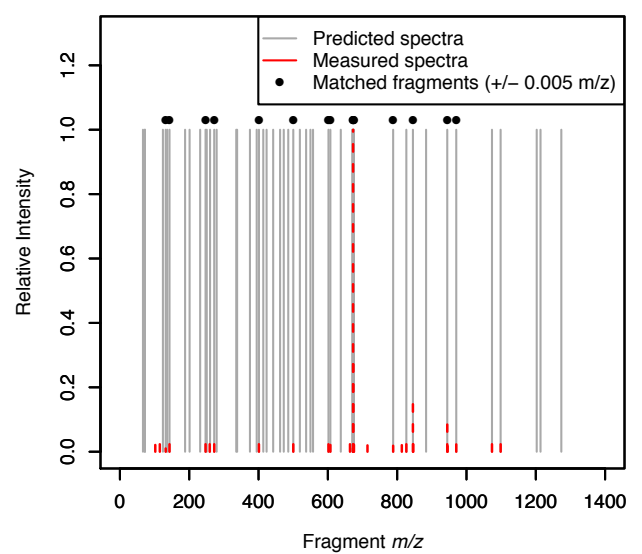

$149-165$

BLAP

peptide name: AAEEVGLRGSQDLANQY

AAEEVGLRGSQDLANQY

170905_07.mzXML_mz910_94_rt12 99_HCD20.txt
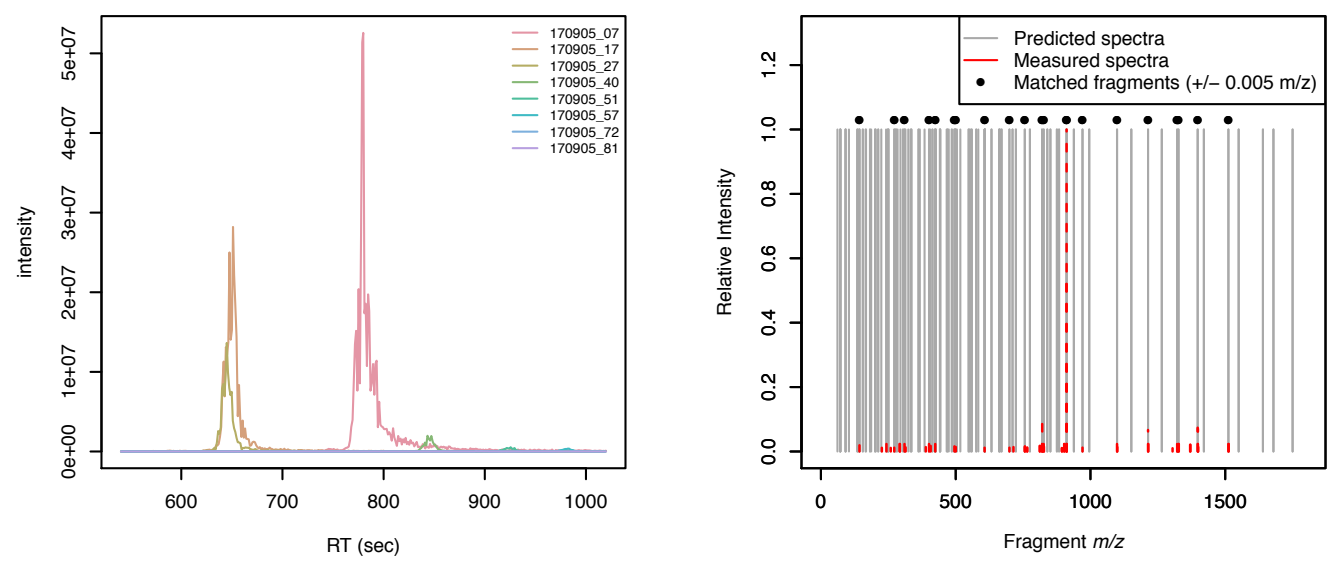

$156-165$

BLAP

peptide name: RGSQDLANQY

RGSQDLANQY
170905_07.mzXML_mz576_28_rt5_83_HCD20.txt
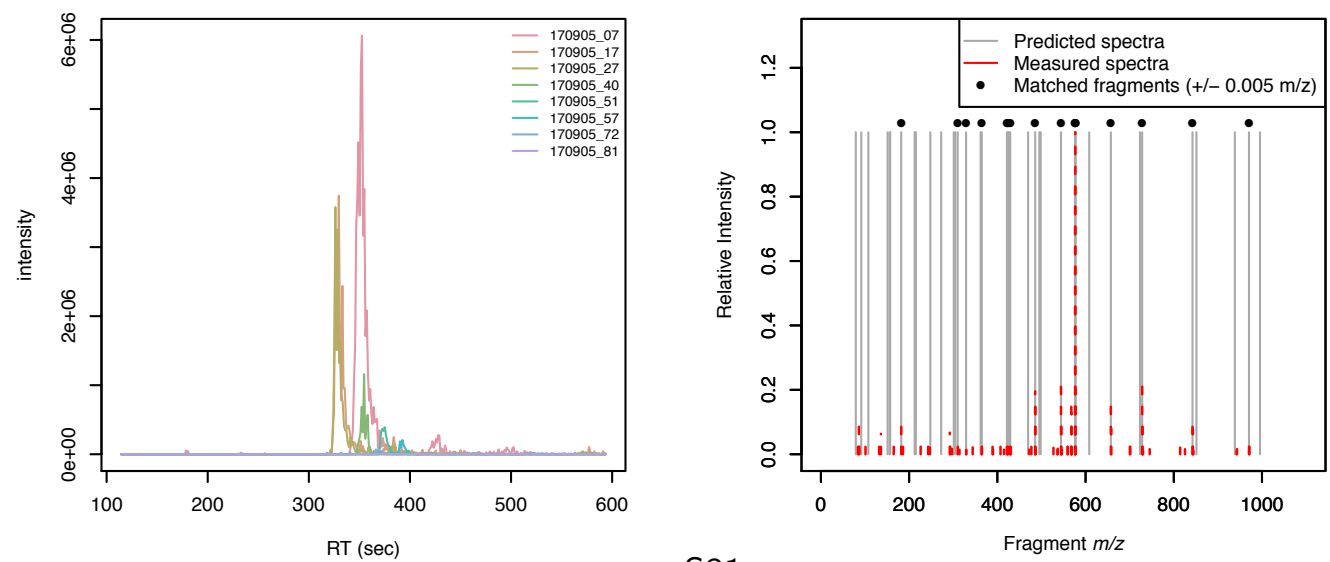


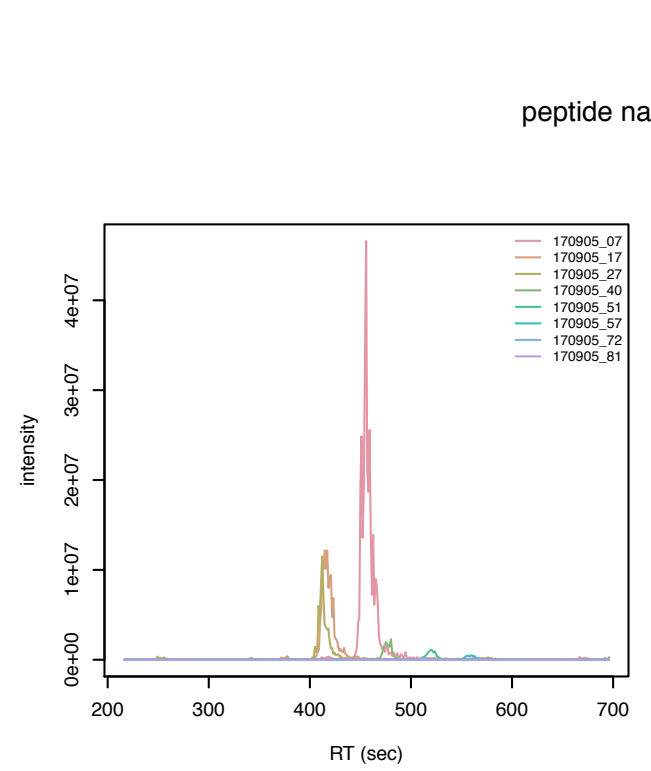

\section{$166-176$}

BLAP

peptide name: KSEGKNVVSAL

KSEGKNVVSAL

170905_07.mzXML_mz377_88_rt7_60_HCD20.txt

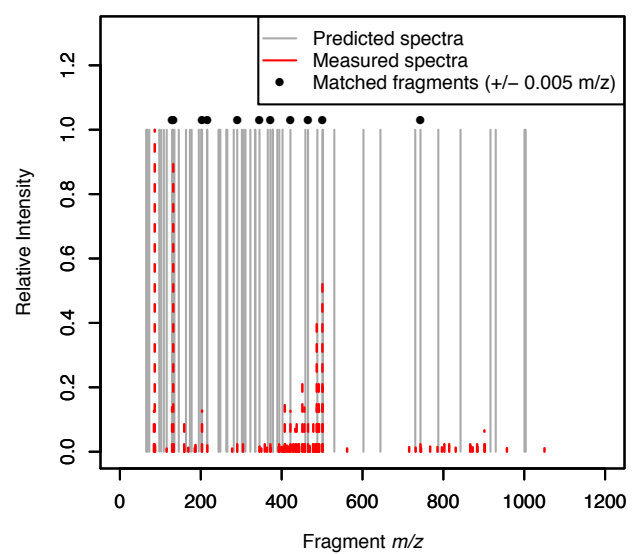

$166-179$

BLAP

peptide name: KSEGKNVVSALQL

170905_07.mzXML mz458 26_rt20 22 HCD20.txt
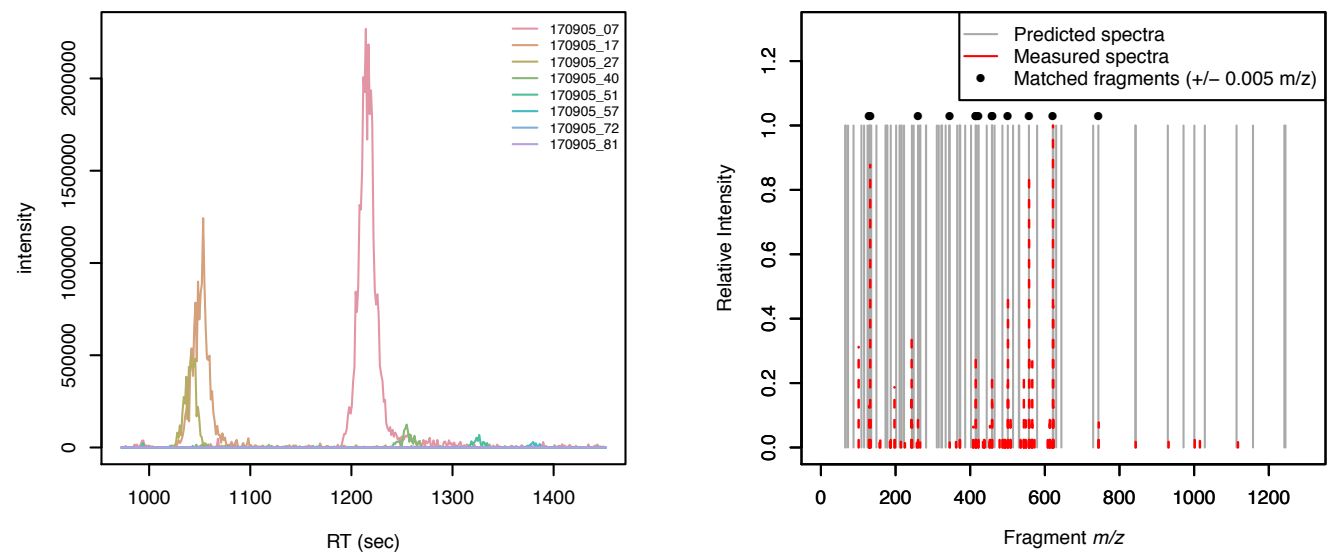

$166-183$

BLAP

peptide name: KSEGKNVVSALQLDMTNY

KSEGKNVVSALQLDMTNY 170905_07.mzXML_mz666_34_rt31_45_HCD20.txt
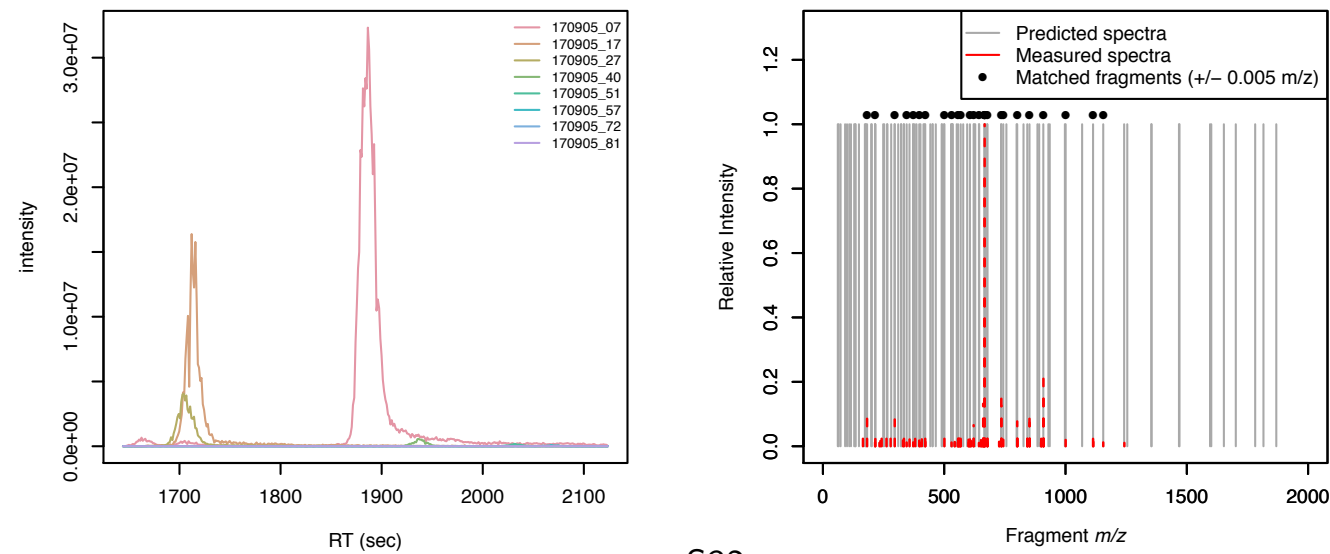
177-196

BLAP

peptide name: QLDMTNY

170905_07.mzXML_mz442_69_rt12_22_HCD20.txt
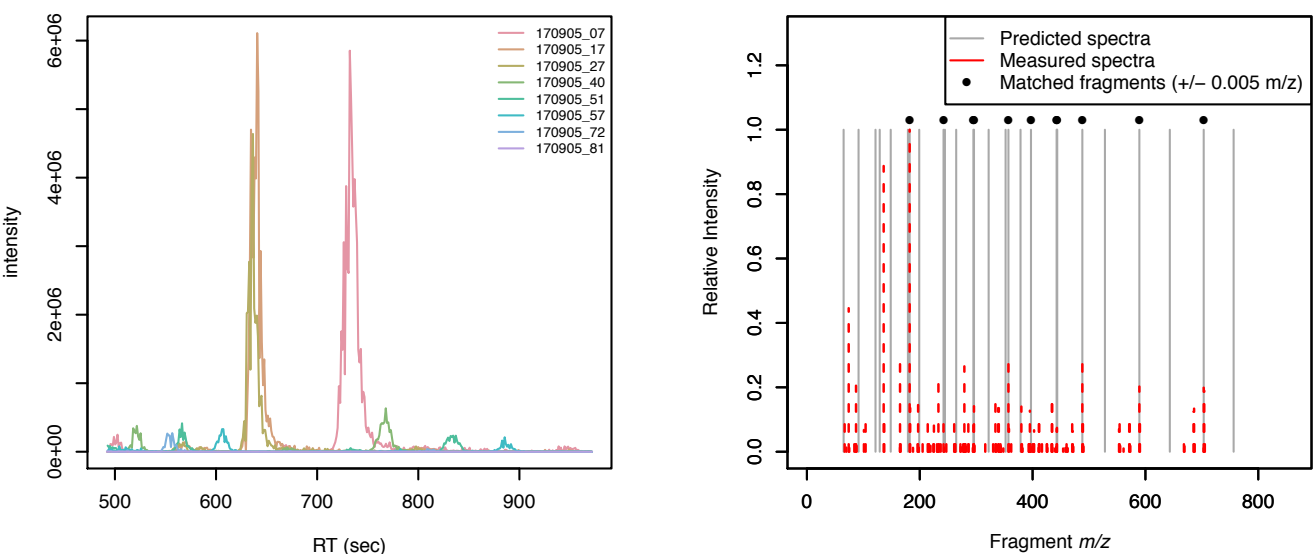

184-192

BLAP

peptide name: KGSAQDVVF

KGSAQDVVF

170905 07.mzXML_mz475 75_rt12 12_HCD20.txt
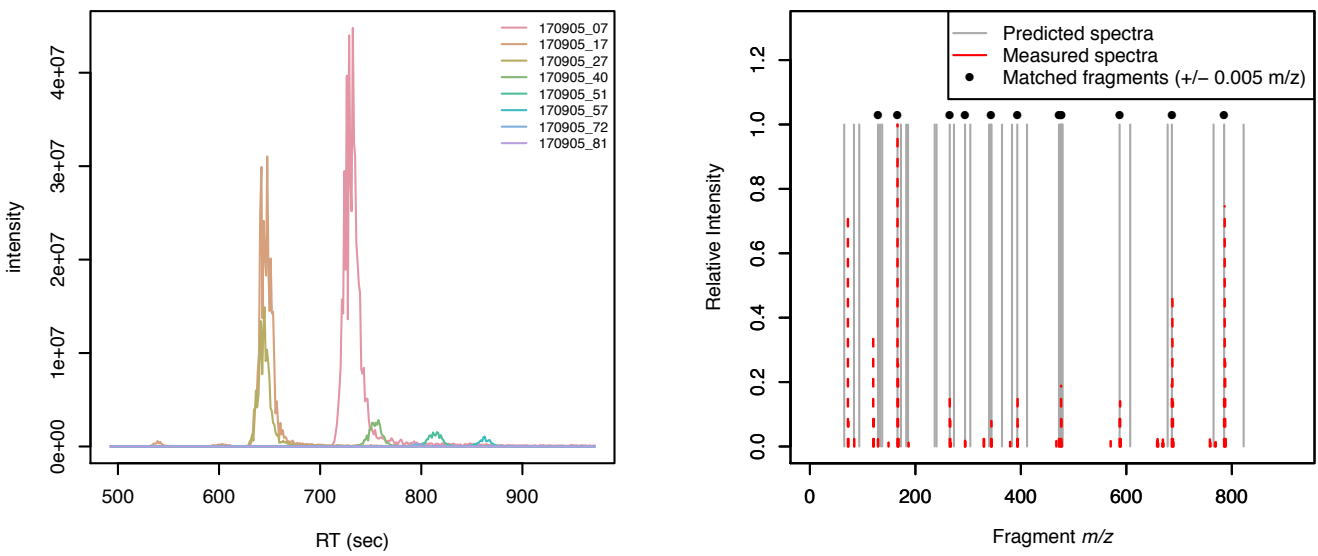

184-196

BLAP

peptide name: KGSAQDVVFITDY

KGSAQDVVFITDY

170905_07.mzXML_mz721_86_rt27_59_HCD20.txt
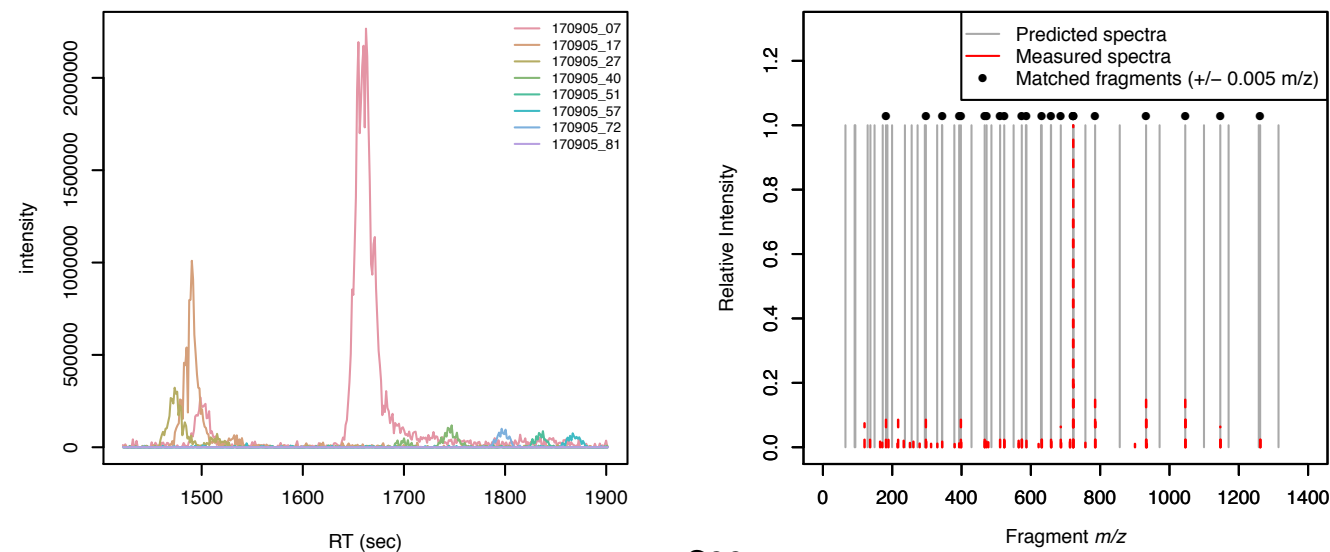


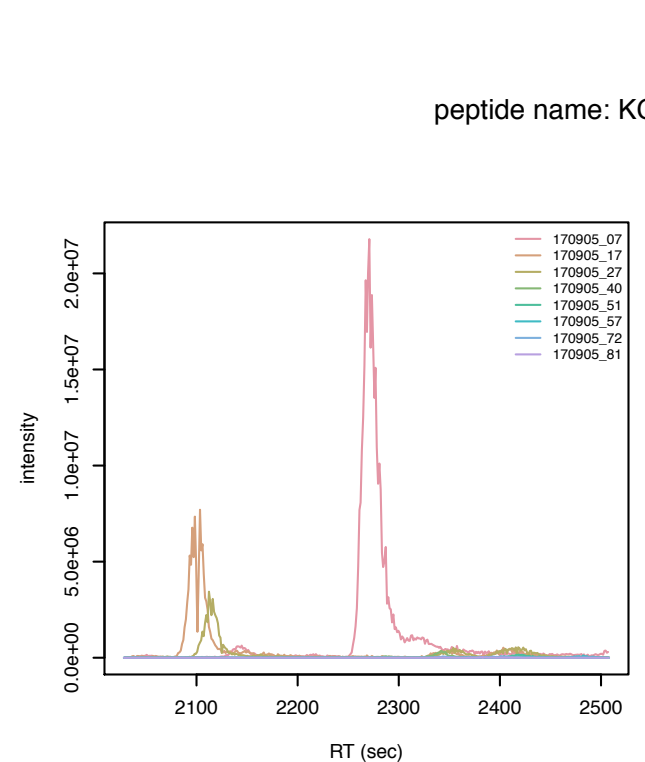

184-204

BLAP

SAQDVVFITDYTDSNFTQY

KGSAQDVVFITDYTDSNFTQY 170905_07.mzXML_mz800_37_rt37_84_HCD20.txt

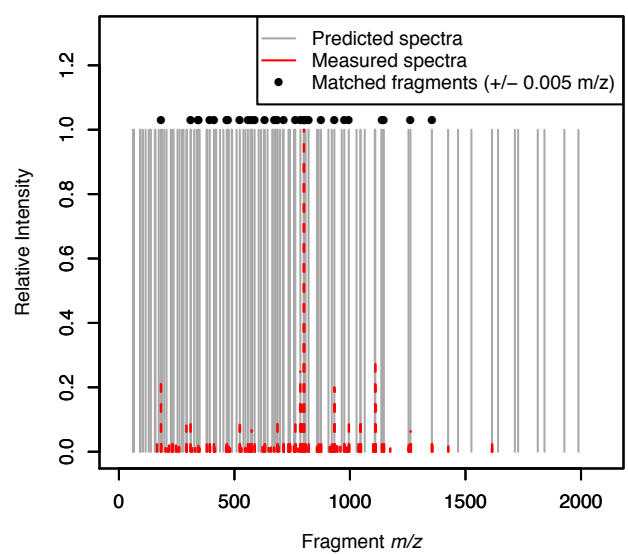

184-205

BLAP

peptide name: KGSAQDVVFITDYTDSNFTQYL

KGSAQDVVFITDYTDSNFTQYL

170905 11.mzXML mz838 07 rt49 89 HCD20.txt
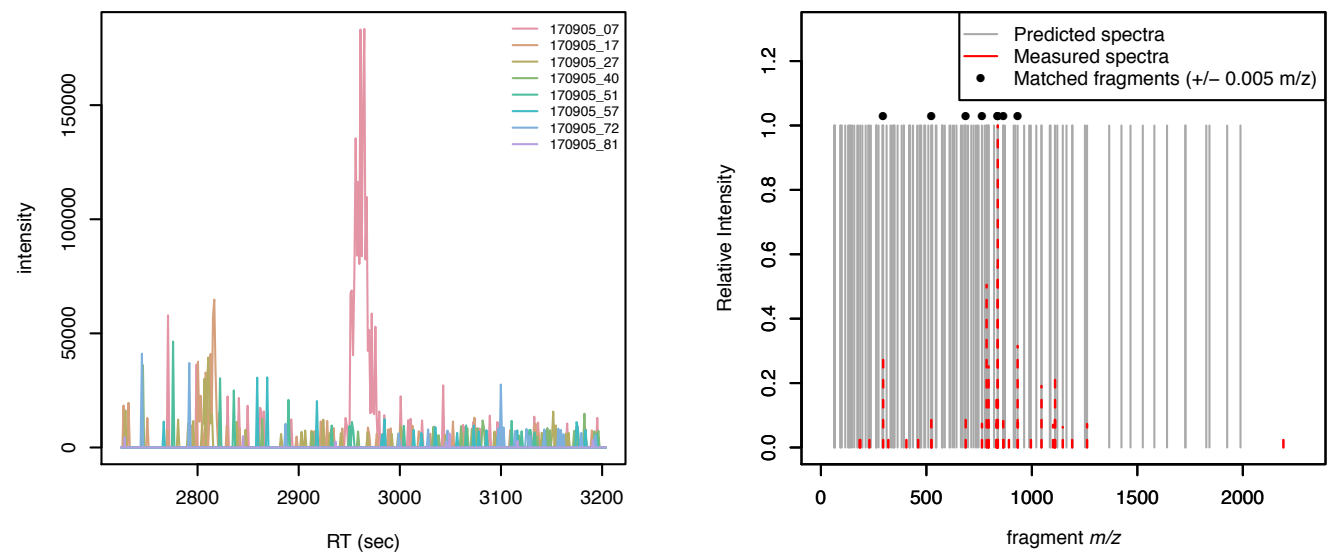

197-204

BLAP

peptide name: TDSNFTQY

170905_09.mzXML_mz488_21_rt9_11_HCD20.txt
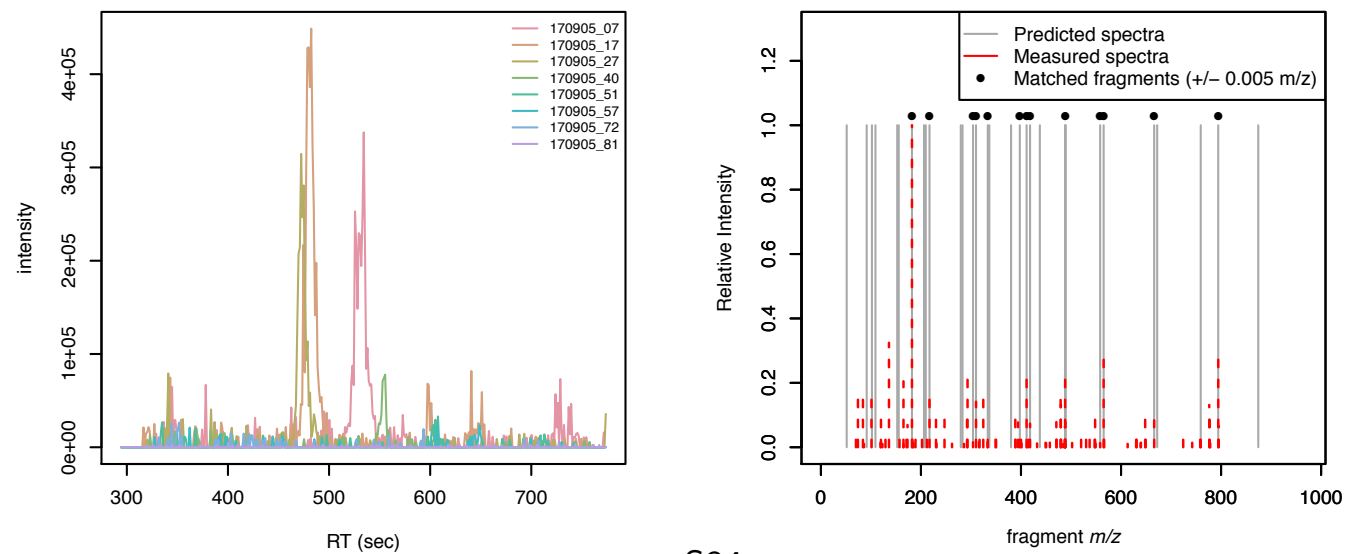


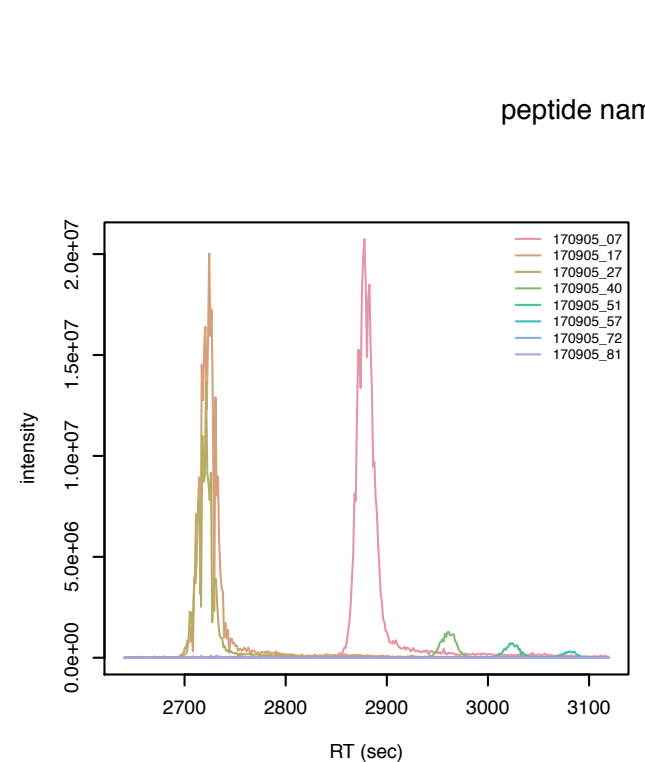

\section{5-218}

BLAP

peptide name: LTQLMDEYLPSLTY

LTQLMDEYLPSLTY

170905_07.mzXML_mz843_92_rt47_99_HCD20.txt

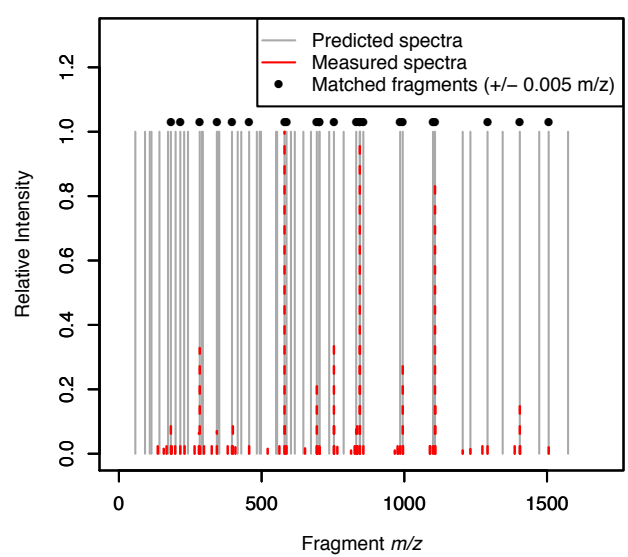

206-218

BLAP

peptide name: TQLMDEYLPSLTY

170905 09.mzXML_mz78738_rt44 30_HCD20.txt
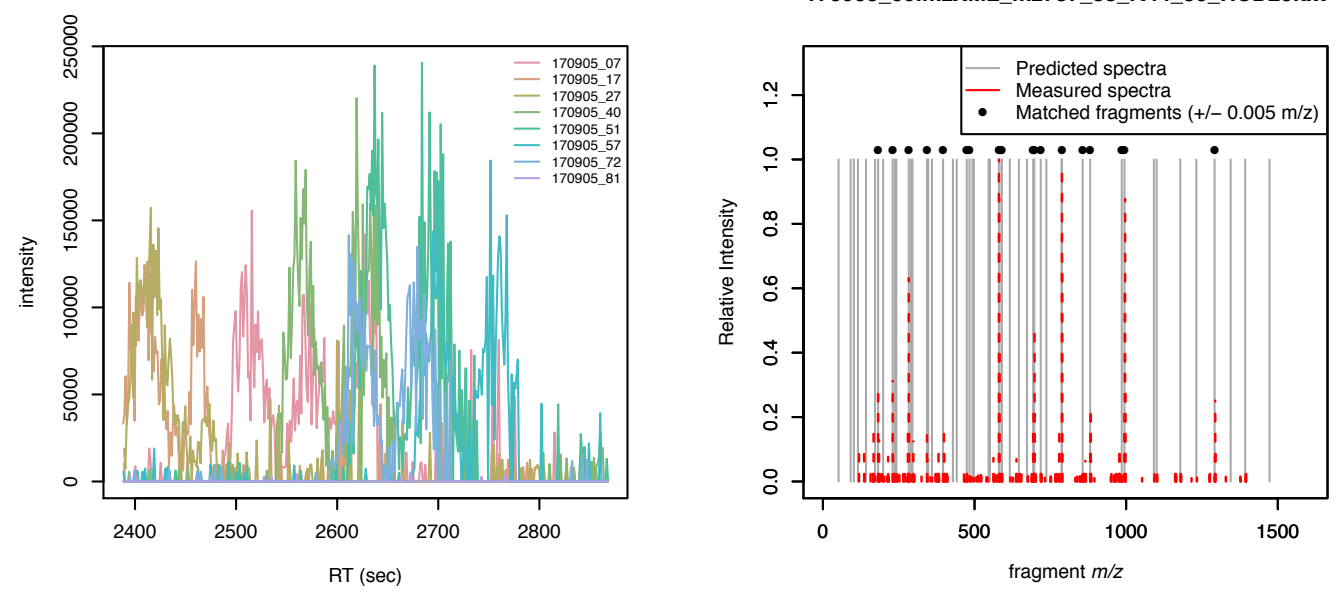

219-225

BLAP

peptide name: GFDTC[+57]GY

170905_07.mzXML_mz410_15_rt9_45_HCD20.txt
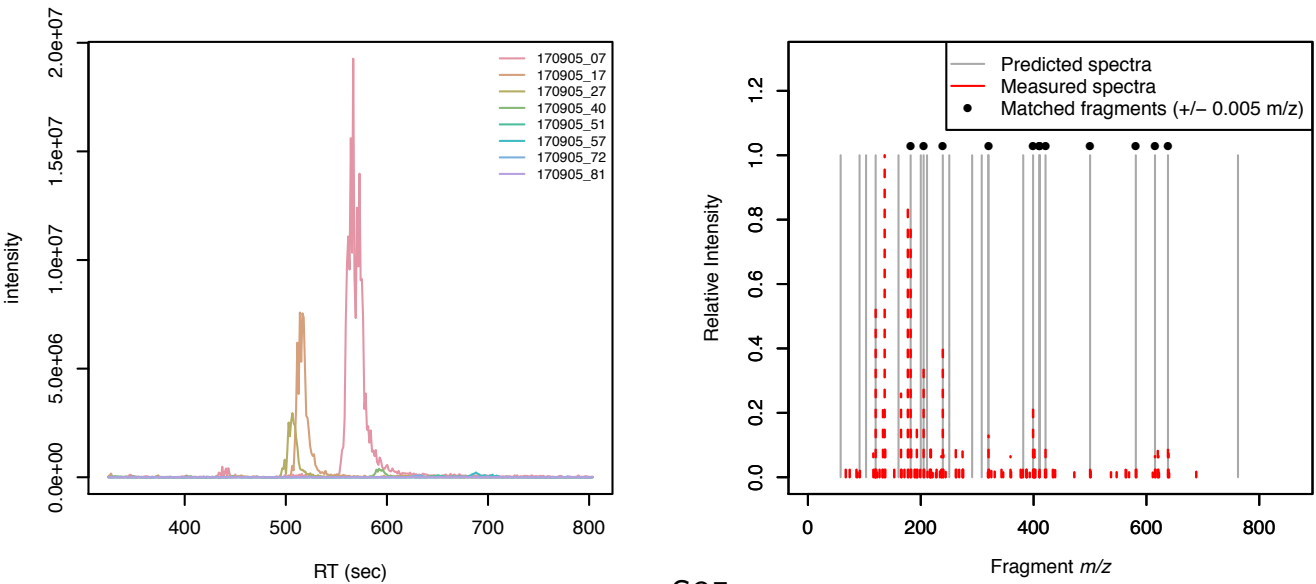


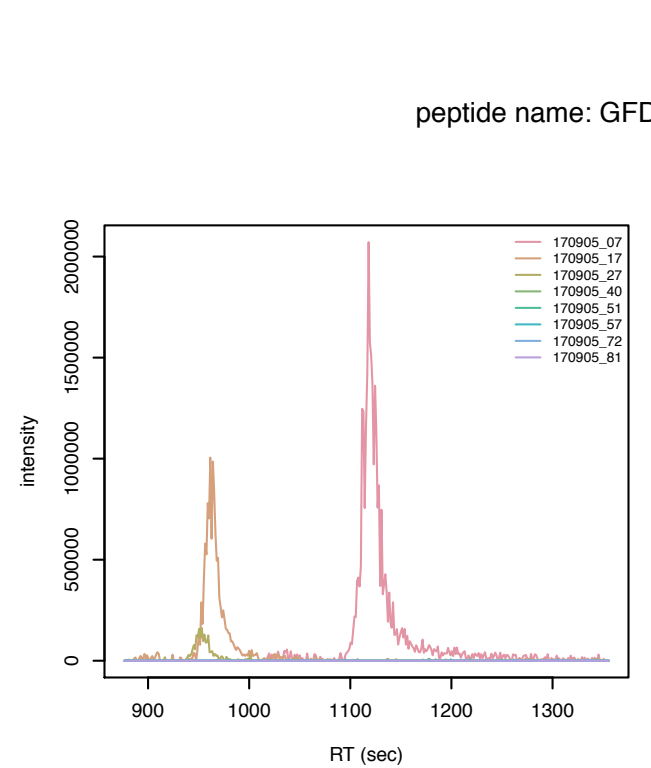

\section{9-233}

BLAP

FDTC[+57]GYAC[+57]SDHASW

GFDTC[+57]GYAC[+57]SDHASW

170905_07.mzXML_mz867_32_rt18_65_HCD20.txt

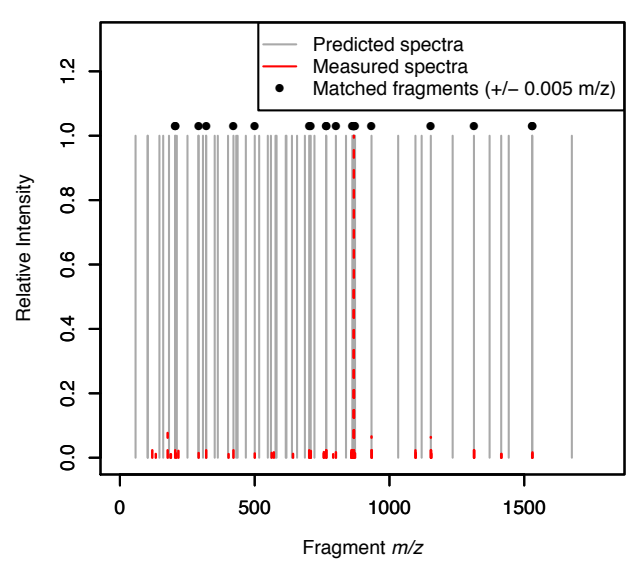

226-233

BLAP

peptide name: $A C[+57]$ SDHASW

170905_07.mzXML mz467_18_rt6 53_HCD20.txt
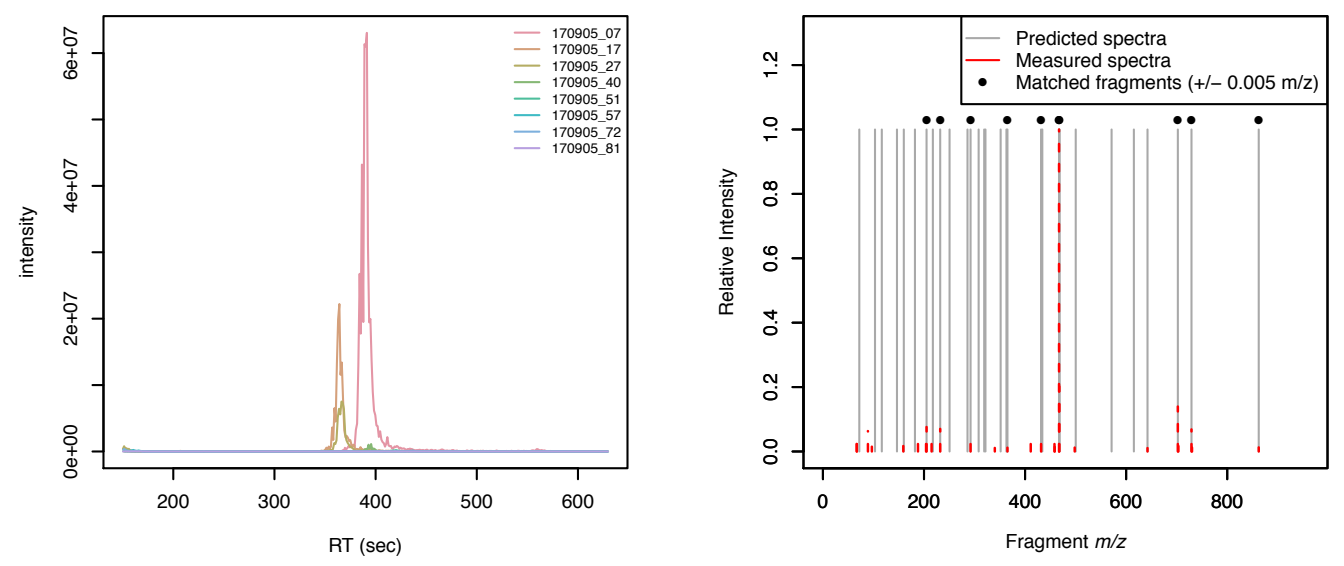

226-244

BLAP

peptide name: $A C[+57]$ SDHASWHNAGYPAAMPF

AC[+57]SDHASWHNAGYPAAMPF

170905_07.mzXML_mz697_29_rt27_97_HCD20.txt
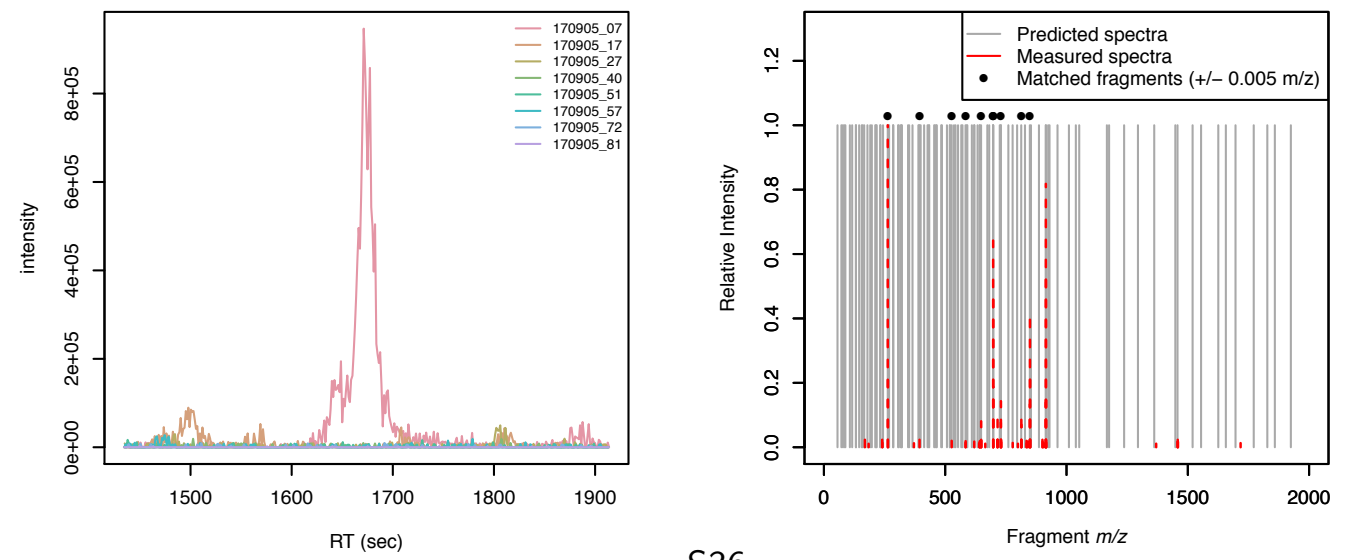


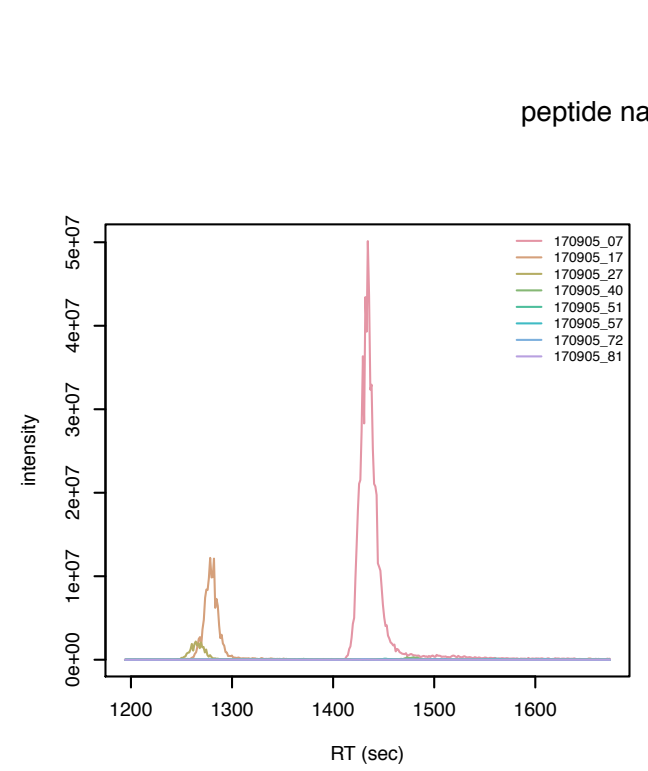

\section{4-244}

BLAP

eptide name: HNAGYPAAMPF

HNAGYPAAMPF

170905_07.mzXML_mz588_27_rt23_91_HCD20.txt

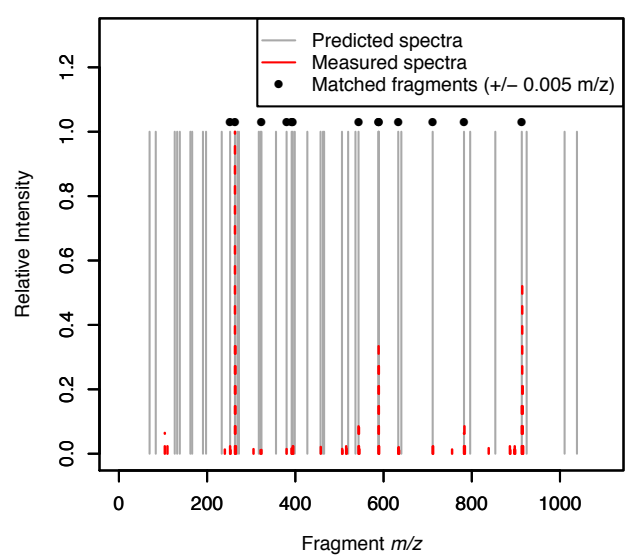

245-247

BLAP

peptide name: ESKF

ESKF

170905 07.mzXML mz255 63 rt3 41_HCD20.txt
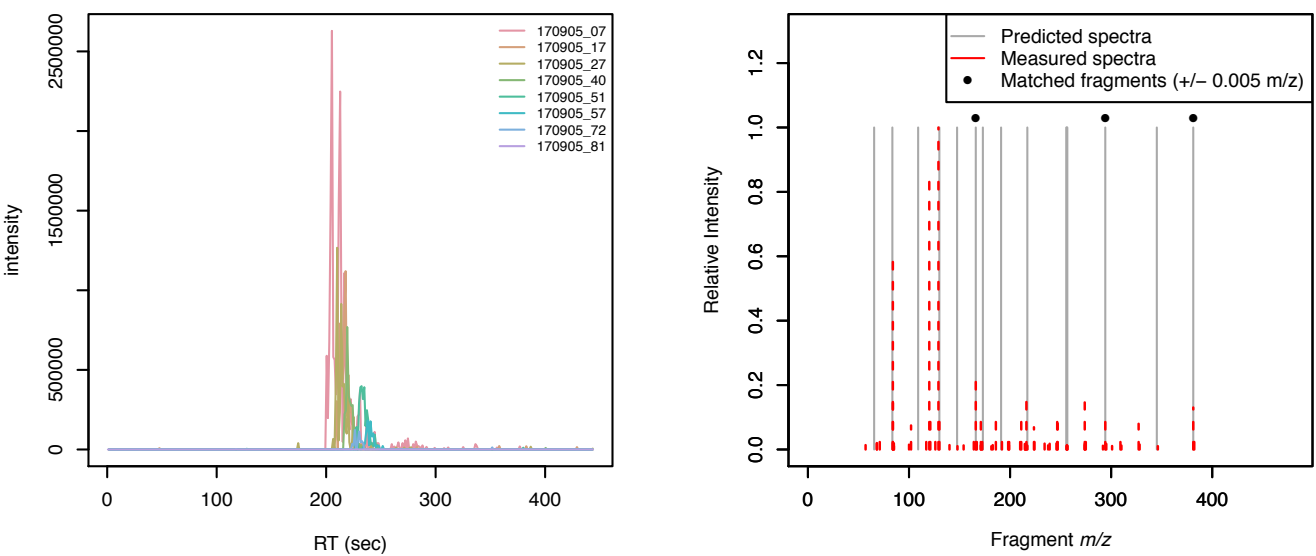

245-262

BLAP

peptide name: ESKFNDYNPRIHTTQDTL

ESKFNDYNPRIHTTQDTL

170905_07.mzXML_mz545_52_rt10_39_HCD20.txt
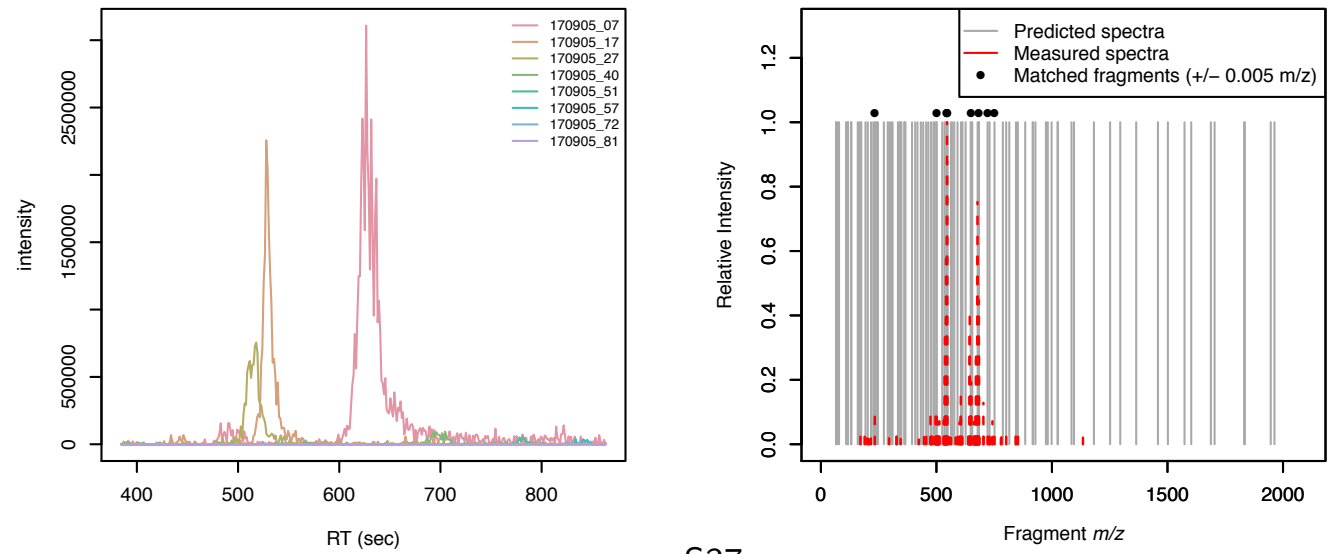


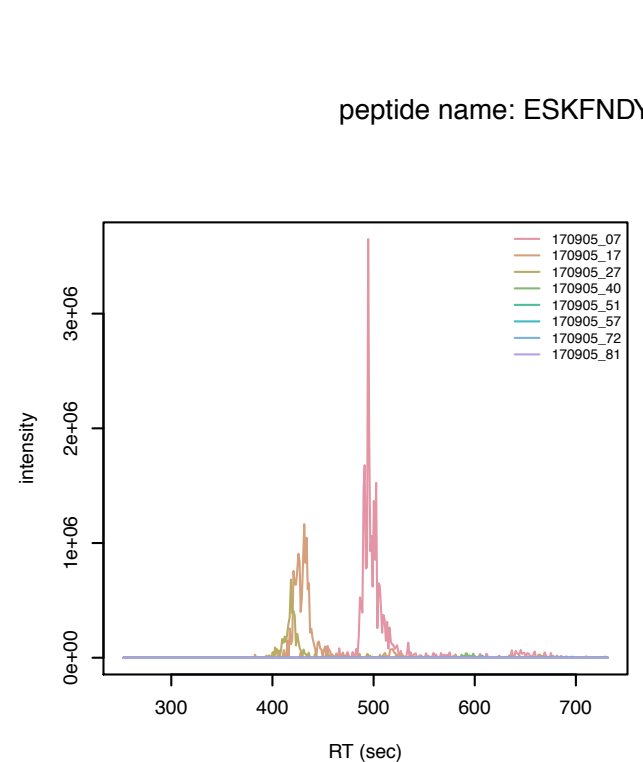

245-275

BLAP

peptide name: ESKFNDYNPRIHTTQDTLANSDPTGSHAKKF

ESKFNDYNPRIHTTQDTLANSDPTGSHAKKF 170905_07.mzXML_mz880_68_rt8_22_HCD20.txt

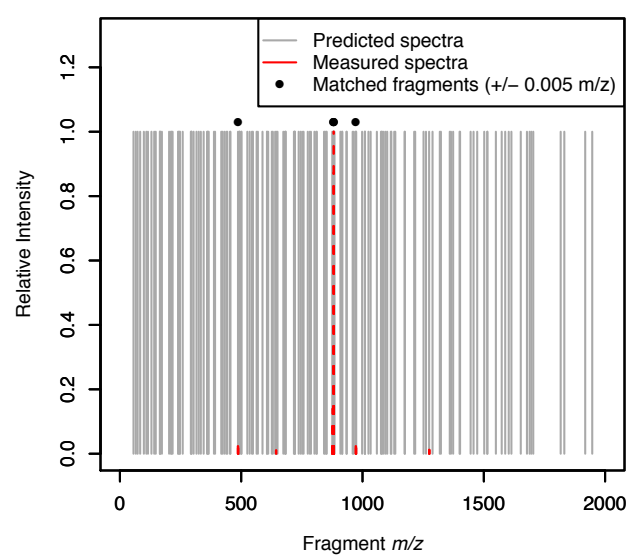

249-262

BLAP

peptide name: NDYNPRIHTTQDTL

NDYNPRIHTTQDTL

170905_07.mzXML_mz563_27_rt7 57 HCD20.txt
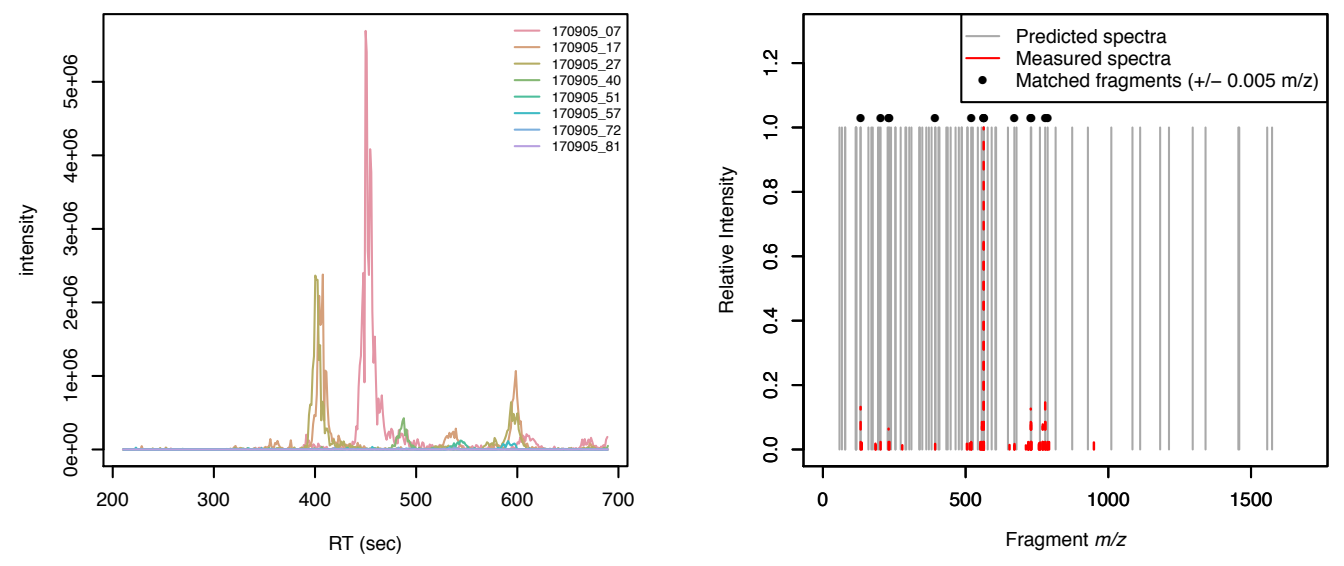

249-275

BLAP

peptide name: NDYNPRIHTTQDTLANSDPTGSHAKKF

NDYNPRIHTTODTLANSDPTGSHAKKF 170905_07.mzXML_mz757_87_rt6_60_HCD20.txt
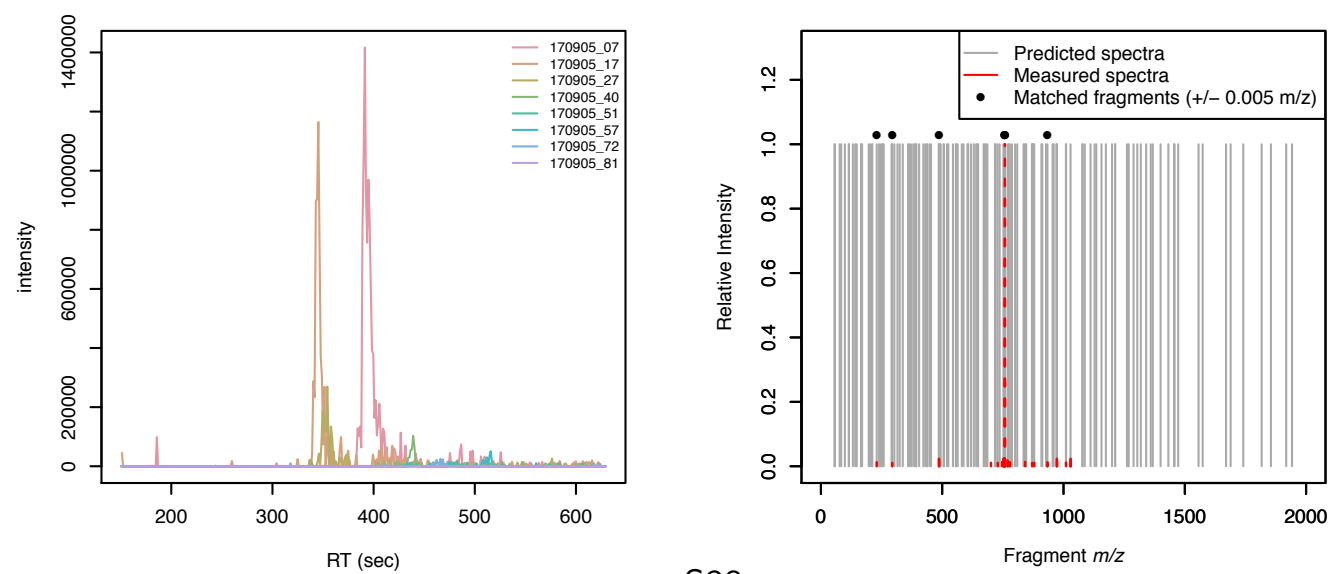


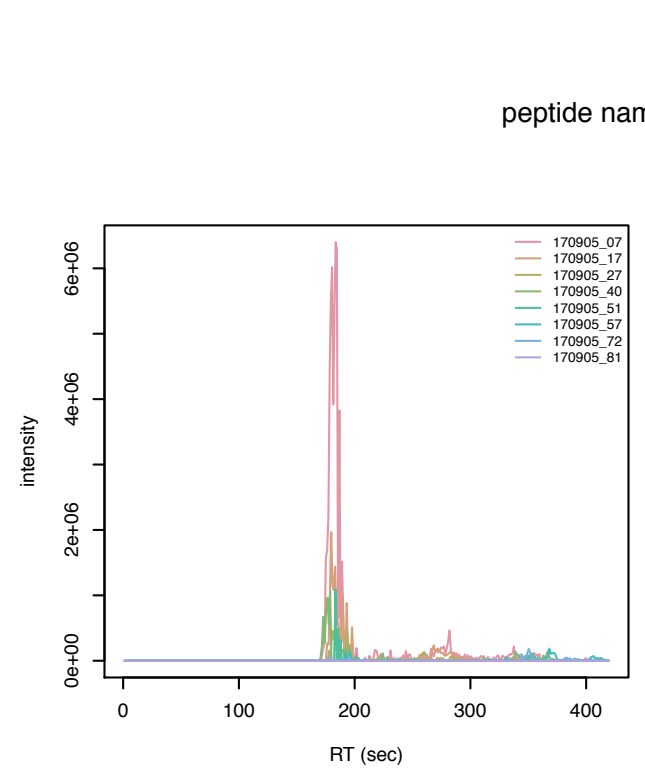

\section{3-275}

BLAP

peptide name: ANSDPTGSHAKKF

ANSDPTGSHAKKF

170905_07.mzXML_mz340_67_rt3_02_HCD20.txt

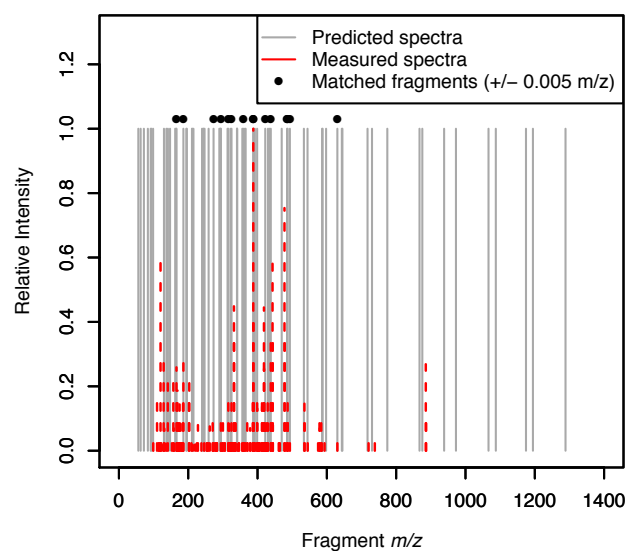

276-280

BLAP

peptide name: TQLGL

TQLGL

170905 07.mzXML_mz53131_rt13 01_HCD20.txt
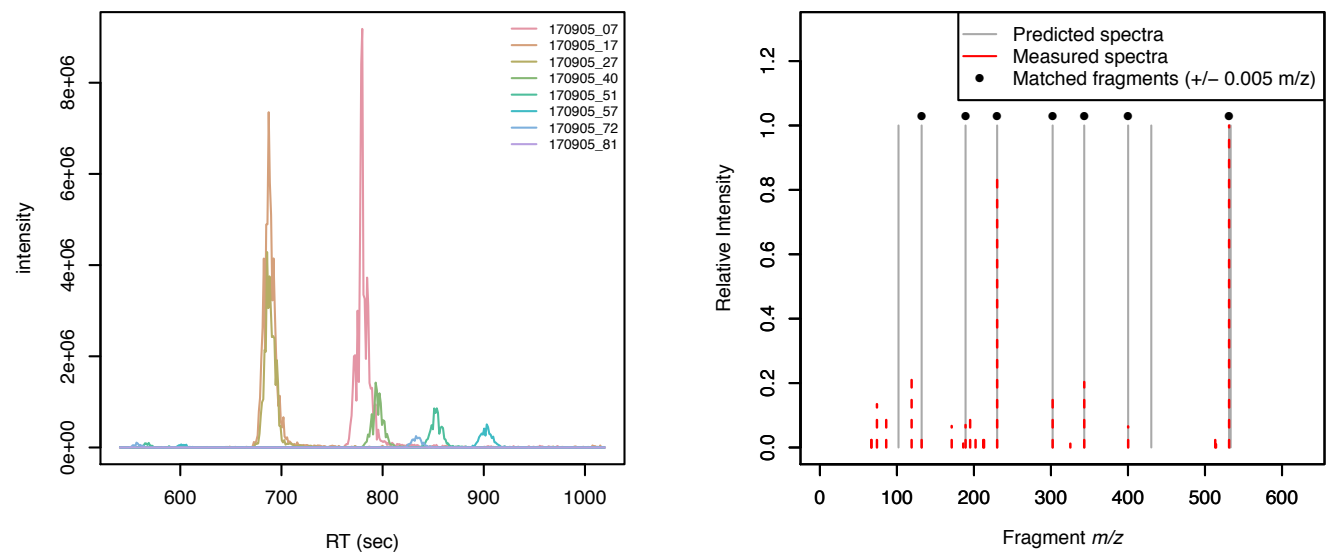

276-282

BLAP

peptide name: TQLGLAY

TQLGLAY

170905_07.mzXML_mz383_21_rt17_59_HCD20.txt
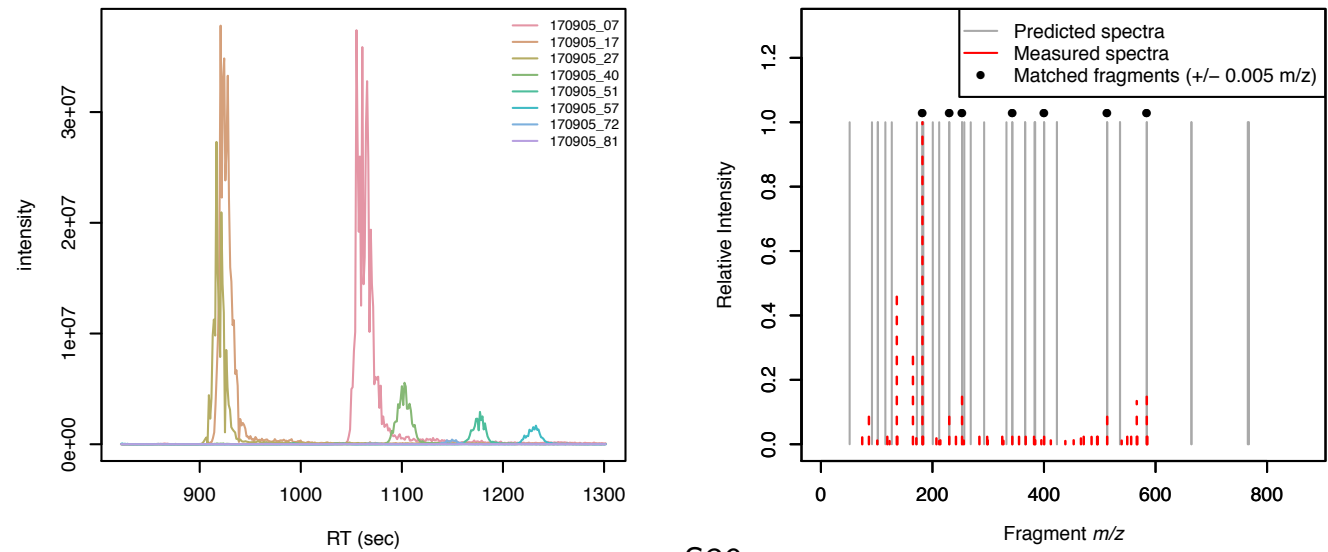


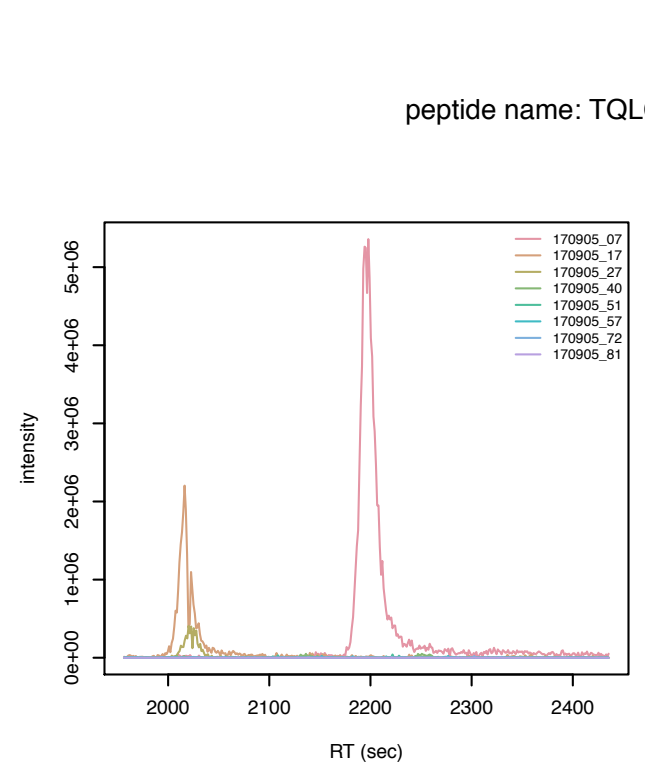

\section{6-299}

BLAP

peptide name: TQLGLAYAIEMGSATGDTPTPGNQ

TQLGLAYAIEMGSATGDTPTPGNQ

170905_07.mzXML_mz798_38_rt36_64_HCD20.txt

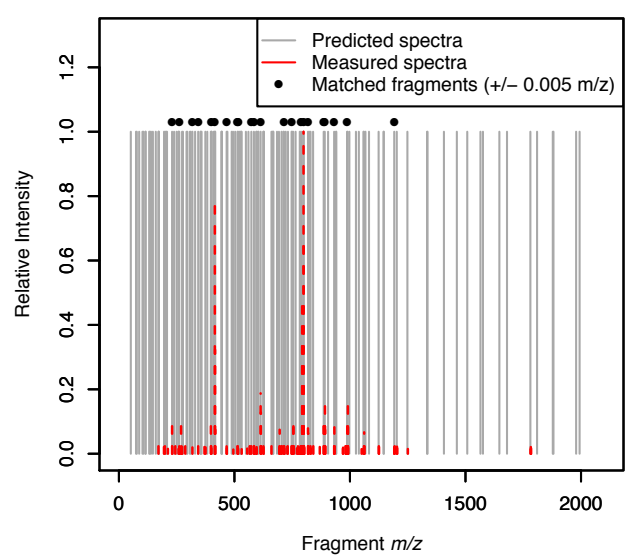

279-282

BLAP

peptide name: GLAY

GLAY

170905 07.mzXML mz423 22 rt7 76 HCD20.txt
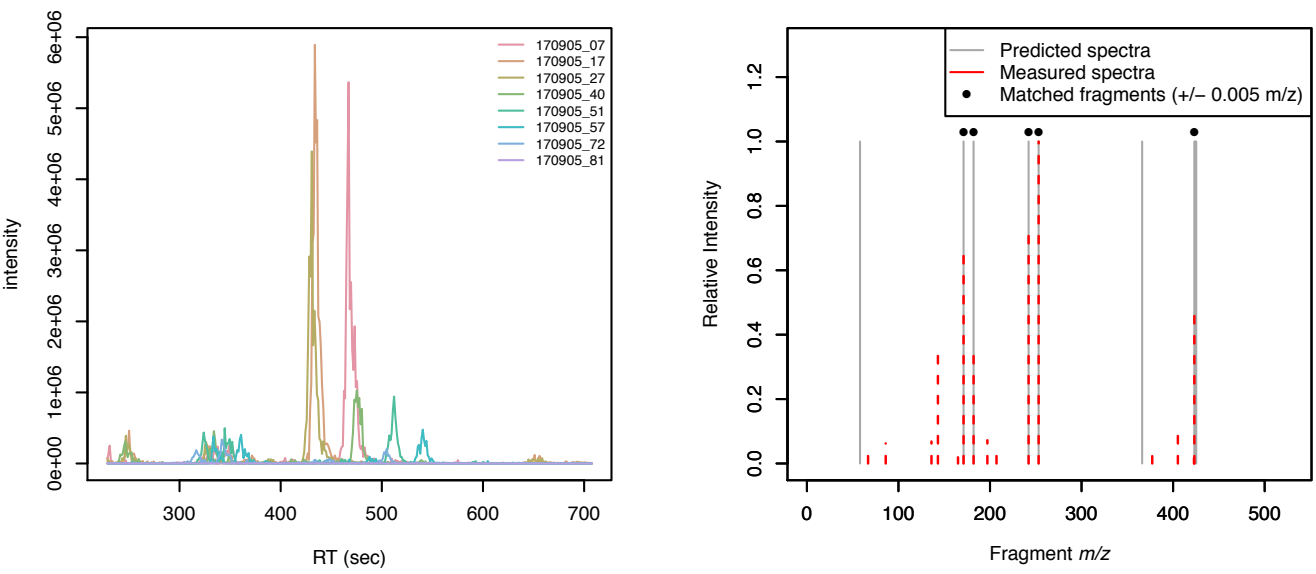

281-299

BLAP

peptide name: AYAIEMGSATGDTPTPGNQ

AYAIEMGSATGDTPTPGNO

170905_07.mzXML_mz940_92_rt14_52_HCD20.txt
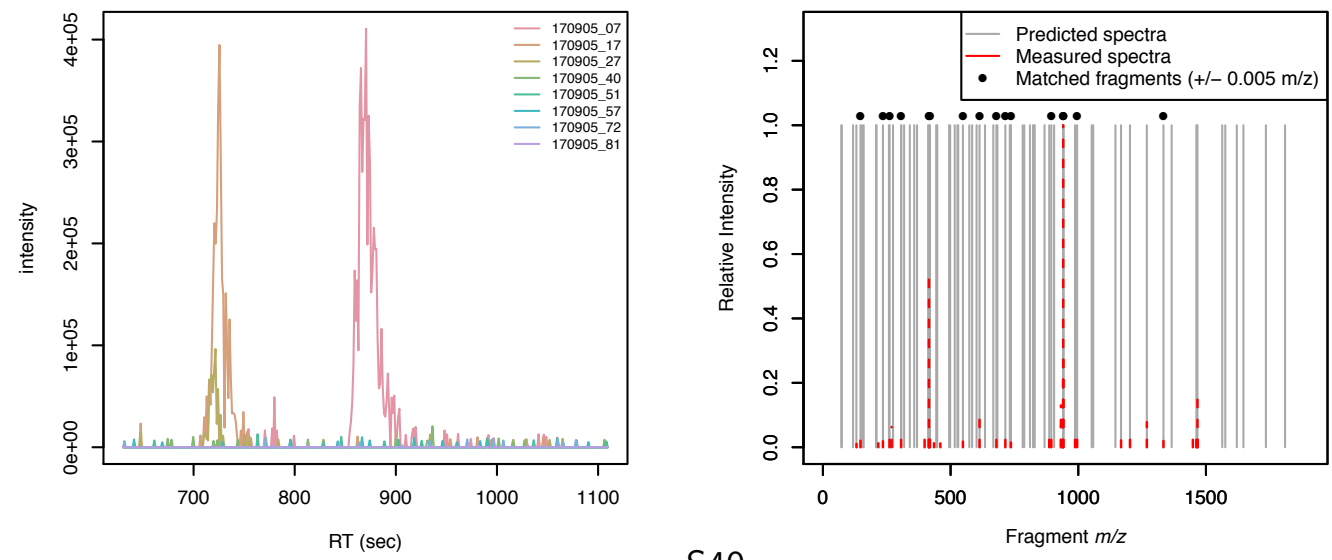
AIEMGSATGDTPTPGNO

170905_07.mzXML_mz823_87_rt7_79_HCD20.txt
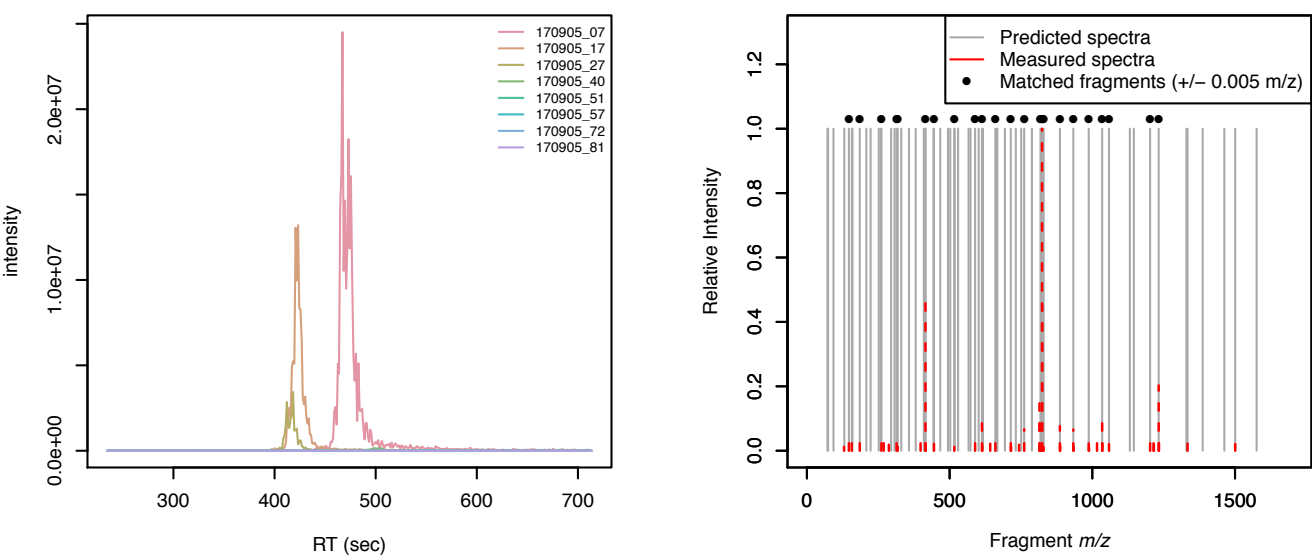

$38-53$

BLAP

peptide name: TTTSGAQASDW[+16]IASEW[+16]

TTTSGAQASDW[+16]IASEW[+16]

170905 19.mzXML mz871_88_rt25 29 HCD20.txt
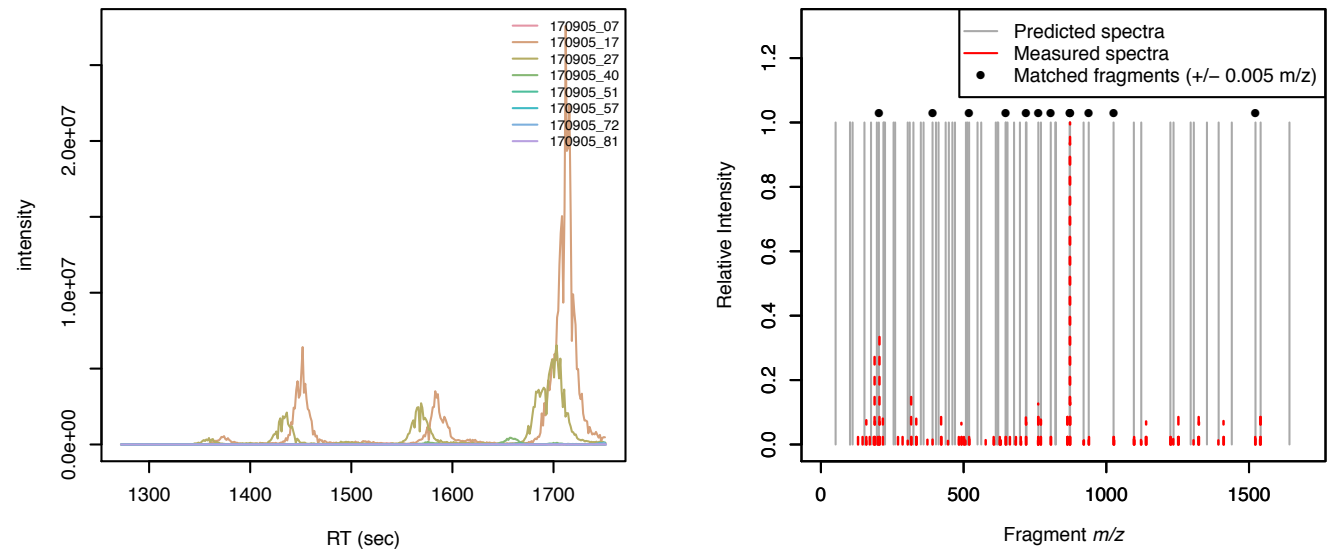

$49-56$

BLAP

peptide name: IASEW[+4]QAL

170905_51.mzXML_mz461_24_rt23_96_HCD20.txt
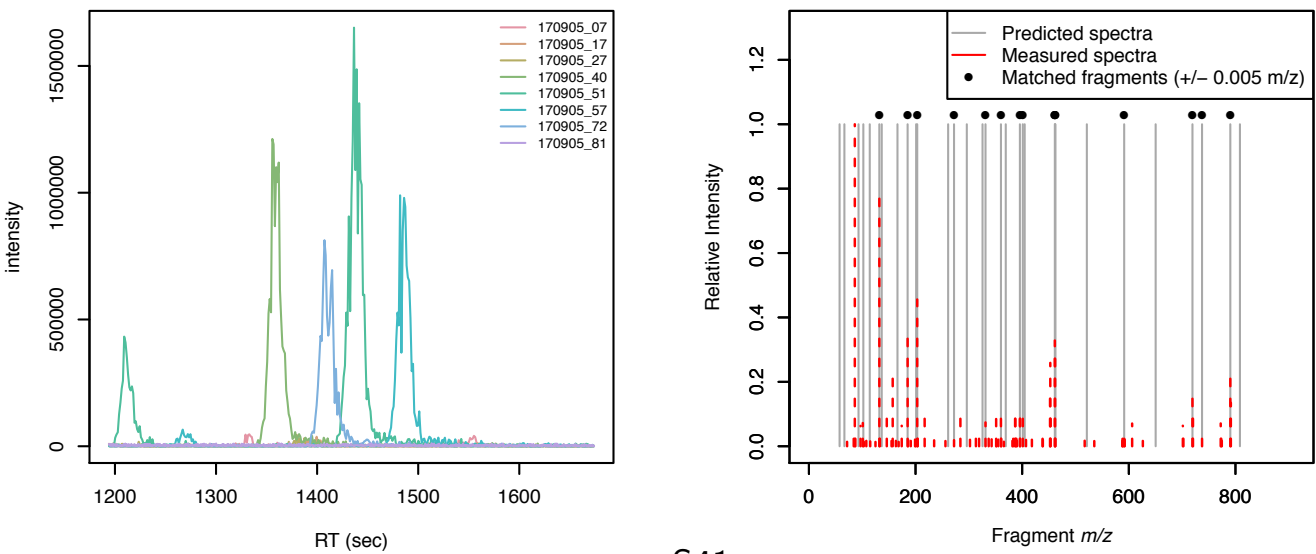


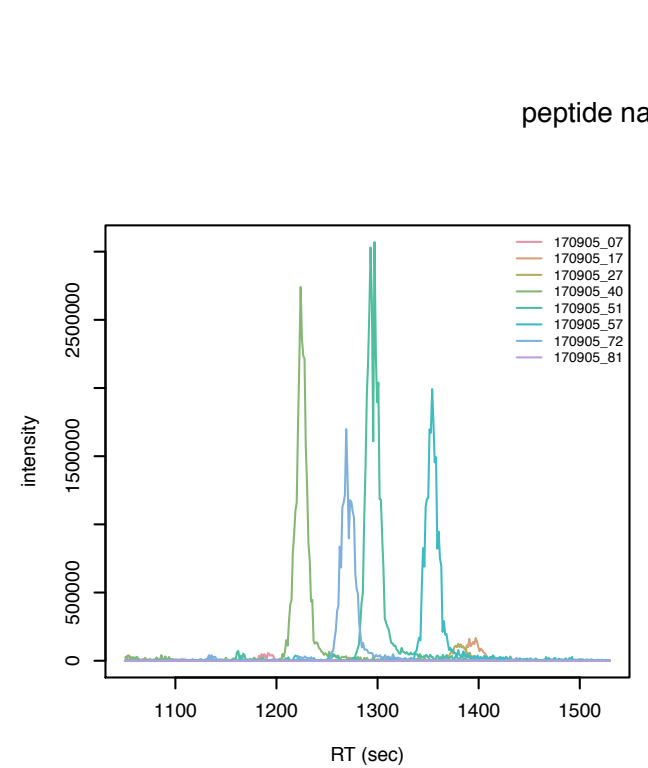

49-56

BLAP

peptide name: IASEW[+32]QAL

IASEW[+32]QAL

170905_51.mzXML_mz475_23_rt21_56_HCD20.txt

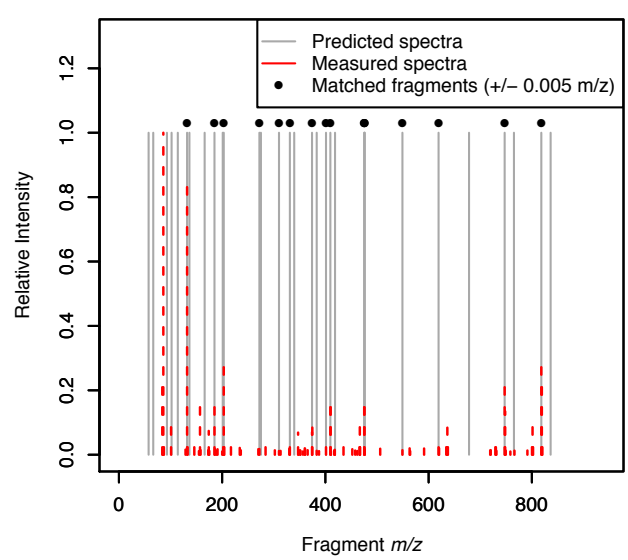

49-73

BLAP

peptide name: IASEWQALSASLPNASVKQVSHSGY[+14]

IASEWQALSASLPNASVKQVSHSGY[+14]

170905 42.mzXML mz882 10 rt49 60 HCD20.txt
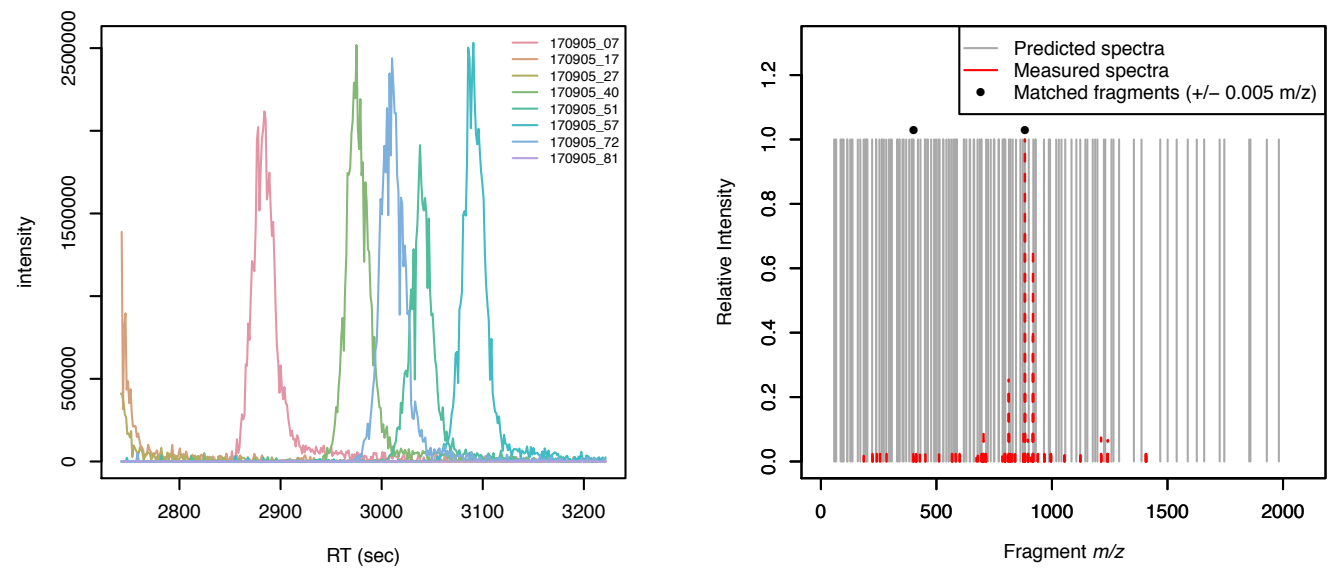

49-80

BLAP

peptide name: IASEW[+64]QALSASLPNASVKQVSHSGYNQKSVVM

IASEW[+64]QALSASLPNASVKQVSHSGYNQKSVVM 170905_17.mzXML_mz1160_91_rt57_22_HCD20.txt
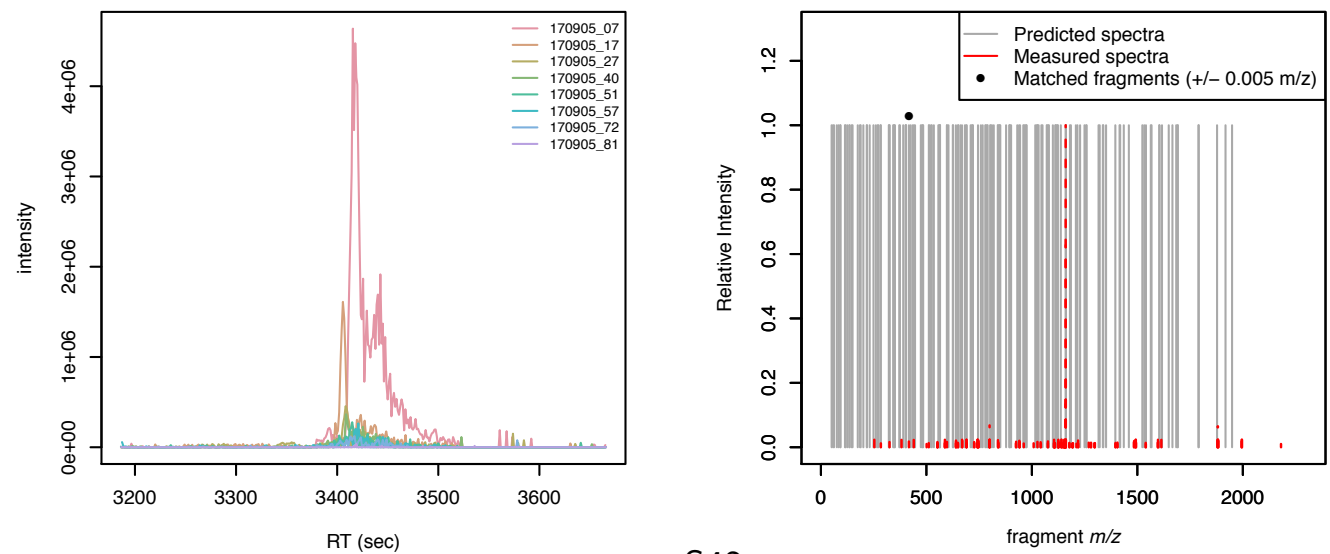


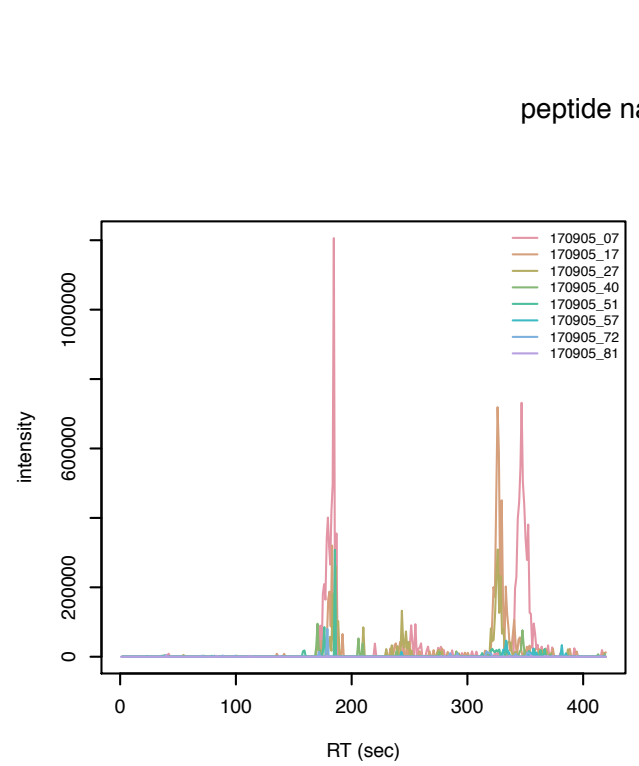

$74-80$

BLAP

peptide name: NQKSVVM[+16]

KSVVM[+16]

170905_17.mzXML_mz411_21_rt60_71_HCD20.txt

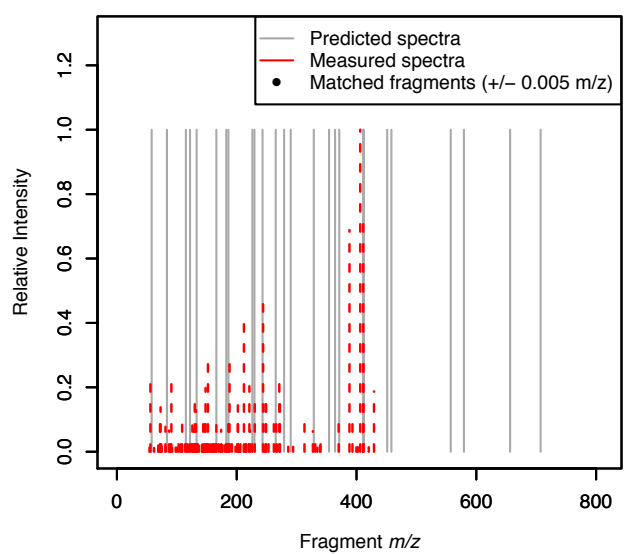

81-98

BLAP

peptide name: TITGSEAPDEW[+48]IVIGGH[+48]L

TITGSEAPDEW[+48]IVIGGH[+48]L

170905 51.mzXML mz66431_rt13 76 HCD20.txt
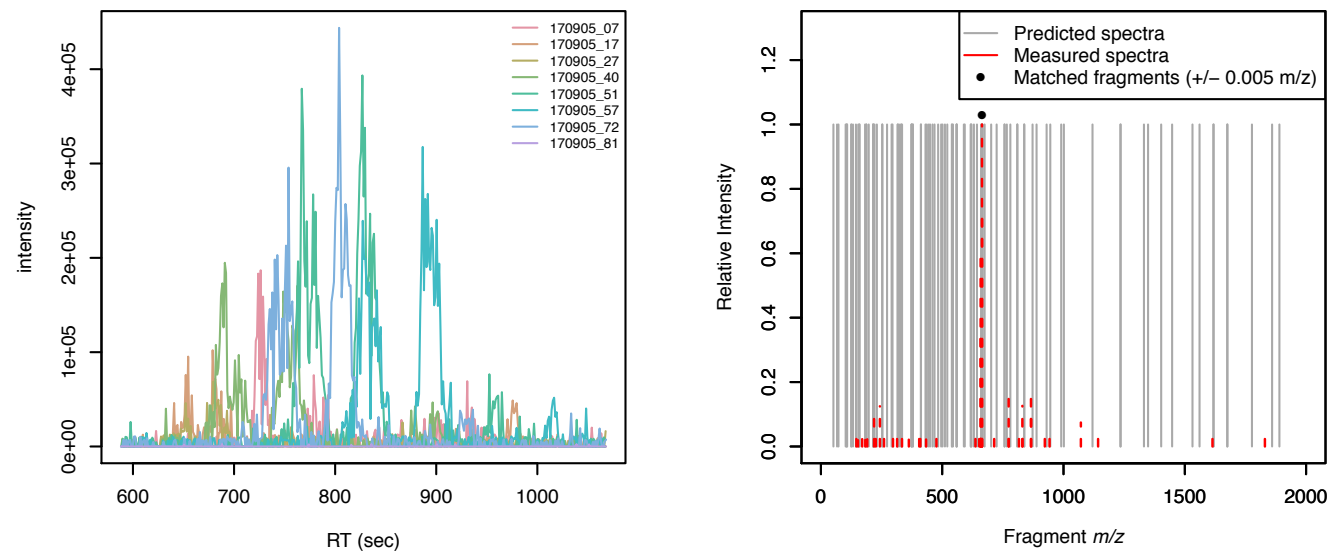

$146-165$

BLAP

peptide name: M[+16]AYAAEEVGLRGSQDLANQY

M[+16]AYAAEEVGLRGSQDLANOY 170905_17.mzXML_mz734_68_rt17_36_HCD20.txt
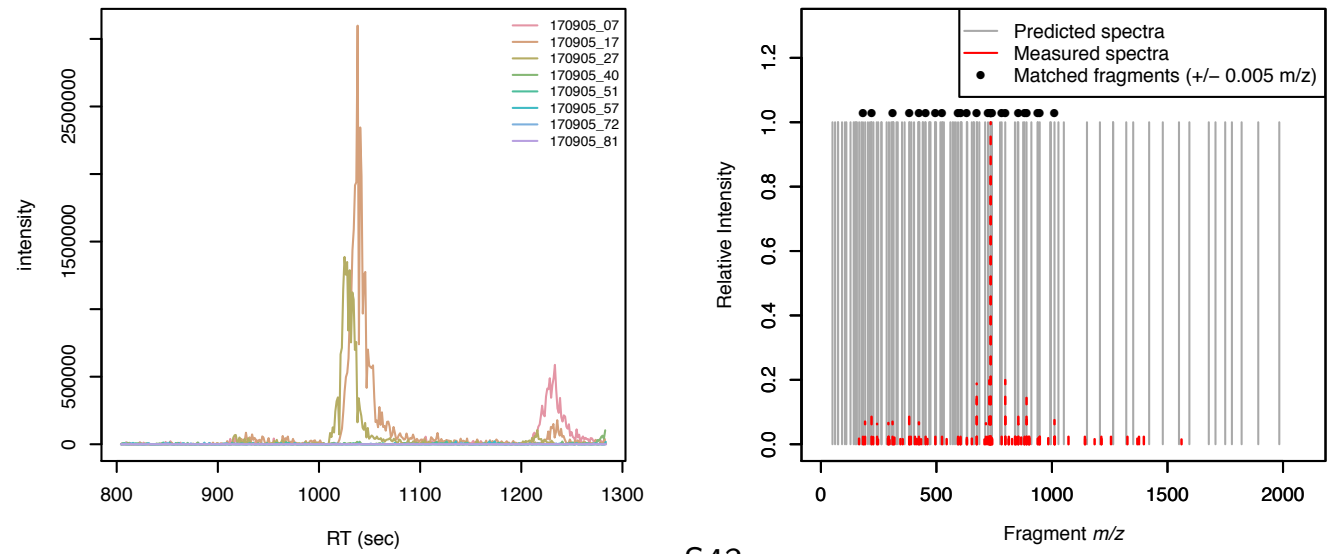


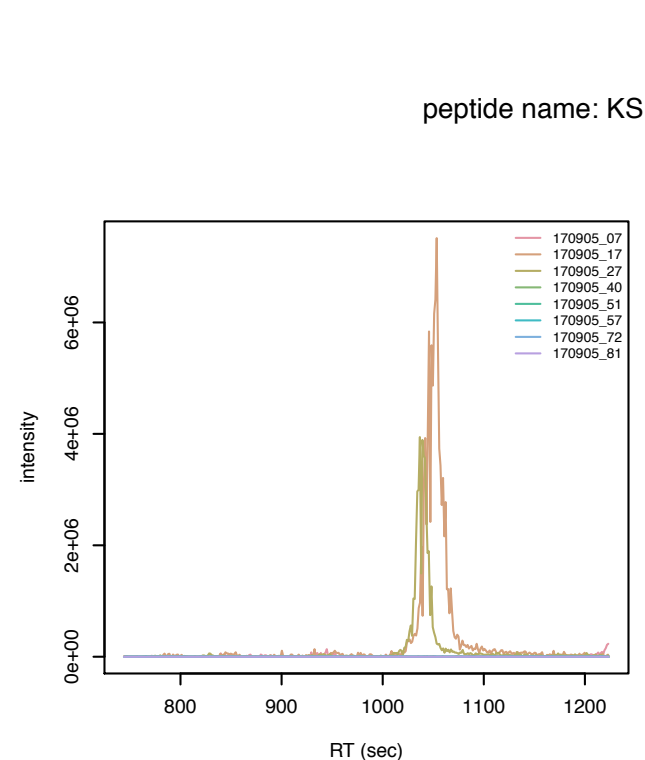

\section{$166-183$}

BLAP

peptide name: KSEGKNVVSALQLDM[+16]TNY

KSEGKNVVSALQLDM[+16]TNY

170905_19.mzXML_mz671_67_rt16_43_HCD20.txt

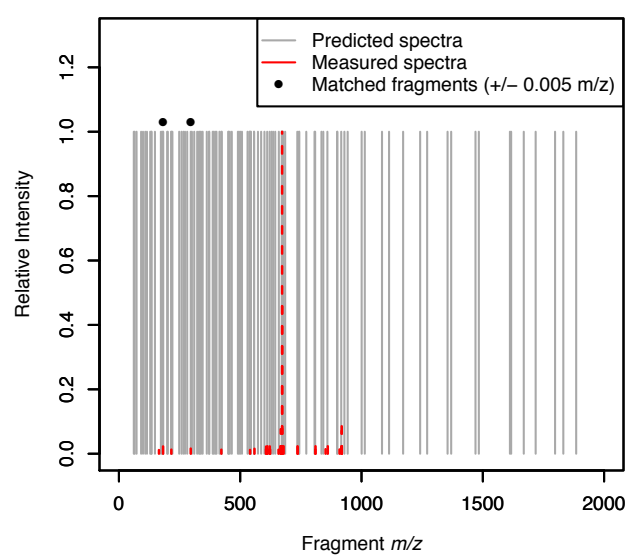

177-196

BLAP

peptide name: QLDM[+16]TNY

QLDM[+16]TNY

170905 27.mzXML mz450 69_rt5 84_HCD20.txt
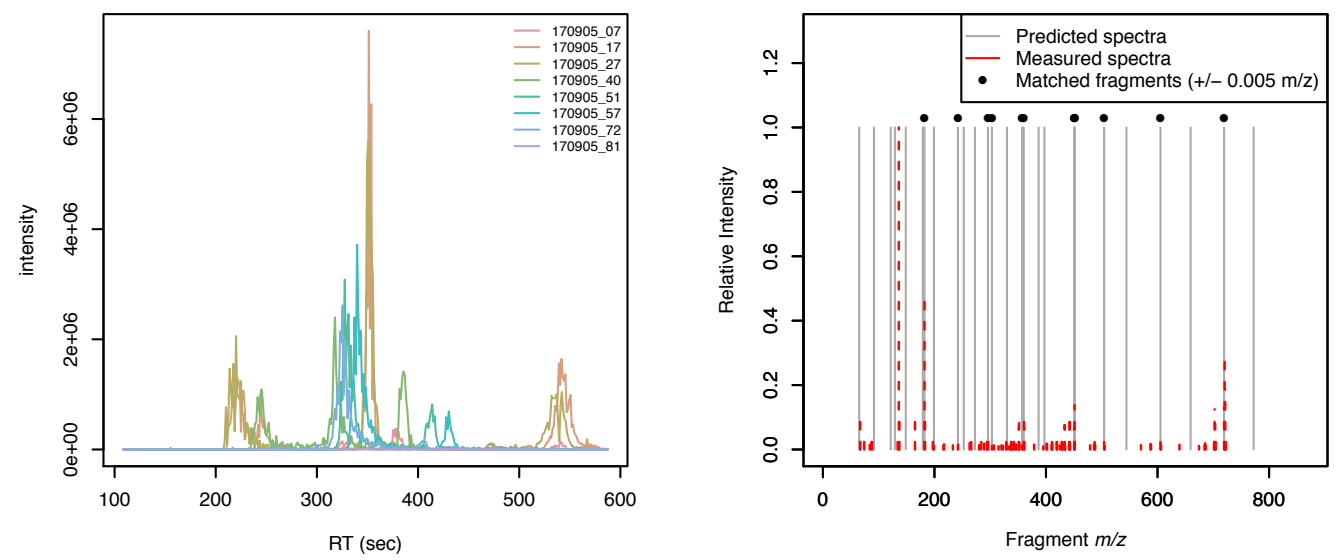

$178-196$

BLAP

peptide name: DMTNYKGSAQDVVFITDY[+16]

DMTNYKGSAQDVVFITDY[+16]

170905_07.mzXML_mz694_98_rt20_19_HCD20.txt
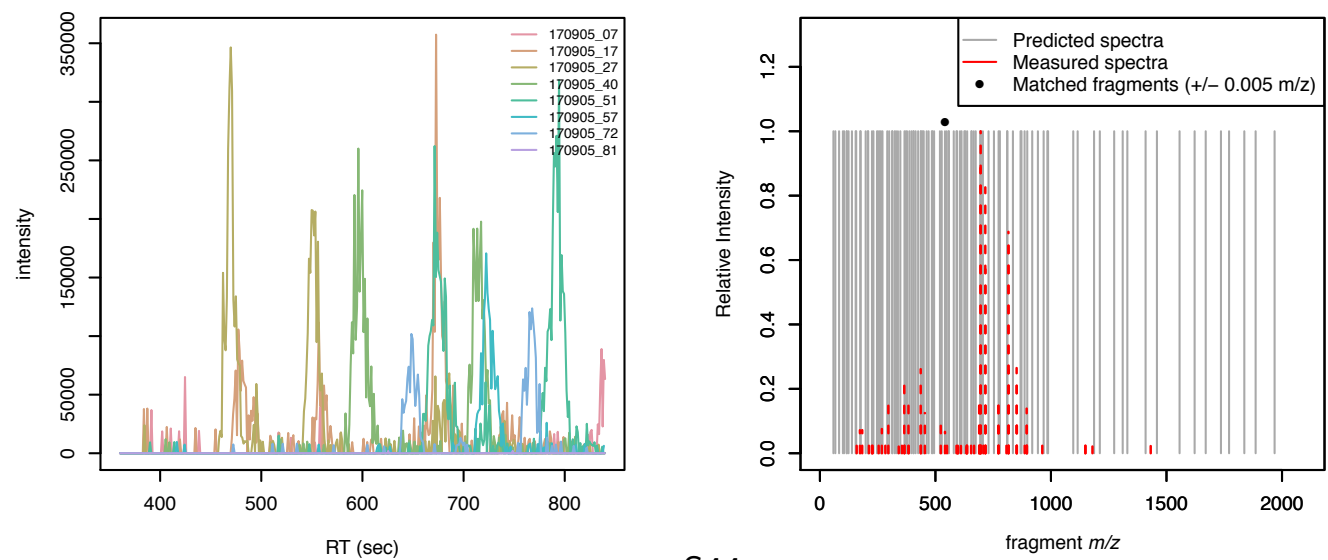
BLAP

peptide name: LTQLM[+16]DEYLPSLTY

LTQLM[+16]DEYLPSLTY

170905_21.mzXML_mz851_92_rt36_09_HCD20.txt
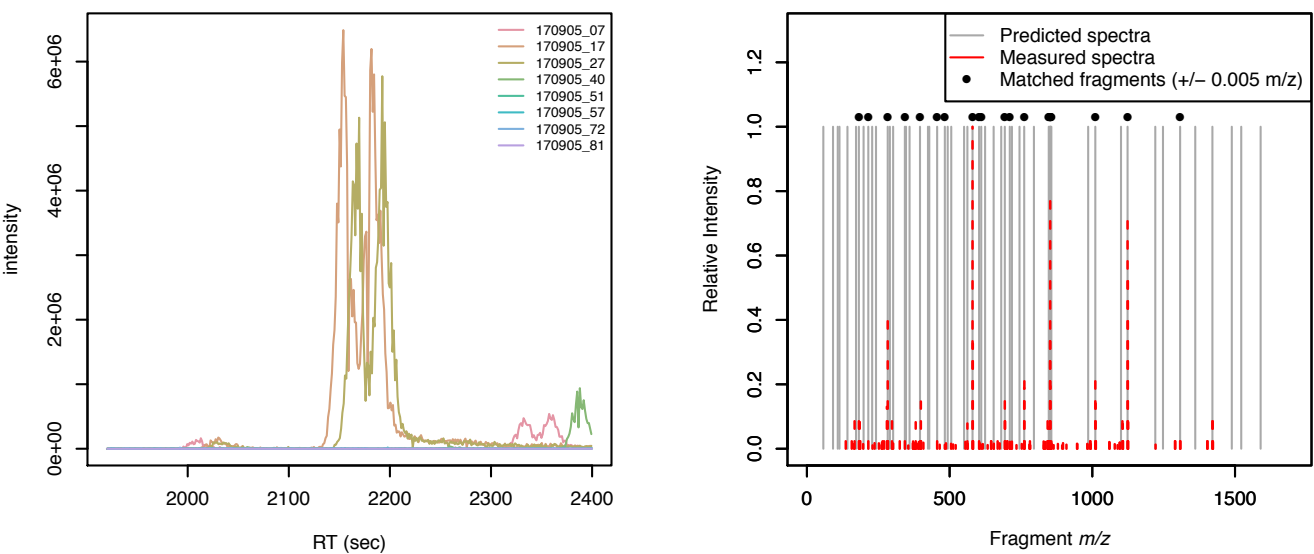

206-220

BLAP

peptide name: TQLM[+16]DEYLPSLTYGF

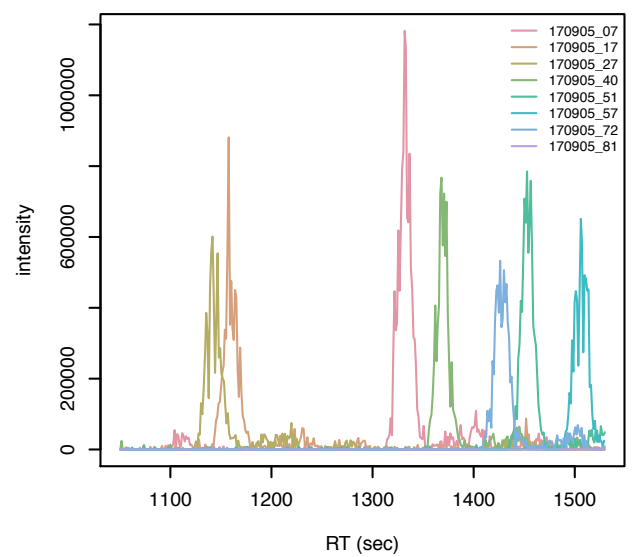

TQLM[+16]DEYLPSLTYGF 170905_13.mzXML not found

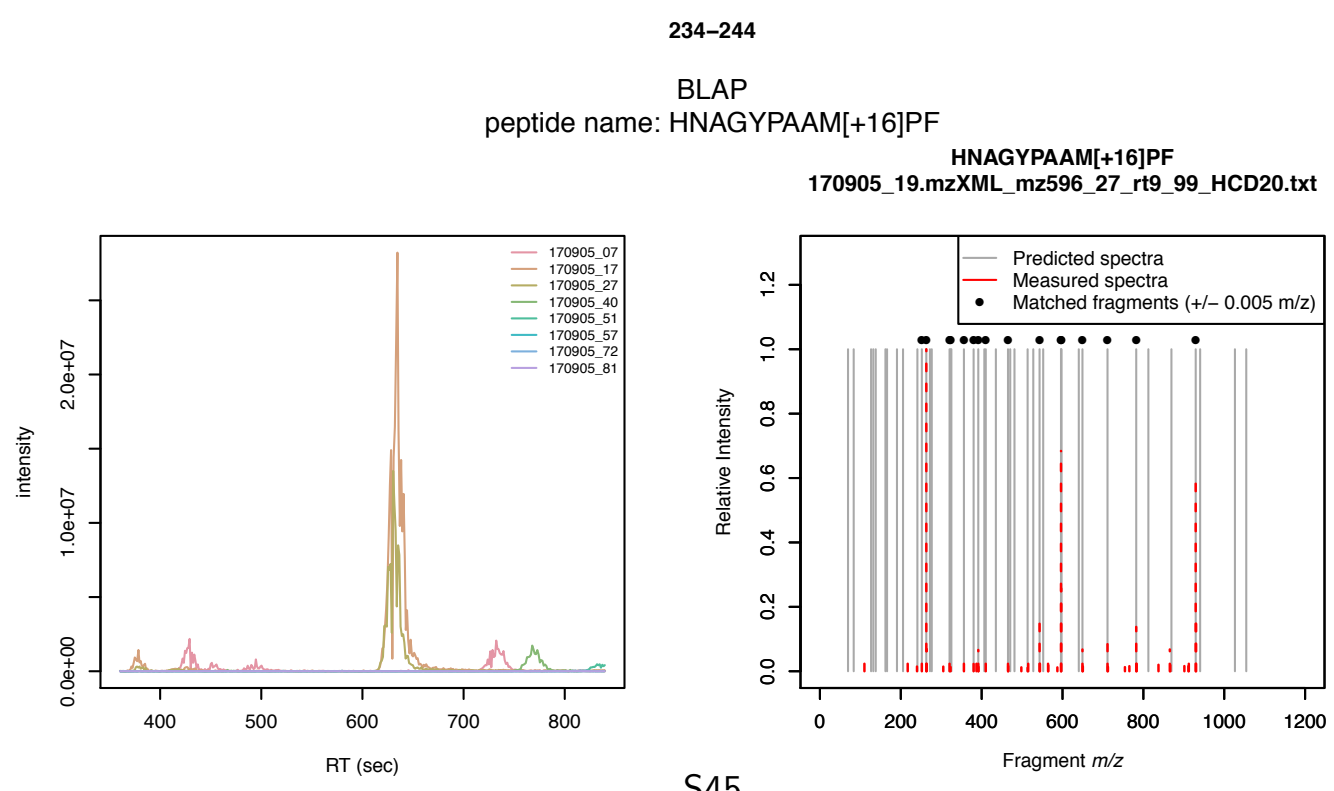




\section{4-244}

BLAP

peptide name: HNAGYPAAM[+32]PF

HNAGYPAAM[+32]PF

170905_23.mzXML_mz604_26_rt14_27_HCD20.txt
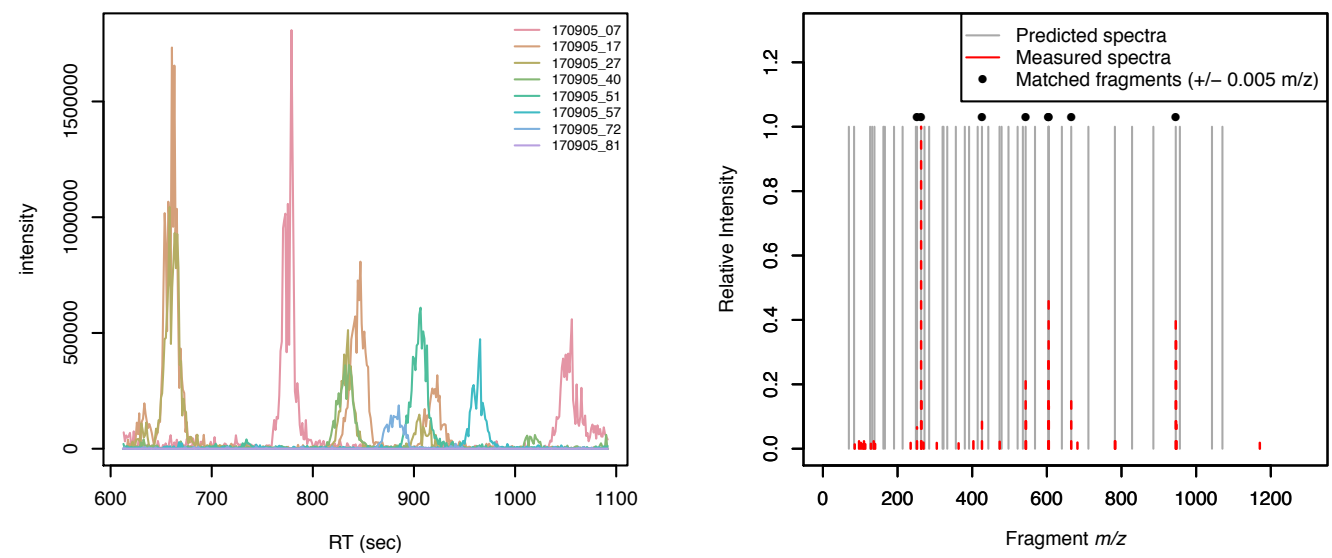

276-299

BLAP

peptide name: TQLGLAYAIEM[+16]GSATGDTPTPGNQ

TQLGLAYAIEM[+16]GSATGDTPTPGNQ 170905 19.mzXML_mz803 71_rt24_33 HCD20.txt
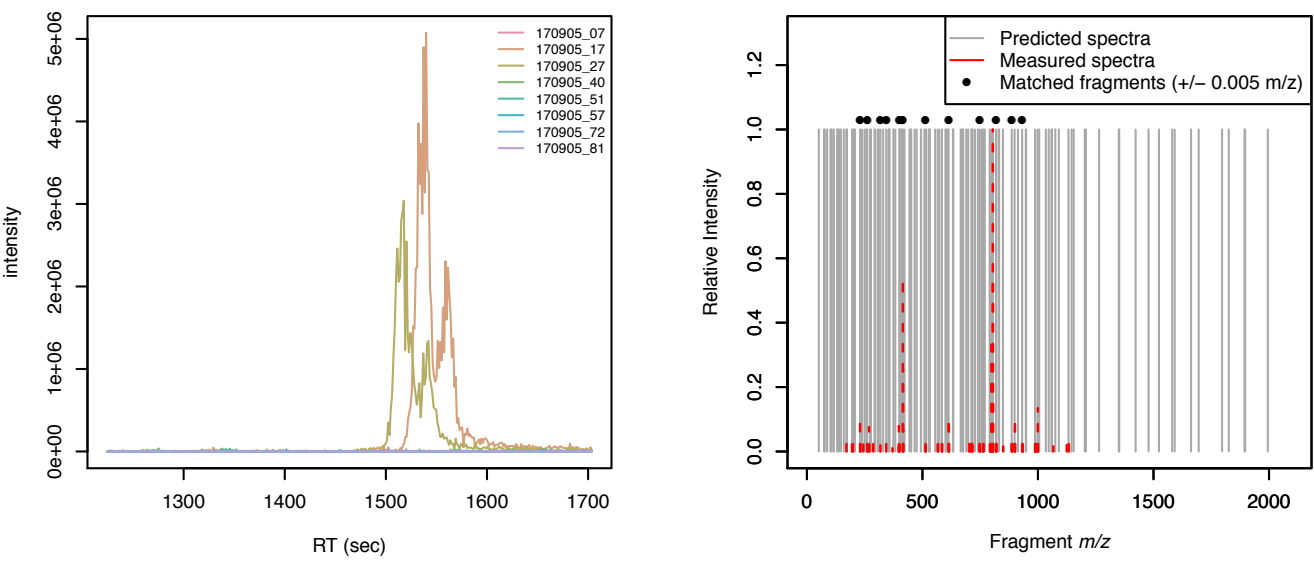

283-299

BLAP

peptide name: AIEM[+16]GSATGDTPTPGNQ

AIEM[+16]GSATGDTPTPGNQ 170905_17.mzXML_mz831_87_rt3_96_HCD20.txt
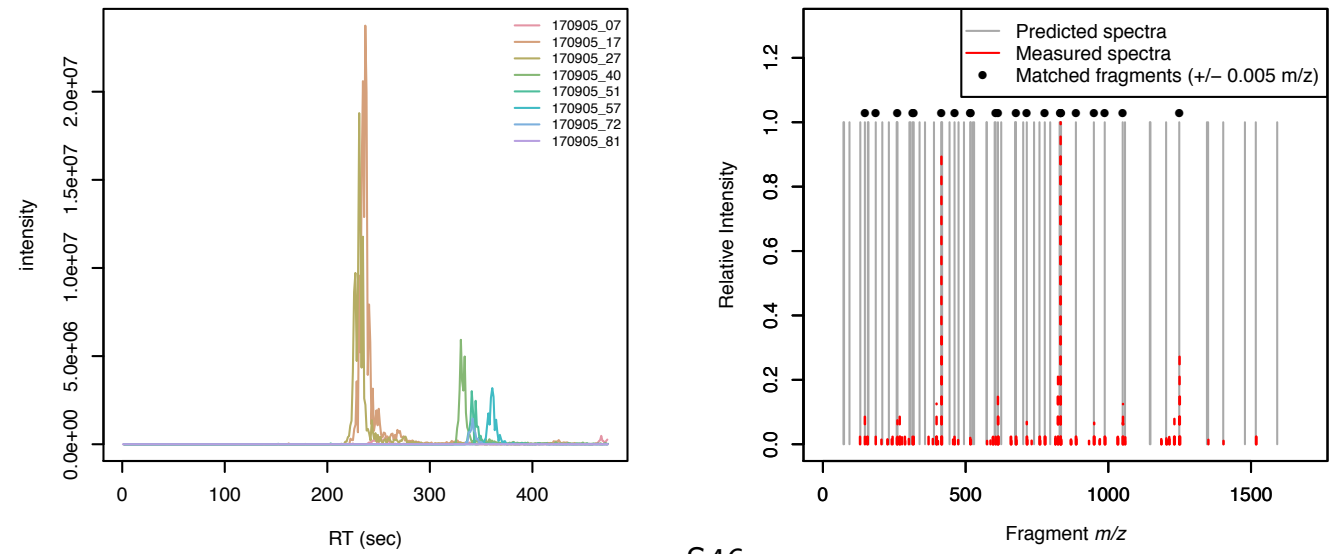
49-80

BLAP

peptide name: IASEWQALSASLPNASVKQVSH[+16]SGY[+32]NQKSVVM[-30]

IASEWQALSASLPNASVKQVSH[+16]SGY[+32]NQKSVVM[-30] 170905_19.mzXML_mz1145_58_rt57_06_HCD20.txt
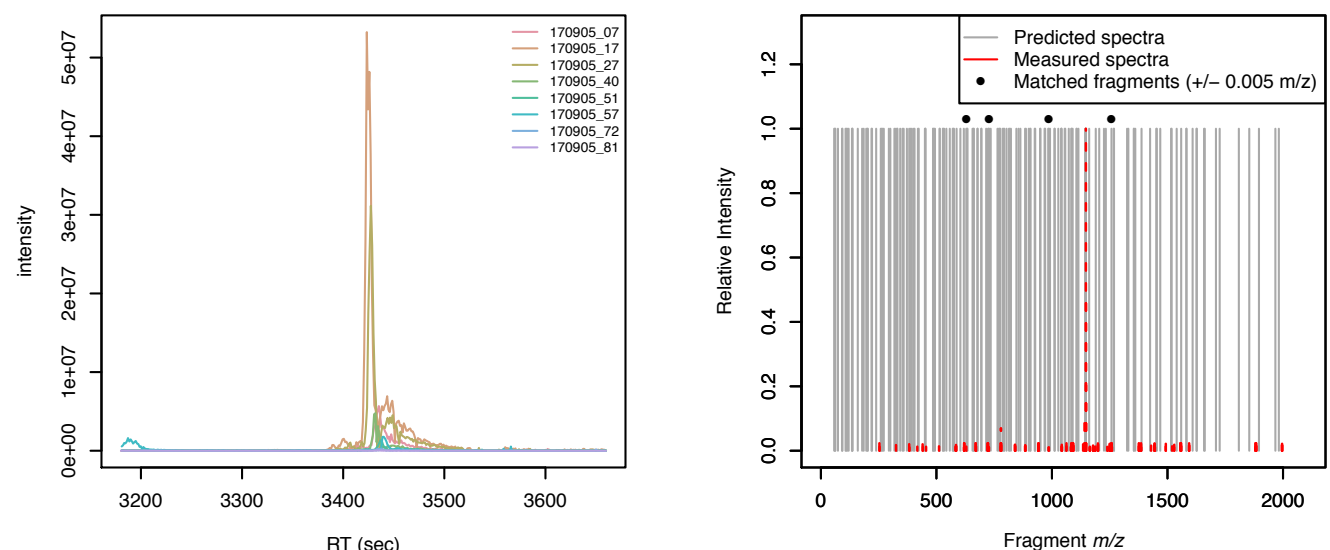


\section{References}

[1] Alexander R. Ivanov, A. V. L. Sample Preparation in Biological Mass Spectrometry; Springer Netherlands, 2011.

[2] Reddy, P. M., Hsu, W.-Y., Hu, J.-F., and Ho, Y.-P. (2010) Digestion completeness of microwave-assisted and conventional trypsin-catalyzed reactions. Journal of the American Society for Mass Spectrometry 21, 421-424.

[3] Lundeen, R. A., and McNeill, K. (2013) Reactivity differences of combined and free amino acids: Quantifying the relationship between three-dimensional protein structure and singlet oxygen reaction rates. Environ. Sci. Technol. 47, 14215-14223.

[4] Lundeen, R. A., Janssen, E. M. L., Chu, C., and Mcneill, K. (2014) Environmental photochemistry of amino acids, peptides and proteins. Chimia 68, 812-817.

[5] Janssen, E. M. L., Erickson, P. R., and McNeill, K. (2014) Dual roles of dissolved organic matter as sensitizer and quencher in the photooxidation of tryptophan. Environ. Sci. Technol. 48, 4916-4924.

[6] Matheson, I. B. C., and Lee, J. (1979) Chemical reaction rates of amino acids with singlet oxygen. Photochem. Photobiol. 29, 879-881.

[7] Devasagayam, T. P. A., Sundquist, A. R., Di Mascio, P., Kaiser, S., and Sies, H. (1991) Activity of thiols as singlet molecular oxygen quenchers. J. Photochem. Photobiol. B: Biol. 9, 105-116.

[8] Fraczkiewicz, R., and Braun, W. (1998) Exact and efficient analytical calculation of the accessible surface areas and their gradients for macromolecules. J. Comput. Chem. 19, 319-333.

[9] Schymanski, E. L., Jeon, J., Gulde, R., Fenner, K., Ruff, M., Singer, H. P., and Hollender, J. (2014) Identifying small molecules via high resolution mass spectrometry: Communicating cfonfidence. Environ. Sci. Technol. 48, 2097-2098.

[10] Kang, P., and Foote, C. S. (2002) Photosensitized oxidation of ${ }^{13} \mathrm{C},{ }^{15}$ N-labeled imidazole derivatives. J. Am. Chem. Soc. 124, 9629-9638.

[11] Chang, S. H., Teshima, G. M., Milby, T., Gillece-Castro, B., and Canova-Davis, E. (1997) Metal-catalyzed photooxidation of histidine in human growth hormone. Anal. Biochem. 244, 221-227.

[12] Tomita, M., Irie, M., and Ukita, T. (1969) Sensitized photooxidation of histidine and its derivatives. Products and mechanism of the reaction. Biochemistry 8, 5149-5160.

[13] Schey, K. L., and Finley, E. L. (2000) Identification of peptide oxidation by tandem mass spectrometry. Acc. Chem. Res. 33, 299-306.

[14] Uchida, K., and Kawakishi, S. (1993) 2-Oxo-histidine as a novel biological marker for oxidatively modified proteins. FEBS Lett. 332, 208-210.

[15] Scholleé, J. E. (2019) MSMSsim, version 1.0.0, Spectral Similarity of Pairs of HRMS/MS spectra - R package. Zenodo, DOI: 10.5281/zenodo.3234737. 
[16] Stravs, M. A., Schymanski, E. L., Singer, H. P., and Hollender, J. (2013) Automatic recalibration and processing of tandem mass spectra using formula annotation. Journal of Mass Spectrometry 48, 89-99. 